Florida International University FIU Digital Commons

9-29-1986

\title{
Learning style and brain hemisphere dominance : interrelationships and influences on organizational role selection
}

Helen Leitch Diehl

Florida International University

DOI: $10.25148 /$ etd.FI14062288

Follow this and additional works at: https://digitalcommons.fiu.edu/etd

Part of the Education Commons

\section{Recommended Citation}

Diehl, Helen Leitch, "Learning style and brain hemisphere dominance : interrelationships and influences on organizational role selection" (1986). FIU Electronic Theses and Dissertations. 2816.

https://digitalcommons.fiu.edu/etd/2816 


\title{
LEARNING STYLE AND
}

BRAIN HEMISPHERE DOMINANCE: INTERRELATIONSHIPS AND INFLUENCES ON ORGANIZATIONAL ROLE SELECTION

\author{
by \\ Helen Leitch Diehl \\ A dissertation submitted in partial fulfillment of the \\ requirements for the degree of \\ DOCTOROFEDUCATION \\ in \\ THE COUEGE OF EDUCATION \\ at \\ FLORIDA INTERNATIONAL UNIVERSITY
}

Committee in charge:

Professor Lorraine R. Gay, Chairperson

Professor Barry Greenberg

Professor William M. Taggart

Professor Jethro W. Toomer

September 1986 
The dissertation of Helen Leitch Diehl is approved.

\author{
Professor
}

Professor

Professor

Professor

Major Professor

Date of Examination:

Sestember 29,1986 


\section{LEARNING STYLE AND \\ BRAIN HEMISPHERE DOMINANCE: INTERRELATIONSHIPS AND \\ INFLUENCES ON ORGANIZATIONAL ROLE SELECTION}

by

Helen Leitch Diehl

A dissertation submitted in partial fulfillment of the requirements for the degree of

DOCTOR OF EDUCATION

in

THE COUEGE OFEDUCATION

at

FLORIDA INTERNATIONAL UNIVERSITY

1986 
Copyright by

HELEN LEITCH DIEHL

1986 


\begin{abstract}
LEARNING STYLE AND

BRAIN HEMISPHERE DOMINANCE: INTERRELATIONSHIPS AND

INFLUENCES ON ORGANIZATIONAL ROLE SELECTION
\end{abstract}

by

Helen Leitch Diehl

This study investigated relationships between learning style, as measured by the Kolb Learning-Style Inventory, and brain hemisphere dominance, as measured by the Herrmann Participant Survey. The possible influence of either or both of these factors on organizational role selection as a supervisor, subordinate or work project group member was also studied. Subjects were 134 graduate management students.

Pearson product moment correlations at $\mathrm{Q}<.01(\underline{n}=125)$ were found between the following dimensions: Concrete Experience and right brain hemisphere dominance, $I=$ .41; Concrete Experience and the Right Limbic, $I=.42$; Abstract Conceptualization and left brain hemisphere dominance, $\mathrm{L}=.23$; Abstract Conceptualization and the Overall Cerebral, $\mathrm{L}=.49 ;$ Abstract Conceptualization and the Left Cerebral, $\mathrm{I}=.42$. Although some results regarding organizational role selection based on learning style or brain hemisphere dominance were significant at $\mathrm{D}<.05$ using chi square analysis, strong evidence was not found to support the concept that individuals would prefer working with others like themselves. There was some evidence, however, that the longevity of the acquaintance may influence students to select right brain hemisphere dominant students in some situations.

The bipolarity of the factors measured by both instruments was assessed. Using a level of $p<.01$, Concrete Experience and Abstract Conceptualization were correlated at 
$-.46(n=133)$, whereas Reflective Observation and Active Experiementation were correlated at $-.52(n=133)$ on the Kob instrument. On the Herman instrument, Overall Left and Overall Right measures were correlated at $-.84(n=126)$, whereas Overall Cerebral and Overall Limbic measures correlated at $-.73(n=126)$. Split-half correlations on the Kob factors yielded reliabilities of .85 to $.90(n=133)$ for the four factors measured. Test-retest correlations for the Herman ranged from .67 to $.81(\underline{n}=30)$ for the subscales. Suggestions for future research using these instruments were made.

Abstract approved by

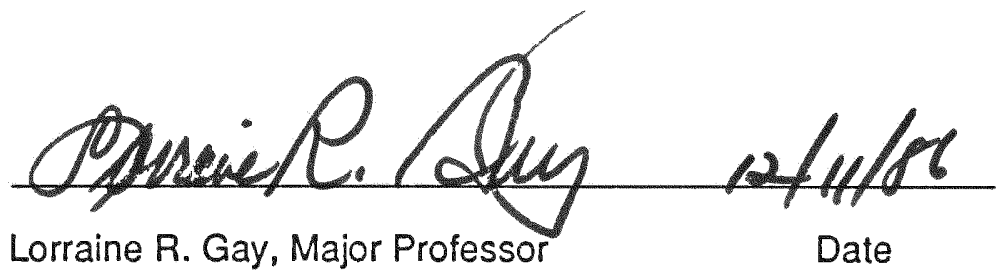


This work is dedicated to

my parents

Helen Kyle and James Kensley Leitch

and to

my sons

Michael and Steven Kirkpatrick Diehl 


\section{ACKNOWLEDGEMENTS}

As this work is completed, I am convinced that I have been blessed with a particularly fine committee. The ways in which their particular talents and interests blended to complement each other and to support my inquiry was indeed fortuitous. For their many efforts in my behalf, I am grateful to Drs. Barry Greenberg, William M. Taggart, and Jethro W. Toomer. In particular, however, I wish to thank Dr. Lorraine R. Gay who, in her role as Major Professor, expended considerable time and energy, and always seemed to know when to be demanding and when to be supportive. Additionally, the faculty and staff of the College of Education at Florida International University were consistently encouraging.

Outside Florida International, I wish to thank a unique group of people who seemed to know how to help me put various stages and phases of the process into a sensible perspective; their efforts were always motivating. These supporters include Drs. Marjorie Abrams, Delores Kory and Mark Safferstone, Deans Ray Kulzick and Richard Sperring, and Messrs. Edsel Lowe and Dennis Davis of the St. Thomas University faculty, and Diana Locke, my graduate assistant. My own students at St. Thomas not only served as subjects but formed a wonderful cadre of listeners and cheerleaders; they continue to teach me more than I can teach them. Also, Dr. Ellen Strot, who had just "been there," and Franklyn and Sandra Glinn were always available when I needed their good counsel.

Finally, my husband, Peter Diehl, contributed intellectual, logistical, technical and emotional assistance to me that gives new meaning to the term helpmate. Thank you all; you really did make it possible. 


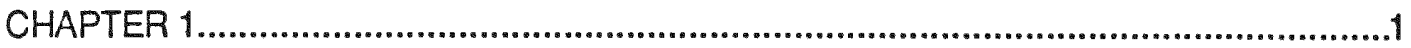

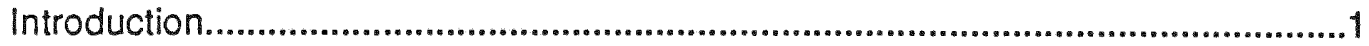

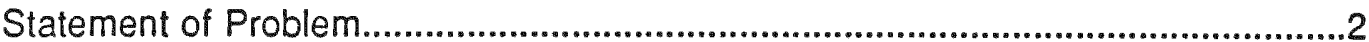

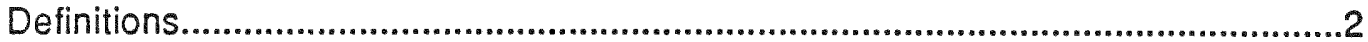

Learning Style

Brain Hemisphere Dominance

Selection Definitions

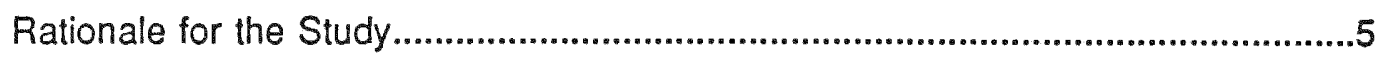

Elements of the Study

Applications of the Study

Limitation of the Study ..........................................................................................

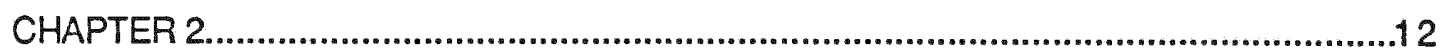

Review of the Literature ......................................................................................
Learning Style
Brain Hemisphere Dominance
Learning Style and Brain Hemisphere Dominance
Selection and Group Success

Summary of the Research.................................................................................43

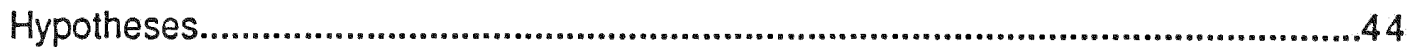

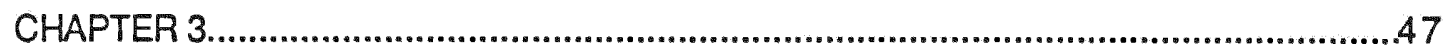

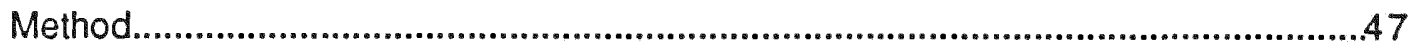

Subjects

Instruments

Design and Procedure

Design Limitations 


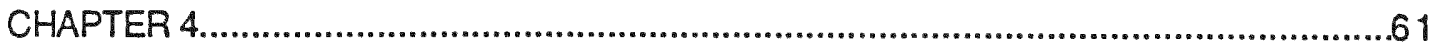

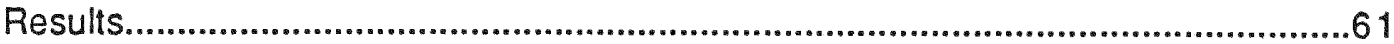

Learning Style of Subjects

Brain Hemisphere Dominance of the Subjects

Findings Related to Hypotheses 1 and 2

Findings Related to Hypothesis 3

Findings Related to Hypotheses 4 through 6

Findings Related to Hypotheses 7 through 12

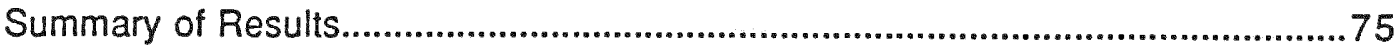

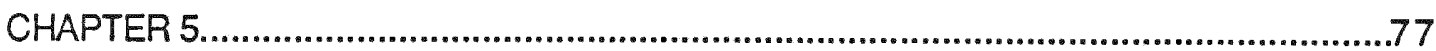

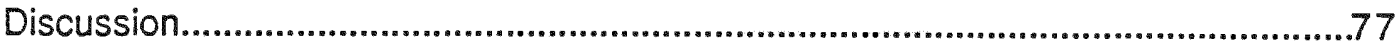

Left or Right Brain Hemisphere Dominance Based on Kolb

Considerations Regarding Selection

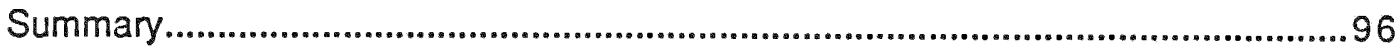

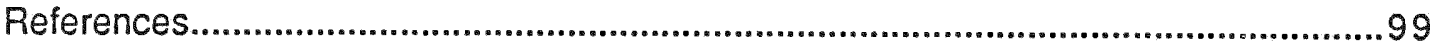

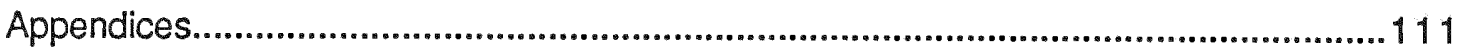

Appendix A: Demographics of Test-Retest Group.................................................111

Appendix B: Data Collection Materials...................................................................112

Appendix C: Feedback Materials.........................................................................119 


\section{UST OF TABLES}

1 Personal Demographics of Subjects by Class Groups.........................................50

2 Educational Program of Subjects by Class Groups...........................................51

3 Working Status of Subjects by Class Groups....................................................51

4 Split-half Reliability of the Kolb (OLSI) and the LSI....................................53

5 Bipolarity and Independence of Kolb OLSI and LSI Subscales.............................54

6 Test-retest Results for the Herrmann Instrument Overall Measures................57

7 Test-retest Results for the Herrmann Instrument Specific Subtests.................57

8 Means, Ranges, and Standard Deviations by Subscales and Combination Scales for the Kolb LSI...........................................................................................61

9 Learning Style Distributions Overall and by Group............................................62

10 Means and Standard Deviations for Overall and Subscales of the Herrmann................................................................................................................63

11 Distribution of Right/Left Brain Hemisphere Dominance Overall and by Group..............................................................................................................63

12 Selections of Preferred Supervisors by Divergers........................................67

13 Selections of Preferred Supervisors by Assimilators......................................67

14 Selections of Preferred Supervisors by Accommodators.....................................67

15 Selections of Preferred Subordinates by Divergers...........................................68

16 Selections of Preferred Subordinates by Assimilators......................................68

17 Selections of Preferred Subordinates by Accommodators...................................69

18 Selections of Preferred Work Project Group Members by Divergers................70

19 Selections of Preferred Work Project Group Members by Assimilators...........70

20 Selections of Preferred Work Project Group Members by Accommodators.......71 
21 Selections of Preferred Supervisors by Left Brain Hemisphere Dominants......72

22 Selections of Preferred Supervisors by Right Brain Hemisphere Dominants....72

23 Selections of Preferred Subordinates by Left Brain Hemisphere Dominants.....73

24 Selections of Preferred Subordinates by Right Brain Hemisphere Dominants...73

25 Selections of Preferred Work Project Group Members by Left Brain Hemisphere Dominants.

26 Selections of Preferred Work Project Group Members by Right Brain Hemisphere Dominants. .75

27 Pearson Product Moment Correlations Between Right/Left Brain Hemisphere Dominance and Kolb LSI Scales........................................................78

28 Pearson Product Moment Correlations Between Cerebral/Limbic Dimensions and Kolb LSI Scales. 80

29 Pearson Product Moment Correlations Between Subscales of the Kolb LSI and the Herrmann

30 Comparison of Means and Standard Deviations of Subscales of the Kolb LSI (1985) Norm Group and the Study Sample.

31 Overall Selections for Supervisor, Subordinate, and Work Project Group Member by All Selectors. 92

32 Selections as Non-Preferred Workers by All Learning Styles. .93

33 Selections as Non-Preferred Co-Workers by Assimilators. 93

34 Chi Squares of Overall Selections by Group for Left Brain Hemisphere Dominants.

35 Significant Results from Selection Data Regarding Classmates with Whom Subjects Preferred not to Work. 95 


\section{UST OF FIGURES}

1 Kolb's Theoretical Model (Kolb, 1984, p. 42).................................................19

2 Individual Learning Styles (Kolb, 1984, p. 42)...............................................20

3 Suggested Relationships Between the Herrmann Overall Scores and the Kolb LSI Diagram..........................................................................................84

4 Right Brain Hemisphere Dominant Subjects Displayed on the Kolb Diagram.......................................................................................................85

5 Left Brain Hemisphere Dominant Subjects Depicted on the Kolb Diagram.........86

6 Overall Cerebral Subjects Depicted on the Kolb Diagram...................................87

7 Predominantly Limbic Subjects Depicted on the Kolb Diagram..........................88 


\section{CHAPTER 1}

\section{Introduction}

Mankind's fascination with the mind probably dates back to and coincides with the onset of individual and collective self-awareness. Differences in mental functioning enable one individual to create and mentally retain many lines of specifically arranged 0 's and 1 's comprising computer microcode although routinely forgetting a specific phone number (Kidder, 1981); at the same time another individual is able to produce music or great art despite experiencing problems with freshman English. Speculation, dispute and responsible investigation sequentially and concurrently characterize the effort to understand human differences. Teachers and researchers are working to provide the best possible development of these individual differences, abilities and talents not only in individual students but also with various student groups. Educators and psychologists are investigating differences in problem solving and learning known as cognitive or learning style. At the same time, researchers in neurophysiology, psychology and education are producing new information related to individual differences in the area of specialized brain function and, more specifically, brain hemisphere dominance. Suggestions have been made that the two avenues of investigation, learning style and brain hemisphere dominance, are related (Blakeslee, 1982; Keefe, 1979; Kolb, 1984; McMullan \& Cahoon, 1979; Thies, 1979); it is this suggested relationship that is a primary focus of this study.

Another area evoking interest is the way in which individuals select others for close personal or working relationships. To select or be selected often has emotional roots in childhood while exacting serious consequences in the world of work. The act of selection is simultaneously mundane and important. Made mundane by the apparently casual and routine nature of daily decision-making, the selection process is important not only in emotional costs but also in tangible outcomes stemming from the selection of one individual over another to perform a particular job or work in a specific group. If, 
among the many factors impacting selection, a perceived, albeit unarticulated or even unaware, preference in learning style and brain hemisphere dominance exists, there are serious implications. These implications include productivity and effectiveness for both groups and individuals. The second focus for this study, therefore, is to investigate possible relationships among learning style, brain hemisphere dominance, and the selection of individuals for close working relationships.

\section{Statement of the Problem}

To be specific, the purposes of this study are to investigate (a) the relationship between learning style and brain hemisphere dominance; (b) the relationship between learning style and the selection of individuals as preferred supervisors, subordinates, or as members of a work project group; and (c) the relationship between brain hemisphere dominance and selection of individuals as preferred supervisors, subordinates, or as members of a work project group.

\section{Definitions}

Several concepts introduced in the paragraphs above require definition before further discussion. These include (a) learning style; (b) brain hemisphere dominance; and (c) the specifics of selection as a preferred supervisor, subordinate, or as a member of a work project group.

\section{Learning Style}

The entire area of learning style research and discussion is often clouded by conflicting and poorly defined terminology (Ferrell, 1981). It appears that some authors almost prefer to invent terminology in support of various approaches and theories thus making comparison and even understanding difficult. In general, learning style may be classified as various combinations of cognitive, sensory, interpersonal, intrapersonal and environmental factors impacting or intrinsic to the learner (Grasha, 1984). Although Keefe (1979) distinguishes between learning style and cognitive style, most writers, including standard indices such as Psychological Abstracts and 
Dissertation Abstracts, combine the two. Keefe (1979), however, provided a workable definition when he said: "Learning styles are characteristic cognitive, affective, and physiological behaviors that serve as relatively stable indicators of how learners perceive, interact with and respond to the learning environment" (p. 4). An approach to learning style that includes both cognitive and affective behaviors is provided by Kolb's Experiential Learning Theory (1984), which is, in turn, behaviorally measured by his Learning-Style Inventory (1985). Although this approach does not take into account the physiological dimensions mentioned by Keefe, these will be tied to this theory by the material presented in reference to brain hemisphere dominance. Operationally for this study, learning style is defined as those dimensions measured by Kolb's Learning-Style Inventory (1985). A more complete discussion of this instrument and its theoretical foundations is provided in the Review of Literature which follows.

\section{Brain Hemisphere Dominance}

Allusions to differentiated brain functioning date back at least as far as Hippocrates, although serious inquiry based on physicians' observations of brain injured patients began to surface in the late 1800's (Bogen, 1973). The work done with so-called split brain patients under the early guidance of Drs. Sperry, Gazzaniga, Bogen and Levy provided a great deal of serious research as well as heavy conjecture on the part of others less careful in their statements (Blakeslee, 1983; Corballis, 1980; Ornstein, 1972;1973, 1976; Wittrock et al., 1977). The split brain patient is one in whom the corpus callosum connecting the two hemispheres of the brain has been accidentally or surgically severed, sometimes in an effort to reduce severe epilepsy. More recently, cautions have come from those concerned that the split brain patient fails to provide a basis for generalizations to other populations (Hardyck \& Haapanen, 1979; Levy, 1983,1985). Solid research using humans and animals continues to progress, but many questions regarding specifics remain unanswered (Gazzaniga, 1985; Kimura, 1985). Although there is general consensus, for example, that for most right handed 
people, language is basically a function of the left brain, the right brain is also normally involved in the language process. The specifics of the relationship, however, are unclear (Gazzaniga, 1983,1985; Kimura, 1985). For the purposes of this study, therefore, although the basis for application of brain hemisphere dominance research is founded in neurophysiological and psychological studies, left brain hemisphere dominance and right brain hemisphere dominance are treated as constructs. Left brain hemisphere dominance is used to refer to more analytical, sequential, orderly and logical approaches to information processing while right brain hemisphere dominance refers to more holistic, artistic, intuitive and spatial approaches to information processing. A more detailed discussion of these issues follows in the Review of the Literature. For the purposes of this study, however, operationally left brain hemisphere dominance and right brain hemisphere dominance are those dimensions as measured by Herrmann's Participant Survey Form (1978).

\section{Selection Definitions}

As indicated in the Statement of the Problem, people make many decisions on a daily basis regarding individuals with whom they prefer to work and play. In the work arena, decisions frequently are made as to those preferred both within the hierarchical structure of the organization and also in peer associations encompassing special task forces, project teams and the like. To narrow the scope of this study to more manageable proportions, the work arena was selected as a focus. More specifically, three roles were investigated within the organizational hierarchy: (a) the supervisor, (b) the subordinate, and (c) preferred peers for work project groups. A supervisor is understood to be that individual who directs and reviews the work of another. Conversely, a suberdinate is that individual whose work is directed and reviewed by another. Within this context it is assumed that not only is there frequent contact between the supervisor and subordinate, but also that the role is considered to be important to each because of the way it impacts one's expectations of success and 
perceptions of the relative attractiveness of the work environment. Within the context of this study a work project group is understood to mean either a temporary or longterm group of organizational peers who are charged with accomplishing a specific task within a definable time period and at a satisfactory level of performance. Again, because of the way this work project group would impact success expectations and perceptions of work environment attractiveness, it is assumed to have a high level of importance to the individuals involved.

\section{Rationale for the Study}

In addition to the implications of this study already stated, it is believed that not only is the study based on theory deserving further exploration, but also the relative recency of interest in these subjects justifies further investigation. It is believed that findings derived from this study may have important implications both in support of their theoretical foundations and also in possible applications in the real world. Further, although similar studies have been conducted using different instruments and populations, it is believed that this study affords a unique perspective and area of investigation. Each of the specific elements of the study contributes to these general statements and will be explored in greater depth.

\section{Elements of the Study}

There are a number of elements contributing to this study, each of which has specific research and applications that make it important to the overall topic. These elements include (a) learning style, (b) brain hemisphere dominance, and (c) possible correlations between the two constructs.

\section{Learning Style}

Education, like other industries, is in an era featuring high accountability. Significant resources are expended in an effort to provide the educated populace needed to sustain a democratic form of government. Learning style research has been looked to as a possible basis for improving curriculum, academic and career counseling, designing 
more effective classroom strategies, and assisting instructors in better understanding their students. Although the literature abounds with various claims, sufficient research exists to support the need for further investigation. Whereas management educators specifically see the need for theoretical foundations for their work both in academia and in the marketplace arena of training and development (Freedman \& Stumpf, 1980; Randolph \& Posner, 1979), critics raise the issues of ambiguity, efficiency and effectiveness in the present state of learning style research (Freedman \& Stumpf, 1978, 1980; Grasha, 1984; Robey \& Taggart, 1981; Schweiger, 1983; Stumpf \& Freedman, 1981). Although this study could not possibly address all these issues, it at least points toward reducing ambiguity by focusing on a particular means of assessing learning style that is included in several current and major management education textbooks and has other widespread educational applications (Ferrell, 1981; Kolb, Rubin \& Mclntyre, 1984).

Brain Hemisphere Dominance

Similarly, concepts relating to brain hemisphere dominance are gaining popularity and are used as a basis for curriculum revision, changes in teaching strategies, and working more effectively with specific students (Blakeslee, 1982; Edwards, 1979; Mintzberg, 1984; Taggart, Robey \& Taggart, 1982). Again, whereas there is some justification in the research for these changes, critics claim that some practitioners may have exceeded responsible practice (Corballis, 1980; Ornstein, 1976). Although there are problems associated with measuring brain hemisphere dominance and some contend that achievable gains based on educational change related to these differences are negligible (Hardyck \& Haapanen, 1979), still it is possible to state that differences among students exist, that some of these differences are based on differences in brain hemisphere dominance, and that further investigation is needed to document which strategies most effectively accommodate these differences. Again, this study could not 
possibly address all these issues, but it was intended to clarify some important relationships and impact the measurement problem positively.

\section{Possible Correlations}

In both the learning style literature and that concerning brain hemisphere dominance, there are apparent similarities in descriptions of behaviors, outcomes and approaches. If what is being measured and investigated in each of these approaches, learning style and brain hemisphere dominance, is either the same or a very similar set of factors, there may be justification for collapsing and consolidating some research.

An element of concern is the confusion and difficulty of terminology in some of the research. This may stem from a fundamental disagreement regarding the stability of the factors under consideration. Although some feel that these factors are relatively stable (Freedman \& Stumpf, 1980; Keefe, 1979; Thies, 1979), others suggest that training individuals, particularly in management, to use both hemispheres and a variety of learning styles is appropriate (Blakeslee, 1982; Edwards, 1979; Freedman \& Stumpf, 1980; Hudson, 1975; Kolb, 1984; Mintzberg, 1984). Rather than insisting on an either/or model, there may be justification for both a belief in stability and the trainability of these factors. Other characteristics such as anxiety and even I.Q. appear to have elements of both state and trait associated with them. An analogy may be that the beginning pianist usually presents a preference in handedness. Through practice and exercise the dexterity and strength of the non-dominant hand and arm are increased to meet the pianist's needs; the process of learning to read music and play the piano allows the pianist to select the more appropriate hand to play a given note.

Similarly, the manager needs to be able to select from a variety of approaches the most appropriate way of addressing a given problem (Agor, 1983, 1984; Albrecht, 1980, 1983; Mintzberg, 1984; Piatt, 1983; Taggart \& Robey, 1981). In addition, the manager needs skill development in using the various approaches associated with different learning styles and brain hemisphere dominance. If learning style and brain 
hemisphere domiance are essentially the same characteristic and alternate means of assessing them are available, initial diagnosis is improved, pre-post test capacity is enhanced, and a variety of additional educational and training needs are met (Blakeslee, 1982).

It was toward addressing the question of relationship between learning styles and brain hemisphere dominance that the first part of this study was aimed. If, indeed, correlations were found among the factors measured by the Kolb (1985) and Herrmann (1978) instruments, it was felt that these relationships would provide a basis for further investigation. From a practical point of view, a correlation of both statistical and practical significance between the instruments would afford practitioners alternate measurement forms to use in different learning situations. If, for example, a quick approximation of learning behavior is needed, the Kolb (1985) instrument might suffice. On the other hand, if more detailed analysis is required because of the seriousness of the decision being made and a longer time frame is available, the Herrmann (1978) could be used in assessment. Similar decisions such as intended purpose, required detail, available time and money attend decisions to use short, groupbased I.Q. measures as opposed to lengthier one-to-one methods. Thus the correlational portion of the study addresses the need for alternate testing methodologies in support of divergent instructional needs. From a more theoretical point of view, if a relationship was found to exist between the two, it would add to the information regarding the concurrent validity of each. The validation of each instrument has been done primarily through correlational studies with other instruments. Specifically the Myers-Briggs Type Indicator (1962) has been correlated with both the Kolb and the Herrmann (Bunderson, Olsen \& Herrmann, 1978; Kolb, 1976) Other validation efforts have been made and will be discussed in the Methods portion of this study. Although several studies may be found that focused on learning style and brain hemisphere dominance, 
apparently only one published study exists using the two instruments in question, and it focused on the issue of career choices (Bush, 1984).

\section{Applications of the Study}

In addition to the correlational investigation, this study explored the possible relationships among learning style, brain hemisphere dominance and selection of individuals as preferred supervisors, subordinates, or as peers in work project groups. The question that was addressed is whether people tend to select those who are like or unlike themselves. If individuals select others as preferred supervisors, subordinates or members of work project groups because they have similar learning styles and/or brain hemisphere dominance, this has serious implications for problem solving as well as overall productivity. It has been suggested that the most creative approaches to problems are developed by groups bringing diverse perspectives and abilities to the problem solving task (Haustein, 1981; Janis, 1984; Likert, 1984). If work groups are composed of more homogeneous styles because individuals of the same style are usually selected, then creativity may be reduced (Manz \& Sims, 1982). On the other hand, the speed of decision-making and group cohesiveness may be negatively impacted when groups are composed of highly diverse members (Yantis \& Nixon, 1982). Thus, if this study showed that individuals tended to pick those who are most like themselves and the situation requires high creativity, then it might be more effective for selection to be made by someone other than the work project group members in order to ensure diversity among group members. In this case, however, training might also be required to enable work project group members to work effectively together as less cohesiveness is associated with more diverse groups. Conversely, if the study showed that individuals tended to pick those who are most unlike themselves, and the situation requires rapid decision-making, intervention in the selection process and training might also be required to enable the group to function effectively. Similarly, if individuals select others who are like themselves as subordinates, and creativity is required, someone 
else may need to intervene in the selection process. Again, training to increase the appreciation of the different styles would be needed to help overcome problems with low cohesiveness and the need to complete work in a timely fashion. Conversely, if individuals select others unlike themselves as subordinates, and high cohesiveness and rapid decision-making are required, intervention into the selection process and training may again be required to ensure effectiveness. The same dynamics and ramifications apply if individuals tend to select preferred supervisors who are like or unlike themselves.

Emphasis in the American workplace is currently on increasing participatory management and group problem solving through interventions such as Quality Circles and Project Management. The desirable composition of these groups is of critical importance from the standpoint both of the quality and quantity of production. In addition, the selection of individuals who are either similar or different carries implications in hiring practices, promotion, appraisal, and other areas of human resource management. These, in turn, impact an organization's position vis-a-vis Equal Employment Opportunity and Affirmative Action.

The second portion of the study, which deals with the possible relationships among learning styles, brain hemisphere dominance and selection addressed these issues. It was felt that if relationships were found, managers might need to be aware of these considerations in their planning, selection, training and other day-to-day operations.

\section{Limitations of the Study}

As with any study, there are certain limitations associated with this one. In this study, graduate management students who were enrolled in large interactive classes were used as the subjects. Although a small portion of the sample was drawn from a large public university, the majority of the students were enrolled in classes at a relatively small, church-related university. Almost all the students used in the study were employed at the time and, therefore, were enrolled in evening classes. Because the 
study was conducted in Miami, Florida, the sample includes not only representatives of Black, Caucasian, and Hispanic backgrounds but also included a number of international students from Central and South America as well as Africa and Asia. These factors must all be considered when implications and generalizations are drawn from the study. 


\section{CHAPTER 2}

\section{Review of the Literature}

Before going into any more detail regarding the study to be undertaken, a review of the research and history of the elements involved needs to be accomplished. This includes the research background on 1) various approaches to learning style, 2) brain hemisphere dominance, and 3 ) issues relating to selection.

\section{Learning Style}

Several years ago, Phi Delta Kappan published an article entitled "Learning Style: The Myth, The Panacea, The Wisdom" (Davidman, 1981). As Davidman suggests, from the beginning of serious interest in identifying and using perceived and measured differences among students in an effort to improve educational effectiveness, the concept of learning style has too often been surrounded not only by myth but also by promises reaching the level of panacea. Many discussions of learning style indicate a lack of clear definitions that include some indication regarding the trait/state issue and and also provide a means of comparison of the various theories.

\section{Background of Learning Style}

Thus, the most basic issue in learning style research involves the apparently simple task of definition (Dunn, 1984; Gregorc, 1979 a \& b, 1984; Hunt, 1979; Pigg, Busch \& Lacey, 1980). Research in the field seems to split between writers who examine two specific dimensions, and those who approach the subject from a multi-dimensional point of view (Doyle \& Rutherford, 1984; Guilford, 1980; Messick, 1976; Smith \& Renzulli, 1984). The two-dimensional approach usually involves a continuum with ends such as Field Dependent/Field Independent (Witkin, Moore, Goodenough \& Cox, 1977), or Leveling/Sharpening (Gardner, 1959). A multi-dimensional approach may include a number of characteristics such as Extroversion/Introversion, Sensation/Intuition, Thinking/Feeling, and Perceiving/Judging within a single 
instrument such as the Myers-Briggs Type Indicator (Myers, 1962). In application, the two-dimensional approaches and measurements related to them run the risk of being too simplistic and so overly generalized that significant differences may not be found (Scott, Osgood, \& Peterson, 1979). On the other hand, a multi-dimensional approach, such as that used by Dunn, Dunn and Price (1978) in their Learning Style Inventory which assesses numerous dimensions, has been criticized as both foolish and too rigid in its complexity (Davidman, 1981).

Other issues relating to the difficulties in determining meaningful distinctions in learning style stem from the basic nature of the differences. Thies (1983), for example, asserts that some differences, such as sensitivity to light, sound, and temperature, are genetic, whereas other differences, such as motivation and persistence, are the result of prior experience. In several studies, differences have been found between males and females (Kolb, 1976; Messick, 1976; Restak, 1979; Witkin, 1976). Whether these differences are inherited tendencies or the result of learned behavior during cultural socialization is not known. It has also been suggested that the characteristics of Introversion and Extroversion may be inherited (Schmeck \& Lockhart, 1983). Again it is difficult to determine whether this is so, or if the characteristic is the result of early training. The suggestion of an hereditary aspect to learning style indicates the strength of the characteristics being studied. Without conclusive evidence one way of the other, however, it may be concluded that some differences may be quite stable throughout the learner's lifetime requiring constant accommodation, others may be stable to the point of requiring relearning to change them, while still others may be developmental, as implied in Piaget's work (Messick, 1976; Witkin, 1976).

Efforts have been made to categorize learning style to allow comparison and contrast. Grasha's (1984) chart, for example, uses the categories of cognitive, sensory, interpersonal, intrapersonal and environmental. Another organizing attempt is 
represented in Gonsalves' (1983) bibliography using the categories of 1) Field Independence and Field Dependence, 2) reflection and impulsivity, 3) psychological differentiation, 4) category width, and 5) cognitive complexity to separate the research found in her computer search. There are problems associated with each of these organizing efforts, and it may be that fewer rather than more categories are needed. While not implying that each writer is talking about exactly the same thing, it may be that the characteristics described are similar enough or describe different aspects of the same process so as to make a broader category meaningful while still allowing enough definition to support measurement. One such categorization that appears to be useful is the Global/Analytical dimension. The Global side of the continuum might encompass such characteristics as Field Dependence, Leveling, and Feeling, while the Analytic end encompasses Field Independence, Sharpening, and Thinking. A second categorization that may be used describes overall conceptual tempo with the Reflexive and Introverted on one end and the Impulsive and Extroverted on the other. Between the two continuums, however, are some descriptions and explanations that fail to fall neatly into either continuum primarily because they are heavily colored with emotion. They may actually belong to the affective domain rather than the more clearly cognitive area. To more fully explore the possibility of categorizing learning style theory using these dimensions, however, it is first necessary to review the characteristics in question and some of the research associated with them. The specific characteristics include 1) Field Dependence/Field Independence, 2) Leveling/Sharpening, 3) Concrete/Abstract, 4) Convergent/Divergent, 5) Reflexive/Impulsive, and 6) Introversion/Extroversion. The major categories are 1) the cognitive, 2) the affective, and 3) the conceptual tempo or behavioral. Although a breakdown by cognitive, affective, conceptual tempo partly follows Keefe's (1979) definition and categorization, there are some differences because he spoke of the cognitive, affective, and physiological. He also placed various theories differently than they are placed here. 


\section{Cognitive Measures of Global and Analytical Function}

The first of the primarily cognitive measures is Field Dependence and Field Independence which measures a student's Global or Analytical information processing on a continuum (Witkin et al., 1977). Field Dependents tend to impose their own structure on a given task and have difficulty distinguishing parts from the whole. Thus they are less likely to perceive objects in the Group Embedded Figures Test (Oltman, Raskin \& Witkin, 1971) normally used to measure Field Dependence and Field Independence. They have been found to be social, outgoing, friendly and people-oriented (Witkin et al., 1977). They are able to recognize people more quickly than Field Independents. In contrast to Field Dependents, Field Independents separate the parts of the task from its existing pattern and will try out alternate patterns if necessary to understand a task (Witkin et al., 1977). They are more introspective than the Field Dependents and not oriented to social interactions. They also rely less on others than Field Dependents and are much more controlled in their expression and behavior. Messick (1976) found Field Dependents to be more often interested in the social sciences, clinical psychology and nursing, whereas Field Independents tend to be more interested in natural science, engineering and math. Both Messick and Witkin (1976) also found more females among the Field Dependents than males, but this may simply reflect cultural socialization forces as noted earlier.

Another approach to the cognitive area is Gardner's (1959) Leveling and Sharpening. Individuals who tend to Level will incorporate new learning with old, remembering whole situations rather than focusing on separate aspects. Sharpeners, on the other hand, tend to remember specifics more clearly than the whole. It would appear that Leveling may be associated with the Global category while Sharpening is more like the Analytical category. Before it is assumed that Field Dependence and Leveling are the same thing, however, it must be pointed out that whereas Field Dependence deals with what is perceived, Leveling is more concerned with how the perceived material is 
mentally processed. Thus the two terms may refer to different aspects of the entire process of information processing.

Kagan (1966) also supports the notion of a Global/Analytical continuum when he used the term Thematic to describe the Global approach to information processing. He uses the term Analytic to describe the opposite of Thematic. Similarly the Thinking and Judging aspects of the Myers-Briggs Type Indicator (1962) may be related to the Analytical end of the continuum while the Perceiving, Intuiting, and Feeling measures may relate more to Global processing. If these last are included, however, a new difficulty arises as the element of emotion or affect is now introduced. Therefore, it is proposed that Global will broadly encompass Field Dependence, Leveling, and Thematic, whereas Analytical will broadly include Field Independence, Sharpening, and Thinking in the cognitive domain. Judging, Perceiving, Intuiting and Feeling, while involving some cognitive aspects, fall more clearly into an affective domain.

\section{Affective Measures}

In addition to the dimensions such as Judging, Perceiving, Intuiting, and Feeling which have affective overtones, Gregorc's (1979a; 1984) distinctions between the Concrete and Abstract also fall primarily into the affective domain. In describing individuals he classifies as Concrete Sequential, he uses terms such as orderly, predictable, practical and down-to-earth, all of which imply relatively low emotionality or affect. In contrast, his Concrete Random individuals operate with high intuition and quickness. Overall Gregorc sees the Abstract as intellectual and ties it into the cognitive Analytical category described earlier. When speaking of Abstract Random learners, however, he describes them as emotional, imaginative, and intuitive, which is a more affective description.

Similarly Messick (1976) describes his Convergent style as logical, consistent, correct and conventional which appears to correspond to Gregorc's Concrete. The other side of Messick's continuum, however, brings in the third aspect of the categories 
because he says the opposite of the Convergent is the Divergent learner who relies heavily on a quantity and variety of output, thus bringing in the aspect of conceptual tempo.

\section{Conceptual Tempe and Jungian Constructs}

While Kagan (1966) used the cognitive characteristics of Analytical vs. Thematic or Global, he also emphasized the importance of conceptual tempo as reflected in either Impulsive or Reflective information processing. Like Messick's (1976) Diverger, Kagan's Impulsive individual often gives quick, and frequently inaccurate, responses, while the Reflective learner takes the time to develop alternative answers, check his or her work and usually is more accurate. Guilford (1980) suggests that this emphasis on conceptual tempo is simply a subset of another pair of concepts: Extroversion and Introversion. Extroversion and Introversion are most commonly associated with the Myers-Briggs Type Indicator (1962) assessment of style, which is based on Jungian psychology. Messick's (1976) research also points toward Field Dependence as associated with Extroversion while Field Independence is associated with Introversion. In dealing with Extroversion and Introversion, caution must be used. Whereas the Extroversion category may be seen as outgoing, talkative and exhibiting a high level of activity, the preferred application of Introversion is not to the shy, quiet and retiring individual Americans generally call introverted. A more appropriate interpretation of Introversion is the European understanding of the reflective individual who measures events and experiences against an internal set of values and understandings, thus implying aspects of the cognitive domain within this particular term (Lawrence, 1982).

It would appear, therefore, that within the overall categories of cognitive, affective and conceptual tempo or behavioral, most of the major two-dimensional learning style theories can be roughly accommodated. This appears to fit Keefe's (1979) definition of learning style that included "characteristic cognitive, affective and physiological 
behaviors that serve as relatively stable indicators of how learners perceive, interact with and respond to the learning environment" (p. 4). It would appear that the cognitive and affective domains are covered in these categories. Keefe's physiological dimension is not, however, really addressed in this categorization. In the area of learning style, however, what is still needed is a formal, agreed-upon, theoretically-based definition encompassing most of these concepts and using similar terminology without being so complex that application and even measurement is difficult, if not impossible. One theory that approaches these criteria, while also having a basis in learning theory other than just learning style, is Kolb's theory of experiential learning (1984). Experiential Learning Theory

Rather than focusing on two dimensions positioned along a single continuum, Kolb suggests a 2-factor bipolar model which provides some specific measures but also allows for multiple combinations. The dimensions Kolb uses are a continuum between the Concrete and the Abstract, and a second continuum between the Active and Reflective. (see Figure1) Rather than being consistent with Gregorc's (1984) Concrete and Abstract, Kolb sees the dimension of Concrete and Abstract in more Piagetian constructs, although the developmental aspects of Piaget are not implied here. He sees this dimension as the one that describes the means by which information is gained or grasped. Kolb uses William James's concept when he speaks of the knowledge of acquaintance, or that information which is grasped through sensory experience. It is also reminiscent of Assagioli's (1973) apprehension of reality in which feeling and intuition are used in a direct and immediate grasping of a Gestalt. On the opposite end of the continuum from the Concrete is the Abstract which represents processed knowledge. It is comprehended or, as he suggests, an order is applied to the flow of perceptions flooding the mind. It corresponds to James's knowledge about and involves some distortion of perceptions because these perceptions have been processed rather than simply apprehended or perceived. 


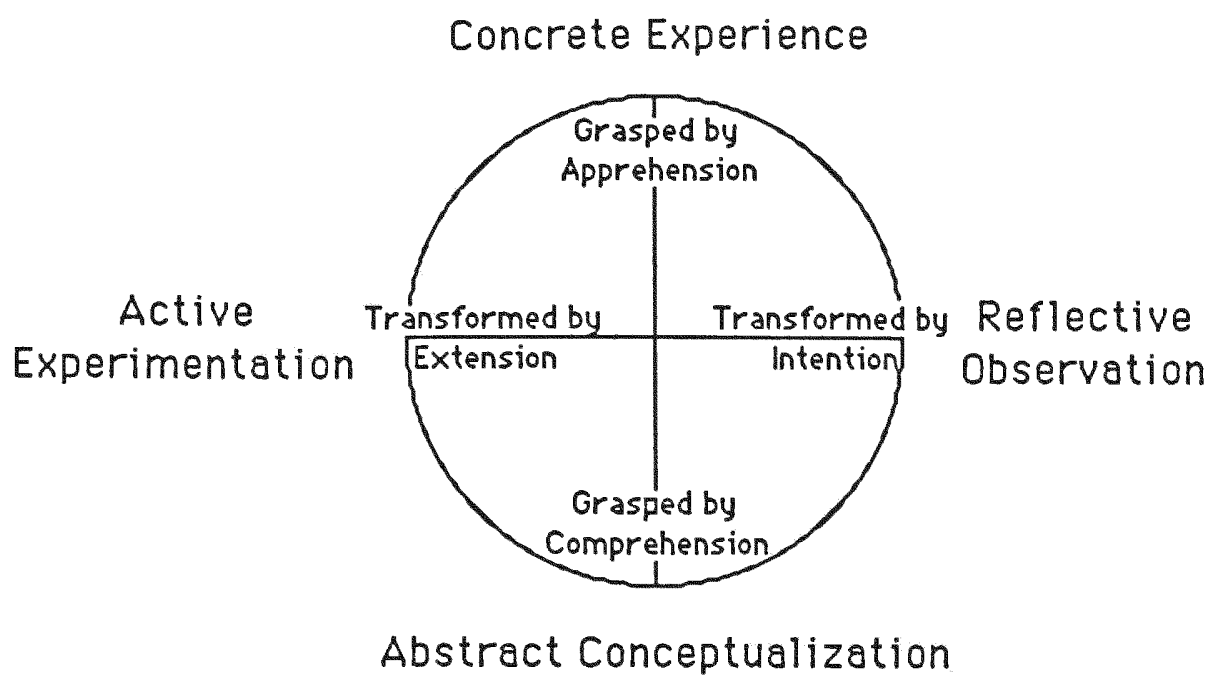

Figure 1; Kolb's Theoretical Model (Kolb, 1984, p. 42).

Kolb's other dimension, the Active/Reflective, is reminiscent of Kagan's (1966) Impulsive/Reflective, and the Jungian concepts of Extroversion and Introversion. Kolb sees this continuum as describing the way information is processed or transformed. He feels that this transformation may either occur through Reflective Observation using the process he calls intention or by Active Experimentation using the process he calls extension. Intention is the process of imagining or reflecting internally about events and concepts, whereas extension is understanding events and concepts by using behaviors and the external world as a focus.

By combining the various poles, Kolb is able to create profiles of at least four prototypical learners. When experience grasped through apprehension is transformed by extension, the resultant learning style is termed Accommodative. (see Figure 2) Relying heavily on Concrete Experience and Active Experimentation, the Accommodator is the most active, risk-taking and adaptive of the four styles. Tending to solve 
problems by intuitive trial-and-error, the Accommodator also tends to rely heavily on other people rather than data or his or her own analysis for information (Grochow, 1973; Stabell, 1973). This style is somewhat reminiscent of Kagan's (1966) Impulsive who often offers the first answer, with frequently inaccurate results, and also of Witkin's (1977) Field Dependents who rely on others for information.

Concrete Experience

Active
Experimentation

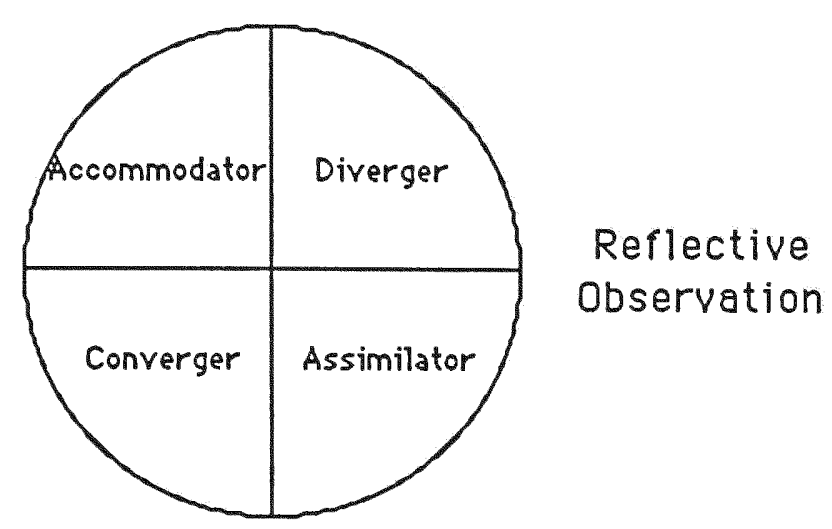

\section{Abstract Conceptualization}

Figure 2: Individual Learning Styles (Kolb, 1984, p. 42)

By contrast, the individual who also grasps experience by apprehension but transforms it by intention, is termed a Diverger. The Diverger shares the Accommodator's use of Concrete Experience but uses Reflective Observation rather than Active Experimentation to process his or her experiences. This emphasis on reflectivity allows the learner to view Concrete Experience from many different perspectives before organizing relationships into a whole picture or a Gestalt. Here the learner excels in the generation of alternate approaches (Guilford, 1977), tends to be imaginative and is concerned with the meaning and value of experience. This learner sounds somewhat like Kagan's (1966) Ihematic who attempts to find a Global pattern in presented material. 
When experience is grasped through comprehension, it may also be transformed either through intention or extension. When intention is used, the learner is similar to Kagan's (1966) Analytic who sees parts and tries to find patterns. Kolb calls this style the Assimilator because the learner assimilates disparate observations into integrated concepts (Grochow, 1973). Concerned less about people than learners with the two previous learning styles, the Assimilator is also not so concerned for the practicality of his or her theories, but rather is concerned with logical soundness and precision. An elegant theory is the aim of the Assimilator.

Finally, persons with the fourth style use comprehension or Abstract Conceptualization as does the Assimilator, but transform it through extension. Thus, the primary concern for this individual is the practicality and applicability of a concept to the situation at hand. Using deductive reasoning rather than the inductive processing of the Assimilator, the Converger, as this type is called, excels at problem solving and decision making. The Converger excels in situations such as conventional intelligence tests in which a single answer is correct (Guilford, 1977; Kolb, 1976). In addition to Messick (1976), Hudson (1975) also uses the terms Converger and Diverger. In his studies Hudson identified Convergers, like Witkin's (1977) Field Independents, as far more controlled in their expression of emotions than Divergers. He characterized the Converger as the scientist and and Diverger as the artist. Kolb's Divergent/Convergent distinction is also supported by Guilford (1980) who saw this "as example of a choice between two intelleclual operations" (p. 731).

Kolb's Experiential Learning Theory, therefore, deals with two continuums, the Concrete/Abstract and the Active/Reflective. While having similarities to other learning style theory, Kolb makes an effort to discuss not only the way information is perceived but also the way in which it is processed. In addition, he attempts to identify four specific styles of learning by combining the poles of his continuums. Kolb also 
suggests some ways of measuring these dimensions and assessing individual learning style through his Learning-Style Inventory (1985).

\section{Measurement and Kolb's theory}

Generally discussions of the validity and reliability of instruments used in studies appear in the discussion of the methods used in the study. In this case, however, because there have been some indications of potential measurement problems, it seems more appropriate to include this discussion in the Review of the Literature. In addition, this very issue presents an ironic illustration of some of the difficulties associated with the use of learning style in a practical situation. Whereas someone may have great skill in creating theories or suggesting ideas, this same person may lack those specific skills required to develop or implement the means of measuring or analyzing the output of a study springing from the original idea. The concept of the skilled and knowledgeable worker who is able to appropriately choose to use skills associated with different task requirements is illustrated here.

Before addressing the specifics of the validity and reliability of the Kolb LearningStyle Inventory, a brief review of some of the concepts associated with validity and reliability may be in order. It must be remembered that these factors are not absolute but instead are relative measures (Gay, 1987). For example, it cannot be said that something is valid, per se, but rather that it has a sufficient level of validity to meet stated statistical or practical needs. Judgment must be exercised in evaluating instruments relative to the purposes for which they are intended, the population of the study, acceptable levels of validity and reliability, and the stability of the characteristic being measured. Thus an instrument intended as the basis for lifetime career decisions must be more rigorous than one intended to stimulate discussion and raise questions. Similarly an instrument intended to provide a picture of current functioning will be different from one intended to carry the weight of lifetime certainty. 


\section{Test construction}

Two versions of Kolb's Learning-Style Inventory exist, an original one (OLSI) first published in the early 1970's and a new version (LSI) with a 1985 publication date. The OLSI consisted of nine sets of four words each which were to be ranked in order of most to least descriptive of the learner. These had been derived from a much longer list by a panel of four experts familiar with Kolb's Experiential Learning Theory and judged by them not only to reflect the theory but also to have equal social desirability. Statistical analyses required that 12 of these words be discarded since overall correlations with the total lists for the subgroups was less than $I=.45$ using Pearson' $s$ product moment correlation formula. Eventually a total of 24 words, six for each of the four characteristics, was used thus yielding four subscales. The words used had correlations with their respective subscales ranging from .46 to .73. Negative correlations were also found between specific words and the opposite pole of the continuum in which they fell and these ranged from -.18 to -.50 . These correlations were based on an initial sample of 287 graduate level management students. A follow-up study with a sample of 807 management students and active managers produced correlations between the Concrete Experience measures and the Abstract Conceptualization measure of $-.57(\mathrm{R}<.01)$. The other scale, Reflective Observation and Active Experimentation, correlated at -.50 ( $(2<.01)$. Kotar (1980) calculated Pearson I's with a sample of 262 and found the following results: Concrete Experience/Abstract Conceptualization, -.53; Reflective Observation/Active Experimentation, -.56; Abstract Conceptualization/Reflective Observation, -.16; Abstract Conceptualization/Active Experimentation, -.21, all at $\mathbb{R}<.01$ (see Table 5). Another study (Reinken, 1977) reported correlations between Concrete Experience/Abstract Conceptualization at -..47 $(\mathbb{R}<.01)$ and between Active Experimentation/Abstract Conceptualization at - .33 $(\mathbb{R}<.01)$. When Kotar calculated Pearson I's using Kolb's combination scores, Abstract Conceptualization minus Concrete Experience (AC-CE) and Active Experimentation 
minus Reflective Observation (AE-RO), he found that the first, $A C-C E$, correlated with Abstract Conceptualization at .89 , whereas it correlated with Concrete Experience at -.86. In correlating the second scale, AE-RO, he found a Pearson $\mathrm{r}$ of .86 with the Active Experimentation scale and -.90 with the Reflective Observation scale. Kolb's visualization of the two dimensions of his instrument as bipolar is reminiscent of Messick's (1976) view of his Convergent and Divergent measures as bipolar; Guilford (1980), however, states that -.30 level of correlation cannot support the bipolarity of Messick's factors. Whether Guilford would accept Kolb's levels at -.57 and -.50 for the Abstract Conceptualization/Concrete Experience and Active Experimentation/Reflective Observation subscales is unknown. Kolb's findings are, however, substantiated by Kotar's (1980) findings of -.53 and -.56 using the same measures respectively.

\section{Norm group}

Although the group used to norm the OLSI was acceptable for the purpose of this study, the norm group for the new instrument is more acceptable. This is because the management norms for the OLSI were based on 741 males, 512 of whom were graduate management students at Harvard and Massachusetts Institute of Technology (MIT) while the other 182 were practicing managers. General norms were based on 1,933 individuals aged $18-60$ of whom $2 / 3$ 's were male and $2 / 3$ 's had a college degree or higher. The new LSI is normed on 1,446 adults, aged 18-60. Of these 638 were male and 801 female; 705 were in the 18-24 age group, 351 aged 25-32, 268 aged 35-45 and 101 over 45 . Thirty-three had high school level educations, 1,253 some college, and 76 more than a college degree. The language on the LSI has been drastically simplified, the test lengthened, and the norm group is said to include ethnically diverse subjects. These changes appear to make the LSI more acceptable for a more diverse group of management students than the more narrow Harvard and MIT sample on which the OLSI was normed. 


\section{Validity of the instrument}

In addition to the appropriateness of an instrument for a particular group, there are other selection issues related to be validity. Kolb's efforts to establish concurrent validity of the OLSI have been varied. Some correlations were done between the MyersBriggs Type Indicator (1962) and the OLSI (Kolb, 1976). Although the results tended to go as predicted, the strongest correlations were between the Myers-Briggs Feeling/Thinking dimensions and the OLSI Concrete/Abstract $([=-.35, R<.01)$; between Introversion and Reflective Observation ( $[=.34, \mathbb{R}<.01)$; and between Extroversion and Active Experimentation $([=-.27, p<.05)$. Correlations were also sought between the Alternate Uses Test (Christensen, Guilford, Merrifield \& Wilson, 1960) and Mednick's (1962) Remote Associates Tests. Although these are often considered to be the most consistent tests of Divergent thinking and the Abstract/Concrete dimensions, insignificant and occasionally contrary results were obtained by Kolb (1976). He stated that perhaps these tests were not appropriate for the group to whom they were administered because of the age and educational level of the subjects. Correlations with the Wonderlic Aptitude Test (1972) for industrial managers were found to be significant with the predicted relationships between the Active and Abstract dimensions (Kolb, 1976). An independent study by Tenore (1984) correlated the OLSI, the Group Embedded Figures Test (Oltman et al., 1971), and his own Learning Style Assessment Inventory; he concluded that operational definitions of learning styles are not uniform. Tenore's (1984) Pearson product moment correlations between Abstract Conceptualization and Field Independence was .24 ( $(2<.01, N=134)$. When Kolb (1985) correlated the OLSI with the total new instrument (LSI) using the Pearson product moment formula, his results ranged from .87 to $.93(\mathbb{R}<.01)$ on the various subscales.

There have been some criticisms of the OLSI's validity which bear investigation. It would appear, however, that the major criticisms have come from individuals who may not have understood the OLSI and the theoretical basis for it, or who may have used the 
instrument inappropriately. Ferrell (1981), for example, conducted a factor analysis involving four learning style instruments. She attempted to see if the measurements actually related to Keefe's (1979) definition of learning styles which involved the cognitive, affective, and physiological aspects. She concluded that none of the instruments was adequate to measure all these dimensions. The OLSI never purported to measure such an ambitious array of behaviors. Because Ferrell questioned the results of learning style instruments as they were being used with students in junior and senior high school, her study sample consisted of senior high and community college students. Based on the original norm group for the OLSI, it may be argued that the instrument is inappropriate for any group with less than several years of higher education.

Another criticism of the OLSI is West's (1982) factor analysis of OLSI results of 42 first year medical students with subscores derived from the Myers-Briggs Type Indicator (1962), the Survey of Interpersonal Values (Gordon,1976) and the Omnibus Personality Inventory (Heist \& Yonge,1968). In this study West failed to find much of significance, although he found that Convergers had higher scores of social acceptability than did Divergers at the $\mathrm{R}<.05$ level. This might be expected because Convergers tend to be more conventional, while Divergers are more artistic and intuitive. West hypothesized that Divergers $(\underline{n}=6)$, would score higher than Convergers on Extroversion. Although his results were not significant, and certainly it can be seen that it is not a large enough sample to consider seriously, West commented that the results actually tended toward Divergers scoring higher in Introversion. As stated, in Kolb's (1976) original validation studies, a correlation was hypothesized and found between Reflective Observation, which is one of the dimensions comprising Divergence, and Introversion. With two groups Kolb found correlations of .34 and $.36(\mathrm{D}<.01)$ between Reflective Observation and Introversion. Thus West's findings tend to support Kolb's original understanding of the instrument rather than the hypotheses of his own study. 
Kolb also undertook validation studies that looked at correlations between learning styles and the undergraduate majors of students in his study. In general, he found that individuals with people-oriented fields such as education, psychology and the arts tended toward Concrete Experience where as Science and Math majors tended more toward Abstract Conceptualization which is consistent with his theory. His findings were consistent in 1976 and 1985, with the exception of the fields of history, nursing and business. The 1985 group of history undergraduate majors included only 8 subjects and may be disregarded. Similarly the nursing undergraduate group from the 1976 study is quite small $(n=13)$, and the shift between the two studies is not large. With business undergraduates, however, the 1976 group included 67 individuals while 45 people were included in the 1985 test; also the shift appears large from the Accommodator area (1976) to the Converger area (1985). This may be related to a more conservative business climate in 1985 when compared to 1976 or to changes in undergraduate business programs and curricula. Another difficulty with this validation effort is that Kolb found his 29 law enforcement undergraduates far into the Reflective Observation dimension. This is not consistent with this author's experience using the OLSI with police officers. This author's observations have informally placed most police officers in the Converger arena; these observations are also corroborated by independent observations made by a professional trainer in the law enforcement area who uses the OLSI extensively in her training activities. (Weaver, B., personal communication, September, 1985). Using a number of different statistical procedures, however, Kotar (1980) found correlations ( $\mathbb{2}<.01)$ between Kolb's learning styles and personal characteristics associated with careers which tend to support Kolb's overall validation efforts.

Merritt and Marshall (1984), following Kerlinger (1973), assessed the OLSI as an ipsative measure and used the same words Kolb had used in an inventory format in which students rated each word as characteristic, somewhat characteristic, somewhat 
uncharacteristic and uncharacteristic of themselves. They intended to develop a normative scale measuring the same characteristics as the OLSI. In analyzing the OLSI as Kolb had originally scored it, their estimates of internal reliability using Stanley's alpha coefficient ranged from .29 to .59 . Using their normative version, internal reliabilities ranged from .52 to .74 . The mean scale reliability for the normative version was .60 while the original form yielded a mean of .46 . Their correlations of equivalency between the OLSI and their normative version ranged from .17 on the Active Experimentation subscale to .44 on the Abstract Conceptualization subscale (Merritt \& Marshall, 1984, p. 467). While tending to substantiate the relative strength of the Abstract Conceptualization subscale, these results also point up the fairly consistent problems with the Active Experimentation subscale.

It would appear that the terminology and methodology of the LSI appropriately relate to Kolb's theory and the constructs underlying it thus providing acceptable face validity. Based on all these measures, it is felt that Learning-Style Inventory (1985) has acceptable content, construct and concurrent validity for the group involved in this study and the purposes intended.

\section{Beliability of the Kolb}

One of the reasons for revision of the OLSI has been a recurrent issue of reliability. Freedman and Stumpf (1978) concluded overall reliability of the OLSI was .58 by calculating alpha coefficients and using test-retest procedures. Their alpha coefficient reliability estimates ranged from .40 for Concrete Experience to .70 for Abstract Conceptualization. The difference scales (AC-CE and AE-RO) yielded a median of .71, which they assessed as moderate reliability (Freedman and Stumpf, 1978). The new version (LSI) yielded .73 to .83 correlations using Cronbach's standardized scale alphas (Kolb, 1985). Tukey's Additivity Powers test resulted in internal reliabilities of .91 to 1.09 . 
Freedman and Stumpf's (1978) test-retest results using 101 students with a five week lapse between testing yielded a range of .39 for Concrete Experience to .63 for Abstract Conceptualization. Kolb also did test-retest studies with the OLSI in his 1976 studies. Based on his belief that learning might occur which would contaminate the testretest results, the time period which elapsed in the four test-retest situations was from three to seven months. The best of these measures resulted in a range of .61 to .71 , and this was the test-retest situation that was three months in time span and in which the subjects experienced very similar situations throughout the testing period. Geller (1979) reports test-retest correlations of .51 to .70 among medical students in a review situation lasting 31 days, while Reinken (1977) found test-retest reliabilities of .60 in a pilot study. It should be kept in mind in evaluating these findings that it has been suggested that anything longer than one month may be too long a period for testretest studies although others feel that three months is an acceptable time period for test-retest studies, depending on the type of instrument (Gay, 1987).

Using a split-half approach with the OLSI, Kolb was able to obtain an overall .80 using the Spearman-Brown correction formula and a sample drawn from a combination of management graduate students, practicing managers and some female undergraduates $(N=490)$. Actually his range on the combined scores ( $A C-C E$ and $A E-R O)$ was from .74 to .86 (Kolb, 1976), while ranges for the subscores were from .55 to .75 . Kotar's study in 1980 with a sample of 262 , using the Spearman-Brown to determine splithalves, yielded the following: Concrete Experience, .44; Reflective Observation, .62; Abstract Conceptualization, .59; Active Experimentation, .42, on the subscales and on the combined scores, AC-CE and AE-RO, .67 and .74 respectively. Reinken's (1977) split-halves were Concrete Experience, .55; Reflective Observation, .62; Abstract Conceptualization, .75; and Active Experimentation, .66. Finally, Kolb did split-half tests using the OLSI terminology and the six sets of new items in the revised LSI test. 
These yielded a range from .71 to $.85(p<.01)$ using the Spearman-Brown correction formula (see Table 4).

One of the considerations found in conjunction with this was the importance of the instructions given at the time of administration (Plovnick,1975; Talbot, 1983; Kolb, 1976). In the particular study Talbot (1983) discusses, the subjects were asked to take the OLSI while thinking about specific situations such as going to a party, completing a required reading, or playing a competitive game. Results were slightly different given the situation involved. Rather than relating to the reliability of the instrument, it is felt that this reflects the situational nature of learning style that enables individuals to use different skills at appropriate times. It does, however, point up the necessity for strict controls in the form of instructions to the subjects.

When discussing the OLSI, Kolb (1976) states that standard measures of reliability such as split-half and test-retest are of limited applicability for his instrument. The split-half argument was based on the shortness of the original test and has been solved with the new revision. Kolb argues that test-retest is a problematic methodology because students carry over their learning from the first administration to the second with such a short test, and also that experience may not only change test results, but that it actually should change the results if real learning is taking place. Although testretest results are not a specific issue with this study because the instrument will only be administered once, certainly caution needs to be exercised in administration based on the Plovnick (1975) and Talbot (1983) studies. Overall the reliability of the Kolb LSI (1985) is assessed at between .71 (Reflective Observation) to .84 (Abstract Conceptualization) using split-half studies, and, using Pearson correlations between the OLSI and LSI, between .87 (Reflective Observation) and .92 (Abstract Conceptualization).

Even though there may be a long way to go in learning to assess learning styles, not the least of which is defining what it is that is being measured, progress is being made 
toward Grasha's (1984) requirement that instrumentation be found or developed which features internal consistency, test/retest reliability, construct and predictive validity, with data that can be readily used thereby providing a high level of satisfaction and improving the ability to acquire and use content while it can "perform its magic in ways that are clearly superior to those possible without it" (p. 47).

\section{Learning Style Studies}

Most of the applications of Kolb's theory and independent studies based on both his model and the Learning-Style Inventory are in the area of management education rather than management in industry. The applications range from using his model in the development of management education courses (Carricato, 1982; Serrapore, 1977), to matching Kolb's categories to types of people in various careers (Gypen, 1981; Kolb, 1976, 1985; Sims, 1981). Several studies (Dorsey \& Pierson, 1984; Leflar, 1980; Posey, 1984) used the instrument to place students in groups in order to increase appreciation of individual differences and also to facilitate learning. Others (Barrie, 1984; Koch, 1984; McCall, 1984; Pollack, 1984) investigated the effects of different teaching methods, learning environments, specific content and teachers' learning styles. They concluded that although learning style and learning environment appear to positively impact learning and some gains are made when teachers and students are matched on some dimensions, in general the results did not justify major efforts to develop specific classes for students and teachers with particular learning styles. Although the subject of matching and mismatching styles emerges throughout the literature, little else that is conclusive has surfaced except the allegation that a prolonged mismatch will produce stress (Cafferty, 1980; Cronbach \& Snow, 1977; Good \& Stipek, 1983; Hyman \& Rosoff, 1984; Pollock, 1984; Practical Application, 1980; Strot, 1985). It does appear, however, that either through teacher/student mismatches or content mismatches, changes in style can be effected (Daves, 1984; Gypen, 1981; Hunt, 1979; Kagan, 1966; Reinken, 1977). 
Differences among students found in the studies range from relatively fixed to those more open to change. Males, for example, seem to consistently test higher in Abstract Conceptualization than females do (Kolb, 1976; 1985; Strange, 1978). Although several studies used the Kolb in teaching computer skills, one (Woelfl, 1984) investigated the way individuals with different styles conducted computer searches. She found that students testing high in the Concrete dimension did multicycle searches while these who were more Abstract in style did single tightly integrated searches. Those who were more Reflective expended more effort, thus developing more references, while the more Active types used less effort and produced more abbreviated products. This would appear to be similar to Kagan's (1966) Reflective/lmpulsive dichotomy. Also, with increasing age, Reflection appears to increase (Dorsey \& Pierson, 1984; Kolb, 1985). Finally, occupations and levels within the organizational hierarchy seem to be related to learning style, but whether this is a function of a changing learning style or a fixed one that predisposes one to certain occupations or makes one more likely to be promoted is unknown (Banks, 1977; Dunn, 1982; Kolb, 1976; 1985). When Dunn (1982) used the OLSI to determine whether there were sufficient differences between business people and educators to justify establishing different norms for educators, he determined that such differences exist. Using t-tests, in general he found business people to be higher on Abstract Conceptualization whereas educators were higher on Active Experimentation and Concrete Experience ( $\mathbb{Q}<.01)$.

To summarize, there are significant differences among people which can be measured with an acceptable degree of reliability and validity using a specific, well-defined theory and given specific situations. Learning style, although relatively stable may change because of age, learning content, situation or instructor. Mismatches of style, while not sufficient to warrant major revision of the learning situation, should be accounted for in planning for education or training. 


\section{Brain Hemisphere Dominance}

The literature relating to differences in brain hemisphere dominance historically stems from the earliest writers and encompasses an array from unfounded conjecture and speculation to very specific, rigorously controlled scientific experimentation. With roots in so-called common sense, mythology (Corballis, 1980), sociology (Lee, 1950), and the observations of early physicians (Bogen, 1973), the concept of differences in brain hemisphere dominance is applied from education to career development and is seen by some as the panacea for American business (Agor, 1983, 1984; Albrecht, 1980, 1983: Harpaz, 1983). Great interest in the subject surfaced during the 1960's when split brain surgery added subjects for study to a population previously only provided by injury. In this surgery, which was conducted initially by Drs. Vogel and Bogen, the corpus callosum, which provides the connection between the left and right halves of the brain, was surgically severed in an effort to reduce the devastating effects of uncontrollable epilepsy. Tightly controlled experiments by Drs. Sperry, Gazzaniga and Levy with these patients provided insights into brain functioning which corroborated some earlier work by Broca, Deikman, and Penfield (Blakeslee, 1983; Bogen, 1977; Deikman, 1973a \& b; Gazzaniga, 1967). These experiments were popularized by Ornstein $(1972,1973,1976)$ who also contributed substantial findings of his own resulting from his EEG studies with nonsurgical clients. Partly because of Ornstein's popular writings, which not only reviewed scientifically based findings, but also tied in ancient concepts of knowing drawn from a variety of cultures including Eastern and primitives, some individuals began to apply Ornstein's and other's ideas in ways that exceeded their research base (Kinsbourne, 1980; Ornstein, 1976; Wittrock, 1978). The difficulty of matching research to practice is illustrated by the fact that language, for example, is primarily found in the left brain hemisphere in right handed individuals. This information needs to be tempered by Gazzaniga's (1983) discovery of some language capacity in the right brain of the split brain patients, and Levy's (1983) 
discovery of the interconnectedness of the hemispheres in receiving, processing and producing language in the normal population. How this all occurs is not entirely clear (Madden \& Nebes, 1980). Another issue is the assertion that creativity is primarily a right brain hemisphere function; this assertion was accompanied by suggestions for changes in education and business to train the right brain. Further research on this subject, however, indicates a far more complicated pattern for creativity based on situation and content. It would appear that both the left and right brain hemispheres have creative potential depending on the specific area of creativity (Katz, 1983; McCallum \& Glynn, 1979; Torrance, 1982; Torrance \& Frasier, 1983). Art and literature, for example, present different creativity patterns (Zangwill, 1976), and strong right brain usage, when present, appears limited to the specific creative event (Martindale, Hines, Mitchell \& Corello, 1984).

Measurement Issues

A further problem in assessing brain hemisphere dominance distinctions stems from measurement methodology in normally functioning human beings. Although all of the common methods for measuring brain hemisphere dominance have been called into question, observation of lateral eye movements, handedness, and self-report questionnaires seem particularly suspect (Beaumont, Young \& McManus, 1984; Giannini, Barringer, Giannini \& Loisell, 1984; Hatta, 1984; Owens \& Limber, 1983; Wittrock, 1978). Other methods of determining brain hemisphere dominance such as EEG's are criticized by some as not specific enough, and require extensive equipment and one-to-one testing which is costly in time and materials (Beaumont, Young \& McManus, 1984; Teyler, 1977). This is all compounded by increasing insistence that the split brain patient, while providing interesting information, is not a good basis for determining normal brain functioning (Bub \& Whitaker, 1980; Corballis, 1980; Hardyck \& Haapanen, 1979; Levy, 1980,1983; 1985; Thompson, 1984). 


\section{Brain Hemisphere Dominance As a Construct}

Rather than abandon all applications of these findings until the neurophysiologists and the measurement experts determine models and measurement strategies, an alternative solution may be proposed. It may be agreed that there are differences in information processing in approaching situations, in manipulating symbols mentally and in preferred media of output and that these differences may be related to differential functioning of the human brain both laterally and also in specific areas. A conservative approach to the problem is to clearly label brain hemisphere dominance as a construct founded in neurophysiological and psychological research until scientific instrumentation and investigation can fully support the apparent direction of the research. As long as caution is observed, this may be the only viable option short of continuing to insist on a rigid methodology that risks ignoring significant data and legitimate areas of inquiry (Deikman, 1973b; Edwards, 1979; Kinsbourne \& Hiscock, 1978; Ornstein, 1976). This can be done because Kaushansky (1984), for example, found that whereas educational practitioners did use brain hemisphere dominance research to some extent to justify their own teaching preferences and to instill humanistic values, in general, they did not distort the data base unduly in their application of this research.

Another partial solution, which is the one proposed by this study, is to look for linkages in other areas of study such as the learning style research. The problem still remains, however, of assessment and definition. As indicated above, some of the major methods for assessing brain hemisphere dominance such as lateral eye movements, handedness, self-report questionnaire and even EEG's, have been questioned. In addition, measurement methods such as EEG's require considerable one-to-one work and are limited by the numbers of subjects who can reasonably be included in studies. What is clearly needed are acceptably valid and reliable paper and pencil tests suitable for administration to groups of subjects with a fair degree of ease. 


\section{Brain Hemisphere Dominance Models}

Several different theorists have developed individual models of brain hemisphere dominance which seek to further delineate the differences between the left and right hemispheres of the brain. Beyond the gross distinctions that the left brain hemisphere dominance is characterized as analytical, sequential, orderly and logical in approaching information processing and that the right brain is perceived as holistic, artistic, intuitive and spatial, attempts have been made to produce further distinctions. Three of these models will be discussed before moving into the model used in this study.

Agor (1984) not only breaks down the distinctions between left and right brain hemisphere dominance more completely, but also suggests an integrated level in which the individual uses the two modes of processing interchangeably. He describes left brain hemisphere dominant individuals as analytical, deductive, using facts to reach decisions, and more comfortable in hierarchical authority systems with structured, planned situations. He also sees problem-solving using the left brain as characterized by breaking the problem into parts and then solving it sequentially using logic. Conversely, the right brain hemisphere dominant individuals are seen as intuitive, inductive, and using feelings to arrive at decisions. He sees persons with these characteristics as more comfortable in collegial, participatory authority systems which are unstructured, fluid and spontaneous, and he believes they solve problems by perceiving the whole problem and by using intuition to achieve a solution.

Taggart and Torrance (1984) present a similar model in which left, right and middle positions are presented but with an important difference from Agor's concepts. They see at least two possibilities in the middle area, which are a mixed strategy and an integrated strategy. "A person with the mixed strategy tends to look at left dominant elements in isolation from the right dominant and vice versa. The integrated style combines left and right in appropriate proportions with the ability to clearly see the linkages between the two." (1984, p. 11). Taggart and Torrance also differ slightly in the terms they use to 
describe basic left/right differences, using such dichotomies as structured/openminded, verbal/spatial, facts/ideas, sequence/relationship, outline/summary, and logic/intuitive. In addition, they support the notion that creativity is not confined to the right hemisphere, but exists in the left as well, and that flexibility in information processing is the key to increasing creativity.

A third model that further describes differences in information processing is presented by Lynch (1983) who adds to the leftright dimensions, an anterior and posterior dimension. In describing the left, Lynch uses such terms as verbal, sequential, analytical, temporal and digital. The right he sees as visuo-spatial, simultaneous, abstract, metaphorical and analogic. The anterior dimension is described as forward-thinking, inquiring, empathetic and open to complexity, while the posterior is more spontaneous, instinctual, energetic and risk-taking. To complete his model, Lynch connects the left and the anterior to produce a position he calls "I Control". When the left and the posterior are connected, it produces a position of "I Desire." The connection between right and anterior produces "I Search," while the right and posterior produces an "I Believe" position.

Finally, the model used in this study, the Herrmann model, allows for four different dimensions but bases them more clearly on MacLean's (1978) triune brain model. The Herrmann model is next discussed in further detail.

\section{Herrmann's Model}

There is a model of brain functioning currently available which also has an instrument to measure not only Right/Left brain hemisphere dominance, but also the Cerebral/Limbic balance. The Cerebral/Limbic dimension derives partly from MacLean's concept of the triune brain which includes the Reptilian brain, the Limbic brain and the Cerebral brain (Hart, 1983; MacLean, 1978). While the specific functioning of the Limbic portion of the brain is not entirely clear (Cone, 1982; Teyler, 1977; Trowbridge, 1978), there is general agreement that this portion of the brain 
accounts for emotions in some way (Bloom, Lazerson \& Hofstadter, 1985). Hermann's model, which was developed over a period of close to ten years, is best described in an article by Herrmann (1981) and augmented in a second article by Gorovitz (1982). Herrmann, who comes from an action research base in industry, rather than an academic research methodology approach, uses a two-dimensional bipolar model in discussing brain hemisphere dominance and the Cerebral/Limbic dimension. Thus he sees the Left Cerebral as logical, analytic, mathematical, technical, and excelling in problem solving (Gorovitz, 1982). The Left Limbic is seen as controlled, conservative and excelling in planning, organization and administration. The Right Cerebral he sees as creative, artistic and excelling in synthesizing and conceptualizing holistically. For Herrmann, the Right Limbic is seen as emotional, musical, spiritual and excelling in interpersonal skills, particularly using speech as a means of relating. While Herrmann sees his model as very clearly based on brain hemisphere dominance research, when accepted as a construct it is a useful model for study. Although Herrmann's own work has primarily been in the area of business research, several other studies have been conducted in educational settings using this model.

\section{Besearch and the Herrmann Model}

In combined studies between the Departments of Biomedical Engineering and Systems Analysis at the University of Texas at Arlington, efforts have been made to assess not only left/right brain hemisphere dominance, but also their relationship to career choice (Schkade \& Potvin, 1981). In these studies, volunteer accounting and senior art students were first screened for brain hemisphere dominance using the Herrmann instrument. Subsequent EEG's with these students showed significant differences at $\mathrm{R}<.01$, with the accounting students showing more left brain activity whereas the art students showed more right brain activity.

Norris (1984) used the Herrmann model and instrument with educational administrators and found that those who tested with more right brain hemisphere 
dominance tended to be more conceptual $(\mathbb{R}<.01)$ while the more technical tended toward left brain hemisphere dominance (NS at $\mathbb{R}<.07$ ). Black's (1983) efforts to match leftright brain hemisphere dominance, learning styles, and teaching styles using the Torrance Test of Creative Thinking (1966) and Herrmann's instrument indicated that whereas a match between these three factors might tend to increase productivity, no significant correlation was found between the tests. When the Herrmann instrument was correlated with the Kirton Adaptor-Innovator Inventory using 106 subjects (Black, 1983), a Pearson I of .51 was found between this Inventory and the Cerebral Right on the Herrmann. Further correlations revealed $\mathrm{I}=.43$ with the Overall Right, -.40 with the Limbic Left and .35 with the Total Left $(2<.05)$. Finally Coulson and Strickland (1983) used the Herrmann to look at the possible differences between chief executive officers (CEOs) of companies and school superintendents and found that the CEOs tended to be more right brain hemisphere dominant, while school superintendents tended toward left brain hemisphere dominance. Specifically the superintendents' composite Limbic Left was $23 \%$ higher than that of the CEO's, whereas the CEO's composite Cerebral Right was $27 \%$ higher than the superintendents. This also supports the contention of others that the most successful businessmen tend to be more right brain hemisphere dominant (Agor, 1984; Albrecht, 1980, 1983).

\section{Learning Style and Brain Hemisphere Dominance}

Support for the idea of connecting learning style inquiries and brain hemisphere dominance studies come from a variety of sources (Black, 1983; Blakeslee, 1982; Federico, 1984; Jeffrey, 1980; Kolb, 1984; McMullan \& Cahoon, 1979; Wittrock, 1978; Zelniker \& Jeffrey, 1976). For example, Federico (1984) investigated the connection between event-related-potential (ERP's) and Witkin's (1962) Field Dependence/Independence, while McMullan and Cahoon (1979) theorized a connection between right brain hemisphere dominance and Concrete Experience and left brain hemisphere dominance and Abstract Conceptualization. Kolb (1984) felt that right 
brain hemisphere dominance and Concrete Experience correspond while there is a connection between left brain hemisphere dominance and Abstract Conceptualization. While many of these studies failed to yield significant results, none used the Herrmann and Kolb instruments together, and most complained about the lack of specificity in terminology (Coleman, 1979; Dunn, Cavanaugh, Eberle \& Zenhausern, 1982; Kuchler, 1983).

\section{Studies Using the Kolb and the Herrmann}

As mentioned earlier, the only published study available using both the Kolb and Herrmann instruments is Bush (1984). Bush chose these instruments based on Schkade's unpublished research using EEG's and correlations between paper-and-pencil tests, which Schkade claims establishes empirically predictive validity (Bush, 1984, pp. 70-71). This study looked at career choice and job satisfaction as a computer programmer or analyst rather than at a correlation between the two instruments as a primary focus of study. The Myers-Briggs Type Indicator (1962) was also used, and the researcher commented that there was a remarkable uniformity among the results but did not go into detail on the specific findings. "The predominantly left lateralized population is also predominantly characterized by Abstract Conceptualization and Active Experimentation learning styles" (Bush, 1984, p. 101).

In a pilot study conducted by this author in preparation for this study, Pearson product moment correlations using the OLSI of Kolb and the Herrmann with 30 subjects, were found as follows: Active Experimentation/Left Limbic, .15 (NS); Concrete Experience/Right Limbic, .33 (NS); Reflective Observation/Right Cerebral, .30 (NS); and Abstract Conceptualization/Left Cerebral, .50 ( $2<.01)$. Although these correlations are not high overall, it is felt that they may be related to the use of the OLSI under less than satisfactory conditions. Further it was found that 21 of the $23(91 \%)$ subjects testing for left brain hemisphere dominance on the Herrmann could be identified by inspection related to their placement on the grid associated with the Kolb, while 4 of the 
$7(57 \%)$ of those testing for right brain hemisphere dominance could be identified by visual inspection on the Kolb.

\section{Selection and Group Success}

Numerous studies have been conducted which relate to the second portion of the study concerning application of learning style and brain hemisphere dominance concepts. Although most of the application work with instrumentation used the Myers-Briggs Type Indicator (1962), it is helpful in that this instrument has at least partially been correlated with both the Kolb and the Herrmann and used in Bush's (1984) study. It must be remembered, however, that the concepts among the three are not totally congruent.

Whereas selection as a preferred supervisor, subordinate, or member of a work project group is the subject of this inquiry, a number of factors should be considered. These include creativity, relative speed in decision-making, tendencies in making selections, group harmony and effective leadership. Whereas some suggest that greater creativity results from having a diverse group of decision makers (Janis, 1984; Likert, 1984; Manz \& Sims, 1982), there are evidently quite different communication patterns, types of decisions and decision-making times associated with such diverse traits as a tendency toward abstract or concrete foci, brain hemisphere dominance, and sex (Christiano \& Robinson, 1982; Firestein \& Treffinger, 1983; Hendrick, 1979; McCausland, 1982; Wood, 1981). Groups classified as more task than processoriented, more abstract than concrete, or having more right brain hemisphere dominance, for example, tend to reach decisions more rapidly than their opposites. Males tend to communicate more than females in work groups, especially with female leaders, but females are found to be more task oriented than males. It has also been found that allowing sufficient time following the initial stages of group problem solving is important to overall effectiveness in problem solving. One of the studies on decisionmaking tendencies also found that individuals with a high tendency toward motion 
sickness, which has been related to a tendency toward right brain hemisphere dominance, tend to strive for win/win or synergistic solutions to problems rather than win/lose, competitive solutions (Mirabile \& Glueck, 1979). However, when the differences among group members are too great or the group members are unable to handle the differences, problem solving may not occur at all (Yantis \& Nixon, 1982). Similarly, perceived leader effectiveness may be influenced by many factors including personality type, cognitive style, and level within the hierarchy (Bonen, 1977; Gillespie, 1980; Sanders \& Malkis, 1982). In addition, the business environment also interacts with style and tendencies toward information gathering and processing (Dunn, 1982; Sood \& Adams, 1984). Although one study found that husbands and wives tend to have opposite learning styles (Thies, 1983), most studies conclude that not only marriage partners but also preferred business successors and performance appraisals appear to be weighted in the direction of like attracts like (Cohen, 1981; Elster, 1977; Lesnik-Oberstein \& Cohen, 1984; Levinson, 1980; Strot, 1985). In studying therapist/client relations, Witkin (1976) found strong liking and disliking based on cognitive style within a period of time sometimes under a half hour, while another study using the Convergent/Divergent dichotomy (Strot, 1985) indicated that teachers rated students with similar learning styles higher than those students with styles opposite the teacher's own style. Levinson's (1980) study involving 100 managers indicated that their preferred successors were very similar to them in job involvement, work values and personality $(\mathbb{R}<.01)$. It was concluded that when persons of like characteristics work together, it produces cooperation and success, but there is also a tendency to reduce risk by replicating oneself in the choice of a successor. On the other hand, in studies of performance evaluations (Cohen, 1981) the only significant correlations $(2<.05)$ between raters and the ratees who were judged highly were on emotional stability and restraint. The researcher suggested, however, that the lack of results may have been 
based on a strong perceived similarity between rater and ratee because of prior selection.

Studies using the Myers-Briggs Type Indicator (1962) ranged from decisionmaking style to the area of expertise, and tendency toward risk-taking (Blaylock, 1981; Henderson \& Nutt, 1980; Kadunc, 1982; Ryberg, 1982;). All of these studies concluded that an individual's style was extremely important in predicting the sorts of decisions that would be made by that individual. Research specialists, for example, were found to rely on intuition more than sensing, while development project managers used more sensing than intuition in their work (Kadunc, 1982). While not specifically dealing with either the Kolb theory of learning or Herrmann's model of brain functioning as they impact groups and business decision-making, certainly these studies provide a basis for asserting that style, whether it is learning style or brain hemisphere dominance, appears to make a difference in business-related areas. It is this direction which supports both the application hypotheses of this study and also their directionality. Summary of Research

The research reviewed for this study has been divided into the three basic areas covered by the study. These are 1) learning style research, 2) brain hemisphere dominance research, and 3) studies relating to preferences in selection for supervisors, subordinates or work project groups and the implications of these selections. In the area of learning style research, many models and theories exist but a primary problem throughout the literature is agreement not only on a definition of learning style but also the terminology to be used in discussing learning style. A two-factor bipolar model using the dimensions of Concrete Experience/Abstract Conceptualization and Reflective Observation/Active Experimentation provides a profile for four types of learner, the Assimilator, the Accommodator, the Diverger, and the Converger. This model also has an instrument with satisfactory validity and reliability which was used in the study. 
In the area of brain hemisphere dominance there is general agreement based on neurophysiological and psychological studies that left brain hemisphere dominance is associated with rational, sequential and analytical approaches to problem solving while right brain hemisphere dominance is associated with more holistic, creative and intuitive approaches. A model that includes these dimensions while also providing for distinctions between Cerebral and Limbic or thinking and feeling kinds of brain functioning is accompanied by an instrument that allows a quantitative representation of specific brain hemisphere dominance. Because of the ongoing nature of the neurophysiological and psychological research related to brain hemisphere dominance, however, it is felt that a conservative approach to the subject is to treat the areas represented as Left or Right Cerebral and Left or Right Limbic as constructs rather than specific physiological locations.

In the area of selection, it would appear that there are tendencies toward persons selecting those who are most like themselves as supervisors, subordinates and work project group members. Although this similarity allows for harmonious relations and speedier decision making, it does not allow for maximum creativity.

Based on these studies, a number of hypotheses were proposed. The probability level selected for assessing significance was $\underline{\alpha}=.01$ for the Pearson product moment correlations used with Hypotheses 1 through 3 , and $\underline{\alpha}=.05$ for the chi squares conducted with Hypotheses 4 through 9.

\section{Hypotheses}

As noted, there are two types of hypotheses proposed in this study. The first category applies to the relationship between learning style and brain hemisphere dominance. These are:

1. There is a significant positive correlation between Concrete Experience and overall right brain hemisphere dominance, and also between Reflective Observation and overall right brain hemisphere dominance. 
2. There is a significant positive correlation between Active Experimentation and overall left brain hemisphere dominance, and also between Abstract Conceptualization and overall left brain hemisphere dominance.

3. There is a significant positive correlation between

a. Concrete Experience and Right Limbic scores

b. Reflective Observation and Right Cerebral scores

c. Active Experimentation and Left Limbic scores

d. Abstract Conceptualization and Left Cerebral scores.

The second set of hypotheses relate to selection and are as follows:

4. In the selection of preferred supervisors,

a. Diverger selectors will pick significantly more Diverger selectees,

b. Assimilator selectors will pick significantly more Assimilator selectees,

c. Converger selectors will pick significantly more Converger selectees,

d. Accommodator selectors will pick significantly more Accommodator selectees.

5. In the selection of preferred subordinates,

a. Diverger selectors will pick significantly more Diverger selectees,

b. Assimilator selectors will pick significantly more Assimilator selectees,

c. Converger selectors will pick significantly more Converger selectees,

d. Accommodator selectors will pick significantly more Accommodator selectees.

6. In the selection of work project group members,

a. Diverger selectors will pick significantly more Diverger selectees,

b. Assimilator selectors will pick significantly more Assimilator selectees,

c. Converger selectors will pick significantly more Converger selectees,

d. Accommodator selectors will pick significantly more Accommodator selectees. 
7. In the selection of preferred supervisors,

a. left brain hemisphere dominant selectors will choose significantly more left brain hemisphere dominant selectees, and

b. right brain hemisphere dominant selectors will choose significantly more right brain hemisphere selectees.

8. In the selection of preferred subordinates,

a. left brain hemisphere dominant selectors will choose significantly more left brain hemisphere dominant selectees, and

b. right brain hemisphere dominant selectors will choose significantly more right brain hemisphere dominant selectees.

9. In the selection of work project group members,

a. left brain hemisphere dominant selectors will choose significantly more left brain hemisphere dominant selectees, and

b. right brain hemisphere dominant selectors will choose significantly more right brain hemisphere dominant selectees. 


\section{CHAPTER 3}

\section{Method}

In reviewing the methodology for this study, the following areas will be discussed: 1) subjects for the study, 2) the instruments used in the study and the materials for the feedback session with the subjects, and 3 ) the overall study design.

\section{Subjects}

This study was conducted using graduate students presently enrolled in managementrelated programs at St. Thomas University (STU) and at Florida International University (FIU). The Graduate School at STU is relatively small, comprising approximately 600 students enrolled in nine Masters level graduate programs. Of these, six programs are business and management-related. Established in Miami, Florida, only 25 years ago, STU begun as a remnant of a pre-Castro church-related Cuban college. FIU is also relatively new, having been founded during the early 1970 's, as one of the nine state universities in Florida. It has a much larger graduate school than STU, including a much wider range of academic disciplines. For this study, seven classes were used, six being from STU where113 of the subjects were enrolled, while the seventh class from FIU enrolled the remaining 21 subjects.

\section{Personal Demographics of Subjects}

The subjects of the study included 80 males and 54 females. They ranged in age from 21 to over 50, with the following age group breakdowns: 23 (18\%) were $21-24$ years of age, $42(33 \%)$ were between 25 and 29,41 (32\%) were in their thirties, 15 $(12 \%)$ in their forties, $7(5 \%)$ were over 50 , and $6(4 \%)$ declined to give their age. Of the 134 subjects, 17 (13\%) were Black, 67 (51\%) Non-Hispanic Caucasian, 29 (22\%) Hispanic including subjects born in the United States with Hispanic surnames, 2 (1\%) who declined to volunteer this data and $19(14 \%)$ Other (see Table 1). The category of Other included international students as well as students from the United States from backgrounds other than Black, Non-Hispanic Caucasian, or Hispanic. The 
international students came from Nigeria, West India, Asia, Belize, Brazil, India, Haiti, Saudi Arabia, the Philippines, the Virgin Islands and Jamaica.

The students in the study were enrolled in five different management-related programs, including $60(45 \%)$ pursing the Master of Science in Management (MSM), $30(22 \%)$ the Master of Business Administration (MBA), 21 (16\%) the Master of Health Management (MHM), 17 (13\%) in Sports Administration (SpoAd), $4(3 \%)$ in the Management Information Systems (MIS) program and 2 (4\%) Special Students (see Table 2). In terms of undergraduate majors, the subjects came from at least fifteen different majors ranging from Biology to English. The largest of these were Business and Management with 27 students, or $22 \%$ of the overall sample. Criminal Justice, Nursing, Education, Psychology, Accounting, and English each represented $7 \%$ of the overall sample, whereas Political Science, Economics and Finance, Health and Physical Education, and Science each represented $6 \%$ of the sample.

Of the 134 students in the study, $117(87 \%)$ were working and attending evening classes at the time of the study, while the remaining $17(13 \%)$ were not working but attending evening classes. Of those students who were working, $66(49 \%)$ had no management experience, $28(21 \%)$ described themselves as 1 st line supervisors, 32 $(24 \%)$ said they represented middle management and the remaining $8(6 \%)$ said they were part of senior management in their workplace (see Table 3).

\section{Class Selection}

The subjects for the study were selected based on class registrations during January,1986. The basic requirements were that the class be large enough to provide representation of the different learning styles as well as different brain hemisphere dominances. It was estimated that a class size of approximately 20 students would meet these requirements. In addition, it was necessary that the classes provide sufficient interaction to allow the students to become acquainted with each other during class sessions and breaks. Classes consisting primarily of lecture were excluded. In addition, 
a total of approximately 120 subjects was desired for the study, so it was thought that six classes would be sufficient. Following January registration, six classes were identified at STU which met the stated requirements and one from FIU. As the researcher is a member of the faculty at STU, it was easier to use more groups from there than from FIU. Seven classes instead of six were selected to ensure an overall sample of 120 . This resulted in a total of 134 subjects in the final study.

The classes selected included three classes in Organizational Design, one of which was the class from FIU. All the students in this particular class were enrolled in the MBA program. One of the Organizational Design classes from STU met on the Main Campus, and the other is conducted in an on-site location with enrollment limited to public employees. Two of the classes were in Applied Research Methods, with one of these limited to students in the MHM Program and public employees enrolled in the MSM Program. The two additional classes were Human Resource Management, which included all but one of the Sports Administration students, and, finally, the Organizational Behavior class which included a mixture of MSM, MBA and MIS students.

The six instructors involved are all experienced in their fields and use many interactive teaching strategies in their classes. Both sections of the Applied Research Methods classes were taught by the same instructor.

\section{Demographics by Class}

The personal demographic breakdowns for each class are presented in Table 1. Overall it was felt that these classes were very similar to each other in personal demographics. In addition to their personal demographics, the subjects reported their educational program of study and current work experience. These factors are reported by group in Tables 2 and 3 .

\section{Limitations to the Sampling Design}

In this study, given the requirements that students get to know each other well enough to at least make preliminary selections of preferred supervisors, subordinates and work 
project group members from among their classmates, it was necessary to select fairly large, interactive classes. As will be discussed later, a mean $n$ of 21 students did not always afford the anticipated representation of learning styles and brain hemisphere dominance. This impacted the selection hypotheses 4 through 9. The South Florida area, the nature of both STU and FIU, and the decision to limit the study to students in management-related programs of study, naturally also limit the generalizability of the findings of this study.

Table 1

Personal Demographics of Subjects by Class Groups

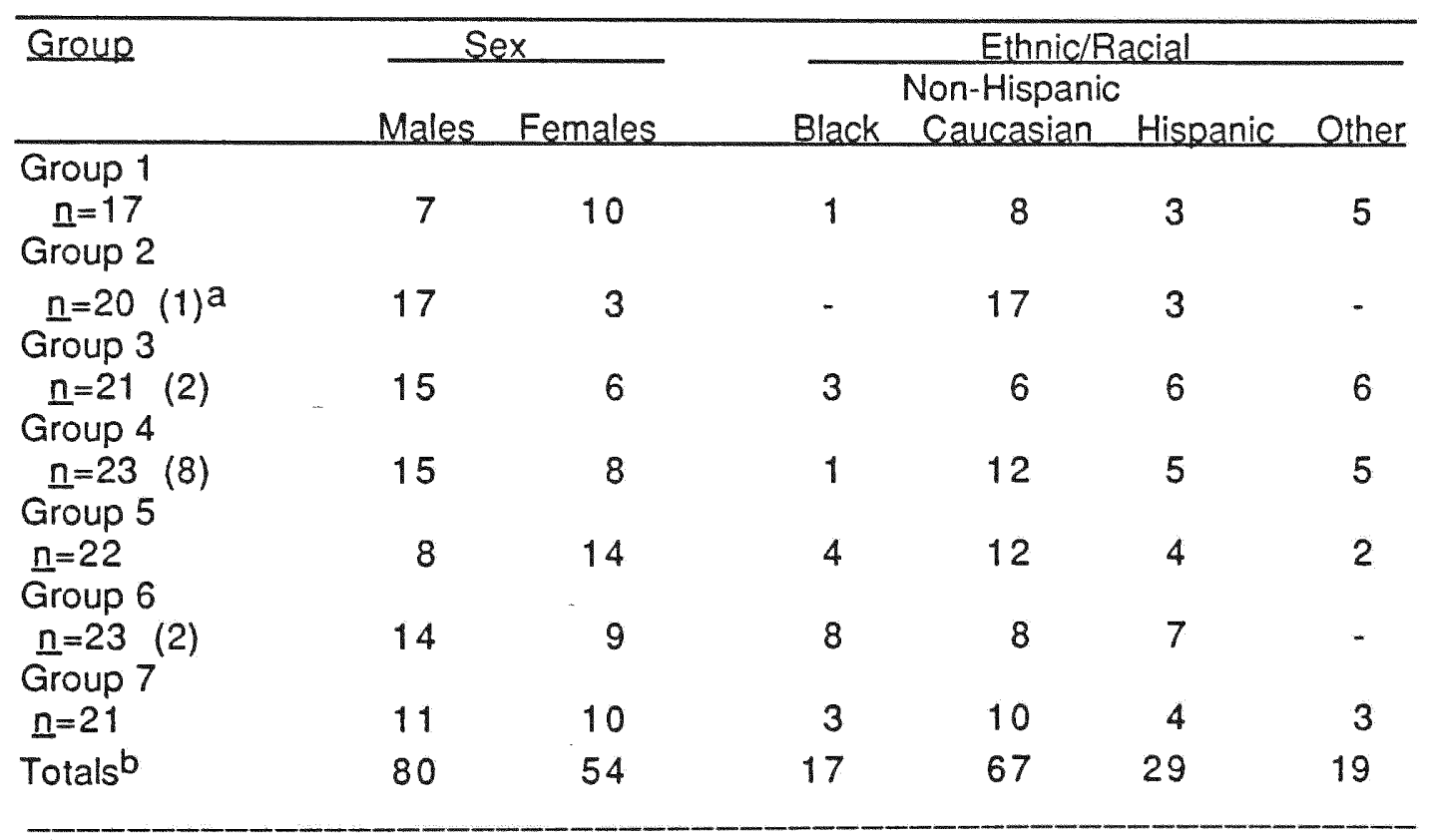

$\bar{N}=134$

a ( ) denotes the number of students in a group who were also included in a previous group.

$b$ Totals will not equal column totals because of the presence of some students in more than one group. 
Table 2

Educational Program of Subjects by Class Groups

\begin{tabular}{|c|c|c|c|c|c|c|}
\hline Group & MSM & MBA & MHM & SpoAd & MIS & Other \\
\hline Group 1 & & & & & & \\
\hline $\begin{array}{l}n=17 \\
\text { Group } 2\end{array}$ & 8 & - & 4 & 3 & - & 2 \\
\hline $\begin{array}{l}n=20(1)^{a} \\
\text { Group } 3\end{array}$ & 3 & 3 & - & 14 & - & - \\
\hline$\underset{\text { Group } 4}{n=21}$ & 13 & 4 & - & - & 4 & - \\
\hline$\underset{\text { Group } 5}{n=23}$ & 18 & 2 & 1 & 1 & 1 & - \\
\hline $\begin{array}{l}n=22 \\
\text { Group } 6\end{array}$ & 6 & - & 16 & - & - & - \\
\hline$\underset{\text { Group } 7}{n=23}$ & 23 & - & - & - & - & - \\
\hline$n=21$ & - & 21 & - & - & - & - \\
\hline Totals $^{b}$ & 60 & 30 & 21 & 17 & 4 & 2 \\
\hline
\end{tabular}

$\underline{N}=134 ;$ Note. $M S M=$ Master of Science in Management; MBA = Master of Business Administration; MHM = Master of Health Management; SpoAd = Master in Sports Administration; MIS = Master of Management Information Systems.

a ( ) denotes the number of students in a group who were also included in a previous group. b Totals will not always equal column totals because of the presence of some students in more than one group.

Table 3

Working Status of Subjects by Class Groups

\begin{tabular}{|c|c|c|c|c|}
\hline Group & Not Supervising & 1st Line & Middle Mat & Senior Mgt \\
\hline $\begin{array}{l}\text { Group } 1 \\
n=17 \\
\text { Group } 2\end{array}$ & 13 & - & 3 & 1 \\
\hline $\begin{array}{l}\mathrm{n}=20(1)^{\mathrm{a}} \\
\text { Group } 3\end{array}$ & 11 & 5 & 4 & - \\
\hline $\begin{array}{l}n=21 \\
\text { Group } 4\end{array}$ & 12 & 3 & 5 & 1 \\
\hline $\begin{array}{l}n=23(8) \\
\text { Group } 5\end{array}$ & 12 & 5 & 5 & 1 \\
\hline $\begin{array}{l}n=22 \\
\text { Group } 6\end{array}$ & 9 & 6 & 5 & 2 \\
\hline $\begin{array}{l}n=23(2) \\
\text { Group } 7\end{array}$ & 5 & 9 & 8 & 1 \\
\hline$n=21$ & 13 & 2 & 4 & 2 \\
\hline Totals $b$ & 66 & 28 & 32 & 8 \\
\hline
\end{tabular}

$\underline{N}=134$

a ( ) denotes the number of students in a group who were included in a previous group. b Totals will not always equal column totals because of the presence of some students in more than one group. 


\section{Instruments}

There were three instruments used in the study: the Kolb Learning-Style Inventory (1985), the Herrmann Participant Survey Form (1978) and a short questionnaire covering demographics and the selection portion of the study.

Kolb Learning-Style Inventory

The first of these, Kolb's Learning-Style Inventory (LSI) is a short self-report survey. It uses twelve sets of short descriptive phrases and asks that each set be identified in rank order as most descriptive to least descriptive of the individual's learning or problem solving methods. The instrument yields four subscores and two combined scores. These combined scores measure the relative strength of Active Experimentation/Reflective Observation (AE-RO) and Abstract Conceptualization/Concrete Experience (AC-CE). Because of the controversy concerning the original version of this instrument, the OLSI, a portion of the Review of the Literature was devoted to this discussion. The LSI correlates with the OLSI at .91; the reliability of the 1985 edition is .81 using Cronbach's alpha, almost 1.0 using Tukey's test, and .81 using Spearman-Brown correction formula with a split-half procedure (Kolb, 1985). In this study, the reliability of the Kolb instrument was determined using an odd-even split-half procedure with the Spearman-Brown prophecy formula. Although the results from the split-half test using data from this study has a probability of $\mathrm{p}<.001$, it is reflected throughout as $\mathrm{R}<.01$ as this was the level of probability designated as acceptable for this study. These results are presented in Table 4 together with comparable results from previous studies.

A concern with the instrument was raised by Freeman and Stumpf $(1980,1981)$ who stated that the forced choice answers on the LSI did not allow a realistic appraisal of an individual's strengths. It does, however, reflect Kolb's theoretical base regarding the dialectic nature of the characteristics being measured. It is also supported by Guilford 
(1980) in his discussion of learning style instrumentation. In this study, the bipolarity and independence of the factors was assessed by computing Pearson product moment correlations. In reviewing bipolarity, Concrete Experience and Abstract Conceptualization are found to be negatively correlated at -.46 , and Reflective Observation and Active Experimentation are negatively correlated at -.52. The independence of each factor is reflected in the significant negative correlations between each factor and all the others in the Kolb diagram. The only exception is a result for Abstract Conceptualization and Reflective Observation which was not significant at the .01 level. With the exception of the Concrete Experience and Active Experimentation correlation which has a probability of $<.01$, all the other correlations reported as Diehl (1986) have a probability of $<.001$. They are, however, reported at the $Q<.01$ level, as this was the acceptance level specificied for this study. These results, as well as a summary of similar results from previous studies, are presented in Table 5.

Table 4

Split-half Reliability of the Kolb (OLSI) and the (LSI)

\begin{tabular}{lccccc}
\hline & \multicolumn{2}{c}{ OLSI } & & \multicolumn{2}{c}{ LSI } \\
\cline { 2 - 3 } \cline { 5 - 6 } & Kolb, 1976 & Kotar, 1980 & & Kolb, 1986 & Diehl, 1986 \\
Factor & $\mathrm{n}=687$ & $\mathrm{n}=262$ & & $\mathrm{n}=268$ & $\mathrm{n}=133$ \\
\hline $\begin{array}{l}\text { Concrete } \\
\text { Experience }\end{array}$ & .55 & .44 & .81 & .86 \\
$\begin{array}{l}\text { Reflective } \\
\text { Observation }\end{array}$ & .62 & .62 & .71 & .86 \\
$\begin{array}{l}\text { Abstract } \\
\text { Conceptualization }\end{array}$ & .75 & .59 & & .84 & .85 \\
$\begin{array}{l}\text { Active } \\
\text { Experimentation }\end{array}$ & .66 & .42 & .83 & .90 \\
\hline
\end{tabular}

a All correlations reflect the Spearman-Brown prophecy formula and are significant at $\mathrm{Q}<.01$. 
Table 5

Bipolarity and Independence of Kolb OLSI and LSI Subscales ${ }^{b}$

\begin{tabular}{|c|c|c|c|c|}
\hline \multirow[b]{2}{*}{ Factors } & \multicolumn{2}{|l|}{ OLSI } & \multicolumn{2}{|c|}{ LSI } \\
\hline & $\begin{array}{l}\text { Kolb (1976) } \\
n=807\end{array}$ & $\begin{array}{l}\text { Kotar }(1980) \\
n=262\end{array}$ & $\begin{array}{l}\text { Kolb (1985) } \\
n=1446\end{array}$ & $\begin{array}{c}\text { Diehl (1986) } \\
n=133\end{array}$ \\
\hline$\overline{\mathrm{CE} / \mathrm{AC}}$ &. .57 & -.53 & -.42 & -.46 \\
\hline $\mathrm{RO} / \mathrm{AE}^{\mathrm{a}}$ & -.50 & -.56 & -.33 & -.52 \\
\hline CE/RO & & NS & -.32 & -.42 \\
\hline CE/AE & & NS & -.22 & -.15 \\
\hline $\mathrm{AC} / \mathrm{RO}$ & & -.16 & -.15 & NS \\
\hline$A C / A E$ & & -.21 & -.30 & -.48 \\
\hline
\end{tabular}

As with any self-report instrument there is an issue in terms of the individual's accuracy of self-perception and reporting. It has been suggested that individuals may want to represent themselves in a particular light even though the instrument is not intended to be judgmental. This concern is countered in the learning style literature by findings indicating a reasonable degree of self-knowledge and relative accuracy in reporting of style by most students (Dunn, 1983).

Another factor in favor of using the Learning-Style Inventory is that it tests the specific concepts which are the subject of this study. It has been used in research relating to a number of different subjects at major universities throughout the United States and is included in standard management textbooks even in the original (OLSI) edition.

\section{Herrmann Participant Survey Form}

The Herrmann instrument uses a variety of measures to provide feedback in the areas of Right and Left Cerebral brain hemisphere dominance and Right and Left Limbic brain 
hemisphere dominance. Although less has been written about the Herrmann Participant Survey Form than has been written about the Kolb, it too has had wide use over the past ten years and has been employed in doctoral level study in major American universities (Black, 1983; Bush, 1984; Norris, 1984). The Herrmann instrument consists of a collection of brain hemisphere dominance measures, many of which are related to existing research in the field. The items on the instrument relate to physical attributes, activity preferences, and a variety of self descriptions. From a physical standpoint, participants are asked to record their handedness, hand position when writing, tendency toward motion sickness, and times of day when energy levels are perceived to be highest. Activity preferences include preferred school subjects and hobbies. In the selfdescription portion, they are asked to select adjectives that best describe themselves and also to respond to a series of twenty questions relating to creative and imaginative tendencies, reactions to predictability and orderliness, and comfort levels in handling ambiguous situations or being alone. Although the instrument may be scored by hand, a computer program is available for scoring which was used in this study. Special training is required to score and interpret the instrument. The Herrmann yields several scores including overall Right and Left brain hemisphere dominance and overall Cerebral and Limbic tendencies. In addition, subscores are produced assessing the participant's Left Cerebral, Left Limbic, Right Cerebral and Right Limbic strengths and an overall profile of types is also available.

The Herrmann instrument has been used in combined studies between departments at the University of Texas at Arlington to screen subjects for later EEG studies on Left/Right brain activity (Schkade \& Potvin, 1981). In these studies a ratio of 1.0 indicates equal use of the hemispheres of the brain. The published results for Left brain hemisphere dominant subjects indicated a mean power ratio of .77 , whereas the corresponding ratio for Right brain hemisphere dominant subjects was 1.2 ( $\mathbb{R}<.01)$. In preparing his dissertation, Bush (1984) reports that subsequent to the Schkade and 
Potvin report, more than 4,000 pieces of data have been recorded by Schkade resulting in empirically predictive validity. Another dissertation (Black, 1983) included construct validity correlations between the Herrmann and the Kirton Adaptor-Innovator Inventory. In this study the Kirton correlated with Cerebral Right and Overall Right on the Herrmann at .51 and .43 , respectively, and with the Limbic Left and Overall Left at -.40 and .35 respectively $(\mathrm{n}=104, \mathrm{p}<.05)$.

An independent validation study (Bunderson, Olsen \& Herrmann, 1978) was also conducted in which 15 measures of brain hemisphere dominance in a learning profile battery were administered. The tests had been suggested by a panel of eleven neuropsychologists and human ability researchers as those measures best able to assess differences between Left and Right brain hemisphere dominance. Following factor analysis, the researchers concluded that there was a "pervasiveness of the left vs. right hemisphere dominance factors," and that there was "strong construct validation" for the instrument (Bunderson, Olsen \& Herrmann, p. 22). The bipolarity and independence of the factors measured by the Herrmann were assessed for this study by calculating Pearson product moment correlations between the Overall Left and Overall Right scores and also between the Overall Cerebral and Overall Limbic scores. Using 126 subjects, Overall Left and Overall Right are correlated at $-.84(\mathrm{p}<.01)$, whereas Overall Cerebral and Overall Limbic are correlated at $-.73(\mathrm{p}<.01)$, thus supporting a high level of bipolarity. In addition, 30 subjects from the study were asked to retake the Herrmann instrument ten weeks following the initial testing period. (See Appendix A for a description of the students involved in the test-retest study). Test-retest results are reported in Tables 6 and 7; although the actual probability levels found were $<.001$, they are reported at the $\mathrm{Q}<.01$ level specified as acceptable for this study. 
Table 6

Iest-retest Results for the Herrmann Instrument Overall Measures

\begin{tabular}{lcccc}
\hline Eactor & 1st Test & 2nd Test & Pearson & $D$ \\
Overall left & & & & \\
Mean & 113 & 110 & .67 & $<.01$ \\
S.D. & 15.7 & 14.7 & & \\
Overall right & & & & \\
Mean & 86 & 92 & .74 & $<.01$ \\
S.D. & 20.7 & 17.5 & & \\
Overall cerebral & & & & \\
Mean & 93 & 94 & .76 & $<.01$ \\
S.D. & 15.2 & 11.7 & & \\
Overall limbic & 106 & 107 & .81 & $<.01$ \\
Mean & 18.1 & 14.0 & & \\
S.D. & & & &
\end{tabular}

\section{Table 7}

Test-retest Results for the Herrmann Instrument Specific Subtests

\begin{tabular}{|c|c|c|c|c|}
\hline Factor & 1st Test & 2nd Test & Pearson $r$ & $p$ \\
\hline $\begin{array}{l}\text { Left Ce } \\
\text { Mean } \\
\text { S.D. }\end{array}$ & $\begin{array}{r}79 \\
21.9\end{array}$ & $\begin{array}{r}77 \\
18.5\end{array}$ & .75 & $<.01$ \\
\hline $\begin{array}{l}\text { Left Lin } \\
\text { Mean } \\
\text { S.D. }\end{array}$ & $\begin{array}{c}91 \\
16.0\end{array}$ & $\begin{array}{r}88 \\
12.8\end{array}$ & .52 & $<.01$ \\
\hline $\begin{array}{l}\text { Right L } \\
\text { Mean } \\
\text { S.D. }\end{array}$ & $\begin{array}{c}68 \\
21.2\end{array}$ & $\begin{array}{r}73 \\
17.9\end{array}$ & .85 & $<.01$ \\
\hline $\begin{array}{l}\text { Right C } \\
\text { Mean } \\
\text { S.D. }\end{array}$ & $\begin{array}{c}61 \\
18.3\end{array}$ & $\begin{array}{r}65 \\
16.2\end{array}$ & .71 & $<.01$ \\
\hline
\end{tabular}

It may be useful to remember that the instrument was developed in the non-academic environment of business and management training. In this context, the instrument has 
been administered to over 4,000 individuals with informal validation on an experiential level. The dates of the doctoral studies using the Herrmann are quite recent and would appear to indicate that ongoing research using this instrument is not only occurring but also is producing further specificity in regard to validity and reliability. Questionnaire

The final instrument to be used in the study was a short questionnaire yielding personal demographic information specific to the group and preferences for supervisors, subordinates, and members of work project groups. The demographic data included sex, age, field of study and other factors that might have impacted the results of the study (see Appendix B for the complete packet of instruments).

\section{Design and Procedure}

A pilot study with 30 students was conducted to determine the feasibility of the study using the Herrmann Participant Survey and the OLSI. The new edition, LSI, was not available at the time of the pilot. All students participating in the study were given a brief overview of the purposes of the study before they took the two instruments. The instruments were presented during one session in each of three classes. The results of the individual tests were returned to the students who had participated and the statistical results were correlated. These were reported in the Review of the Literature.

Based on class registrations, class sections used in the regular study were selected in January, 1986, both at STU and at FIU. Instructors were asked to provide approximately one hour of class time for students to complete the instruments as it was important not only that the conditions be tightly controlled, but also that students take the instruments at the same time to allow for maximum uniformity. With the exception of the class from FIU, this class time was made available. The students from FIU were given verbal instructions at the end of one class and then returned the instruments the following week. In every other case the researcher gave a brief overview of the study and then provided brief verbal instructions for completion of the instruments. During 
the administration of the instruments, the researcher was available to clarify directions and answer any questions the participants had. Following administration of the instruments, brief discussions were conducted with each class regarding questions and concerns the participants had regarding specific items of the instruments and the overall hypotheses of the study. In addition, some information was given regarding the concepts being tested and their implications for management.

The administration of the instruments was made during the sixth week of the semester. By this time all students had been together in class from 24 to 27 hours over a six week period. As mentioned earlier, the classes were selected both for size and also for the interactive nature of the class experience.

Approximately two weeks following the administration of the instrument, the researcher returned to each of the classes to provide feedback to the individual participants (see Appendix $\mathrm{C}$ for the feedback materials). In addition to providing specific, individualized feedback to the participants, some class time was spent discussing the overall concepts and specific applications in management settings. The amount of time spent on feedback varied widely, depending on the amount of class time the individual instructors were able to make available. In addition, four of the six instructors also took the instruments and shared their feedback with the students involved.

Ten weeks following the administration of the test instruments, thirty-five of the original subjects were contacted and asked to participate in a test-retest study using the Herrmann. Thirty of the students responded and were used in the test-retest study.

\section{Design Limitations}

Although good cooperation was received from the six instructors whose classes participated in the study, the lack of available class time for the FIU students to complete the instruments with assistance available from the researcher is of concern. An additional concern in regard to the STU students is that, although many of the students in 
the group were not known to the researcher, the researcher was either known by the participants or they were aware of the researcher's faculty status at STU. Although this produced a high level of cooperation in terms of returns, it also required stringent assurances of confidentiality. The only apparent reluctance to participate in the study, however, was on the part of one or two students in three classes to complete the selection portion of the data collection. Their reluctance was based on concerns regarding their lack of more complete knowledge of their classmates. In the FIU class, however, six $(29 \%)$ of the participants did not participate in the selection portion of the study. They did respond to the two test instruments and are included in the correlational aspects of the study. 


\section{CHAPTER 4}

\section{Results}

Various statistical procedures were used to analyze the data obtained in the study as it pertained to the hypotheses. As the personal demographics of the subjects were presented in the previous section, this section begins with an overview of the descriptive statistics concerning the subjects as they relate to the two instruments. A discussion follows regarding findings relating to each hypothesis.

\section{Learning Style of the Subjects}

Of the 134 subjects in the study, all but one returned usable data on the Kolb LSI. The means, range, and standard deviation of the overall group on the various subscales and the combination scales are presented in Table 8. In terms of specific learning style, there were $28(21 \%)$ Divergers, $63(47 \%)$ Assimilators, $16(12 \%)$ Convergers, and $26(20 \%)$ Accommodators. These findings, in addition to learning style breakdowns by class are presented in Table 9. Based on the pilot study and prior experience with the older version of the instrument, it had been anticipated that more Convergers and fewer Assimilators would be present in the sample population. Given that the sample population was drawn entirely from graduate students, however, this heavy emphasis on the Abstract Conceptualization and Reflective Observation may be appropriate.

\section{Table 8}

Means. Ranges, and Standard Deviations by Subscales and Combination Scales for the Kolb LSI

\begin{tabular}{lccc}
\hline Scale & Mean & Range & Standard Deviation \\
\hline Concrete Experience & 26 & $13-46$ & 7.5 \\
Reflective Observation & 31 & $13-46$ & 7.1 \\
Abstract Conceptualization & 32 & $15-48$ & 7.0 \\
$\begin{array}{l}\text { Active Experimentation } \\
\text { Active Experimentation minus }\end{array}$ & 31 & $12-48$ & 8.1 \\
$\begin{array}{l}\text { Reflective Observation } \\
\text { Abstract Conceptualization minus }\end{array}$ & 35 & $5-68$ & 13.3 \\
Concrete Experience & 42 & $12-71$ & 12.4 \\
\hline $\mathrm{n}=133$ & & &
\end{tabular}


Although the distribution is fairly consistent across groups, in Group 3, Accommodators were underrepresented. Conversely, in Group 5, Assimilators are somewhat underrepresented and Accommodators somewhat overrepresented. Although this distribution within groups did not impact the results in the first hypotheses dealing with correlations, it did have negative implications for the selection hypotheses. These implications are discussed with the specific hypotheses as well as in Chapter 5 .

Table 9

Learning Style Distributions Overall and by Group

Group Divergers Assimilators Convergers Accommodators

Group $1, n=17$

Group 2, $n=20$

$4(22 \%) \quad 8 \quad(47 \%)$

$4(20 \%) \quad 9 \quad(45 \%)$

$1(6 \%)$

$(10 \%)$

$5(24 \%) 12(57 \%) \quad 3(14 \%)$

Group 3, $n=21$

$6(26 \%) \quad 9 \quad(39 \%)$

Group 4, $\mathrm{n}=23$

Group 5, $n=22$

Group 6, $\bar{n}=23$

Group 7, $\underline{n}=20$

$5(23 \%) 6(27 \%)$

$4(17 \%) 12$

$(52 \%)$

$4(17 \%)$

$\begin{array}{rc}4 & (24 \%) \\ 5 & (25 \%) \\ 1 & (5 \%) \\ 4 & (17 \%) \\ 9 & (41 \%) \\ 4 & (17 \%) \\ 2 & (10 \%) \\ 26 & (20 \%)\end{array}$

$\underline{n}=133$

Note: Some overlap between groups existed so the numbers in the Total Sample does not equal the sum of the groups.

\section{Brain Hemisphere Dominance of the Subjects}

Of the 134 subjects in the study, 126 provided usable data regarding brain hemisphere dominance as measured by the Herrmann instrument. The means and standard deviations of the overall scales and the subscales are presented in Table 10. 
Table 10

Means and Standard Deviations for Overall and Subscales of the Herrmann

\begin{tabular}{lccc}
\hline Factor & Right & Left & Overall \\
\hline Cerebral & & & \\
Mean & 66 & 77 & 95 \\
S.D. & 18.8 & 21.3 & 13.8 \\
Limbic & & & \\
Mean & 71 & 89 & 107 \\
S.D. & 21.2 & 17.7 & 16.9 \\
Total & & & \\
Mean & 90 & 110 & \\
S.D. & 21.5 & 17.3 & \\
\hline n $=126$ & & &
\end{tabular}

Of these, overall $87(71 \%)$ were assessed as primarily left brain hemisphere dominant, $34(27 \%)$ were assessed as primarily right brain hemisphere dominant; the remaining 3 could not be assessed on this dimension as their overall left and right brain hemisphere dominance scores were equal. The distribution of right and left brain hemisphere dominance, both overall and by group, is presented in Table 11.

Table 11

Distribution of Right/Left Brain Hemisphere Dominance Overall and by Group

\begin{tabular}{lcc}
\hline Group & Right Dominant & Left Dominant \\
Group 1, $\mathrm{n}=15$ & $4(27 \%)$ & $11(73 \%)$ \\
Group 2, $\mathrm{n}=19$ & $6(32 \%)$ & $13(68 \%)$ \\
Group 3, $\mathrm{n}=19$ & $2(11 \%)$ & $17(89 \%)$ \\
Group 4, $\mathrm{n}=20$ & $4(20 \%)$ & $16(80 \%)$ \\
Group 5, $\mathrm{n}=22$ & $7(32 \%)$ & $15(68 \%)$ \\
Group 6, $\mathrm{n}=21$ & $8(38 \%)$ & $13(62 \%)$ \\
Group 7, $\mathrm{n}=20$ & $5(25 \%)$ & $15(75 \%)$ \\
Total, $\underline{\mathrm{n}}=121$ & $34(28 \%)$ & $87(72 \%)$
\end{tabular}

Note: The sum of the group n's is not equal to the Total because of overlapping group members. 


\section{Findings Related to Hxpotheses 1 and 2}

The first two hypotheses were concerned with the overall relationships between right and left brain hemisphere dominance and the subjects' position on the diagram related to the Kolb LSI (see Figures 1 and 2). Based on the pilot study and other information (Bush, 1984; Kolb, 1985), it was hypothesized that there would be a relationship between right brain hemisphere dominance and the Concrete Experience/Reflective Observation dimensions on the Kolb, whereas, conversely, a relationship would be found between left brain hemisphere dominance and the Abstract Conceptualization/Active Experimentation dimensions. In the pilot study, $91 \%$ of the left brain hemisphere dominant individuals could be identified by inspection of their relative placement on the Kolb diagram. Bush (1984) states that the left hemisphere dominant population is characterized by Abstract Conceptualization and Active Experimentation. Specifically Hypothesis 1 stated that, "There is a significant positive correlation between Concrete Experience and overall right brain hemisphere dominance, and also between Reflective Observation and overall right brain hemisphere dominance." Conversely, Hypothesis 2 stated that, "There is a significant positive correlation between Active Experimentation and left brain hemisphere dominance, and also between Abstract Conceptualization and overall left brain hemisphere dominance."

Pearson product moment correlations were performed between appropriate subscales of both instruments using the SPSS computer program. The overall right brain hemisphere dominance scores correlated with Concrete Experience at $.41(p<.01)$ and with Reflective Observation at $-.22(p<.01)$. The overall left brain hemisphere dominance scores correlated with Active Experimentation at -.03 (NS) and with

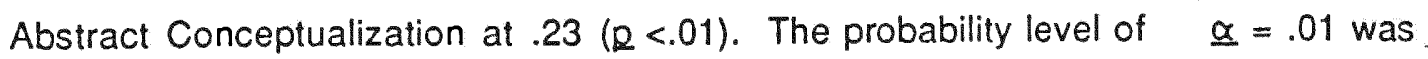
stated as the level of acceptance for correlations in this study; Hypotheses 1 and 2 are, therefore, not supported by the results of this analysis. A further discussion of these 
findings as well as additional statistical analyses are presented in Chapter 5 (see Table 27 for a complete presentation of the correlations between the four dimensions of the Kolb instrument and overall left and right brain hemisphere dominance).

\section{Findings Related to Hypothesis 3}

In Hypothesis 3, a variety of relationships between subscales of the Herrmann and the LSI were suggested. Specifically, it was hypothesized that, "There is a significant positive correlation between a) Concrete Experience and Right Limbic scores, b) Reflective Observation and Right Cerebral scores, c) Active Experimentation and Left Limbic scores, d) Abstract Conceptualization and Left Cerebral scores."

In regard to the specific relationships hypothesized, Pearson product moment correlations were calculated using SPSS with the following results: Concrete Experience and Right Limbic, $\underline{I}=.42(\mathrm{R}<.01)$; Reflective Observation and Right Cerebral, $\underline{r}=-.16$ (NS); Active Experimentation and Left Limbic, $\underline{\underline{I}}=.03$ (NS); and Abstract

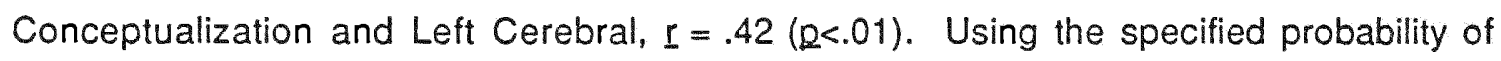
$\underline{\alpha}=.01$, subportions (a) and (d) of Hypothesis 3 , in which it was hypothesized that there are significant positive correlations between Concrete Experience and Right Limbic and between Abstract Conceptualization and Left Cerebral, are supported. Subportions (b) and (c), in which significant positive correlations between Reflective Observation and Right Cerebral and between Active Experimentation and Left Limbic are hypothesized, are not supported by the data analysis. Further discussion of these results, as well as additional related analyses are presented in Chapter 5 (see Table 29 for complete correlations between the four dimensions of the Kolb and the four subscores of the Herrmann).

\section{Findings Related to Hypotheses 4 through 6}

Hypotheses 4 through 6 predicted that subjects would prefer working with others of their same learning style as supervisors, subordinates, and work project group members. Specifically, Hypothesis 4 stated that "In the selection of preferred 
supervisors, a) Diverger selectors will pick significantly more Diverger selectees, b) Assimilator selectors will pick significantly more Assimilator selectees, c) Converger selectors will pick significantly more Converger selectees, and d) Accommodator selectors will pick significantly more Accommodator selectees." To test this Hypothesis, the chi square procedure was used. From an original sample of 133 who provided usable data on the Kolb LSI, 115 provided usable information regarding the individual they preferred as a supervisor from among their classmates. This data is provided in Tables 12,13 , and 14. Results could not be calculated for Convergers because of their small representation in the population $(n=16$ ). To handle the smaller numbers of Divergers and Accommodators in the sample, chi squares were calculated using only two cells: the selectors' own learning style and all others as a combination cell. The expected frequencies (fe) were determined based on the proportional representation of each learning style within the overall study population (see Table 9). The pattern of distribution within the classes used in the study (see Table 9) limits the usefulness of these statistics and will be discussed in more detail in Chapter 5 . In all tables the hypothesized relationship has been placed at the bottom of the table.

In regard to Hypothesis 4 , in which it was hypothesized that individuals would choose supervisors with their own learning styles, it may be seen by reviewing the data, that this Hypothesis is not supported by the findings. Specifically, the result for Divergers is not significant (see Table 12). Assimilators, although having significant findings, were not in the direction hypothesized (see Table 13), and, in fact, appeared to prefer working with Divergers or Convergers. Convergers could not be tested because of their small numbers; and the result for Accommodators was not significant (see Table 14). 
Table 12

Selections of Preferred Supervisors by Divergers

\begin{tabular}{lrrrrr}
\hline Group & fe & fo & df & $x^{2}$ & p \\
\hline All Others & 18.17 & 18 & & & \\
Divergers & 4.83 & 5 & 1 & $.01^{a}$ & NS \\
\hline $\mathrm{n}=23$ & & & & &
\end{tabular}

a Chi Square using the Yates Correction formula

Table 13

Selections of Preferred Supervisors by Assimilators

\begin{tabular}{|c|c|c|c|c|c|}
\hline Group & $\mathrm{fe}$ & fo & $d f$ & $x^{2}$ & $D$ \\
\hline Divergers & 11.55 & 19 & & & \\
\hline Convergers & 6.60 & 12 & & & \\
\hline Accommodators & 11.00 & 9 & & & \\
\hline Assimilators & 25.85 & 15 & 3 & $14.14 \quad(\underline{g}=.45)$ & $<.05$ \\
\hline
\end{tabular}

Table 14

Selections of Preferred Supervisors by Accommodators

\begin{tabular}{lrrrrr}
\hline Group & fe & fo & df & $x^{2}$ & p \\
All Others & 19.2 & 21 & & & \\
Accommodators & 4.8 & 3 & 1 & $.85^{\mathrm{a}}$ & NS \\
\hline
\end{tabular}

$n=24$

a Chi square using the Yates Correction formula

Hypothesis 5 stated that "In the selection of preferred subordinates, a) Diverger selectors will pick significantly more Diverger selectees, b) Assimilator selectors will pick significantly more Assimilator selectees, c) Converger selectors will pick significantly more Converger selectees, and d) Accommodator selectors will pick 
significantly more Accommodator selectees." In testing this hypothesis, the chi square statistic was also used and these results are reported in Tables 15, 16, and 17. Again, for Divergers and Accommodators combined cells were used in the calculations; computations could not be performed for Convergers due to the small numbers. A review of these findings indicates that Divergers indicated no particular preference for supervisors and, therefore, the result was not significant (see Table 15). Assimilators showed a preference for working with Divergers rather than fellow Assimilators; the result was, therefore, significant, but not in the direction hypothesized (see Table 16). Results for Convergers could not be determined because of their small numbers in the study population. Accommodators indicated no particular preference so the result was not significant (see Table 17). Therefore, Hypothesis 5 is not supported at the $<.05$ level.

\section{Table 15}

Selections of Preferred Subordinates by Divergers

\begin{tabular}{lrrrrr}
\hline Group & fe & fo & df & $x^{2}$ & $p$ \\
All Others & 17.38 & 18 & & & \\
Divergers & 4.62 & 4 & 1 & $.08^{\mathrm{a}}$ & NS \\
\hline$\underline{\mathrm{n}}=22$ & & & & &
\end{tabular}

a Chi square using the Yates Correction formula

Table 16

Selections of Preferred Subordinates by Assimilators

\begin{tabular}{lrrrrrr}
\hline Group & fe & fo & df & $x^{2}$ & $p$ \\
\hline Divergers & 11.34 & 21 & & & & \\
Convergers & 6.48 & 8 & & & & \\
Accommodators & 10.80 & 12 & & & & \\
Assimilators & 25.38 & 13 & 3 & $14.76 \quad(\underline{C}=.46)$ & $<.05$ \\
\hline n $=54$ & & & & & &
\end{tabular}


Table 17

Selections of Preferred Subordinates by Accommodators

\begin{tabular}{lrrrrr}
\hline Group & fe & fo & df & $x^{2}$ & $p$ \\
\hline All Others & 18.40 & 18 & & & \\
Accommodators & 4.60 & 5 & 1 & $.04^{\mathrm{a}}$ & NS \\
\hline$\underline{n}=23$ & & & & &
\end{tabular}

a Chi square using the Yates Correction formula

Hypothesis 6 was similar to Hypotheses 4 and 5 in that each subject was asked to choose classmates for a work project group and to identify those with whom they preferred not to work in this situation. Specifically Hypothesis 6 stated that "In the selection of work project group members, a) Diverger selectors will pick significantly more Diverger selectees, b) Assimilator selectors will pick significantly more Assimilator selectees, c) Converger selectors will pick significantly more Converger selectees, and d) Accommodator selectors will pick significantly more Accommodator selectees." In the case of Hypothesis 6, however, each subject was asked to identify as many as three classmates he or she would prefer to work with in a work project group. In some instances, students chose fewer than three classmates, and in other instances, the classmates they chose were not included in the group of students for whom usable learning styles had been determined. For this reason, the number of usable selections rather than selectors was used in determining the chi squares and are reported on each appropriate table. As with the two previous hypotheses, frequencies expected were determined based on the proportional representation of each learning style in the total study population (see Table 9). The increase in selections from one per student to a possible three meant that chi squares could be calculated for all groups except the Convergers in which the critical expected cell (selection of Convergers by Convergers) was still too small to bear analysis. The results for Hypothesis 6 are reported in Tables 
18, 19, and 20. As may be seen by reviewing these tables, Divergers did not express clear preferences for fellow work project group members and therefore the result for Divergers was not significant (see Table 18). As in Hypothesis 4, Assimilators indicated a preference for working with Divergers or Convergers rather than fellow Assimilators; therefore, the result was significant, but not in the direction hypothesized (see Table 19). The result for Convergers could not be determined due to their small numbers, and the result for Accommodators was significant in the direction hypothesized at the $0<.05$ level $\left(\underline{x}^{2}=18.00, R<.001\right.$; see Table 20). Therefore, sections (a), (b), and (c) of Hypothesis 6 relating to Divergers, Assimilators, and Convergers are not supported, whereas section (d) relating to Accommodators is supported. Further discussion of the results of Hypotheses 4, 5, and 6 may be found in Chapter 5 .

Table 18

Selections of Preferred Work Project Group Members by Divergers

\begin{tabular}{lrrrrl}
\hline Group & fe & fo & df & $x^{2}$ & $p$ \\
Assimilators & 31.96 & 38 & & & \\
Convergers & 8.16 & 10 & & & \\
Accommodators & 13.60 & 13 & & & \\
Divergers & 14.28 & 7 & 3 & 4.64 & NS \\
\hline
\end{tabular}

Usable selections $=68$

Table 19

Selections of Preferred Work Project Group Members by Assimilators

\begin{tabular}{|c|c|c|c|c|c|}
\hline Group & fe & fo & $d f$ & $x^{2}$ & $\underline{0}$ \\
\hline $\begin{array}{l}\text { Divergers } \\
\text { Convergers } \\
\text { Accommodators } \\
\text { Assimilators }\end{array}$ & $\begin{array}{l}36.12 \\
20.64 \\
34.40 \\
80.84\end{array}$ & $\begin{array}{l}49 \\
29 \\
33 \\
61\end{array}$ & 3 & $12.91(\underline{c}=.26)$ & $<.05$ \\
\hline
\end{tabular}

Usable Selections $=172$ 
Table 20

Selections of Preferred Work Project Group Members by Accommodators

\begin{tabular}{lrrrrr}
\hline Group & fe & fo & df & $x^{2}$ & $p$ \\
\hline Divergers & 15.12 & 14 & & & \\
Assimilators & 33.84 & 19 & & & \\
Convergers & 8.64 & 16 & & & \\
Accommodators & 14.40 & 23 & 3 & $18.00 \quad(\underline{\mathrm{C}}=.45)$ & $<.05$ \\
\hline
\end{tabular}

Usable Selections $=72$

\section{Findings Relating to Hypotheses 7 through 9}

Hypotheses 7 through 9 are those addressing the selection preferences of the subjects for working associations based on left or right brain hemisphere dominance. Generally, it was hypothesized that subjects would prefer their working relationships with those who shared their brain hemisphere dominance. Specifically, Hypothesis 7, Part (a) stated that "In the selection of preferred supervisors, left brain hemisphere dominant selectors will choose significantly more left brain hemisphere dominant selectees." Part (a) was tested using the chi square statistic, and these results may be found in Table 21. The frequencies expected were determined based on the proportional representation of left and right brain hemisphere dominant subjects in the overall study (see Table 11). As may be seen by reviewing this table, rather than preferring to work for fellow left brain hemisphere dominant supervisors, the left brain hemisphere dominant selectors indicated a significant preference for working with right brain hemisphere dominant supervisors. The resultant chi square is $9.82(\mathrm{p}<.005)$, but it is not in the direction hypothesized so Hypothesis 7, Part (a) is not supported. 
Table 21

Selection of Preferred Supervisors by Left Brain Hemisphere Dominants

\begin{tabular}{llllll}
\hline Group & fe & fo & df & $x^{2}$ & $p$ \\
\hline Right Brain Dominant & 20.79 & 33 & & & \\
Left Brain Dominant & 56.21 & 44 & $19.78^{\mathrm{a}}(\underline{\mathrm{C}}=.34)$ & $<.05$ \\
\hline $\mathrm{n}=77$ & & & & &
\end{tabular}

a Chi square using the Yates Correction formula.

Conversely, Hypothesis 7, Part (b) stated that "In the selection of preferred supervisors, right brain hemisphere dominant selectors will choose significantly more right brain hemisphere dominant selectees." Data relating to Part (b) are reported in Table 22. As may be seen, right brain hemisphere dominant selectors indicated no clear preferences in supervisors; the resultant chi square is not significant so Hypothesis 7 , Part (b) is not supported.

Table 22

Selections of Preferred Supervisors by Right Brain Hemisphere Dominants

\begin{tabular}{lrllll}
\hline Group & fe & fo & df & $x^{2}$ & 0 \\
\hline Left Brain Dominant & 19.71 & 17 & & & \\
Right Brain Dominant & 7.29 & 10 & 1 & $1.36^{\mathrm{a}}$ & NS \\
\hline
\end{tabular}

$\underline{n}=27$

a Chi square using the Yates Correction formula

Hypothesis 8 dealt with the subjects' preferences for subordinates. Specifically, Hypothesis 8, Part (a) stated, "In the selection of preferred subordinates, left brain hemisphere dominant selectors will choose significantly more left brain hemisphere dominant selectees." The chi square results for Part (a) are presented in Table 23. As may be seen by reviewing these results, left brain hemisphere dominant selectors 
indicated no clear preference in subordinates. The chi square relating to this hypothesis is not significant so Hypothesis 8, Part (a) is not supported.

Table 23

Selections of Preferred Subordinates by Left Brain Hemisphere Dominants

\begin{tabular}{lccccc}
\hline Group & fe & fo & df & $x^{2}$ & $p$ \\
\hline Right Brain Dominant & 20.79 & 19 & & & \\
Left Brain Dominant & 56.21 & 58 & 1 & $.22^{\mathrm{a}}$ & NS \\
\hline $\mathrm{n}=77$ & & & & &
\end{tabular}

a Chi square using the Yates Correction formula.

Hypothesis 8, Part (b) stated, "In the selection of preferred subordinates, right brain hemisphere dominant selectors will choose significantly more right brain hemisphere dominant selectees." The chi square analyses for Part (b) may be found in Table 24. As may be seen by reviewing these findings, right brain hemisphere dominant selectors indicated no preference in their choice of subordinates; the result is not significant so Hypothesis 8, Part (b) is not supported.

Table 24

Selections of Preferred Subordinates by Right Brain Hemisphere Dominants

\begin{tabular}{lrrrrr}
\hline Group & fe & fo & df & $x^{2}$ & 0 \\
\hline Left Brain Dominant & 18.98 & 18 & & & \\
Right Brain Dominant & 7.02 & 8 & 1 & $.18^{\mathrm{a}}$ & NS \\
\hline
\end{tabular}

$\underline{n}=26$

a Chi square using the Yates Correction formula.

Finally, Hypothesis 9 was concerned with the subjects' selections for preferred work project group members and those classmates with whom they would prefer not to work in this situation. Each subject was given the opportunity to identify three classmates he 
or she preferred for a work project group and three who were not preferred.

Specifically, Hypothesis 9, Part (a) stated that, "In the selection of work project group members, left brain hemisphere dominant selectors will choose significantly more left brain hemisphere dominant selectees." As in Hypothesis 6, some students chose three classmates while others chose only one, two or none; in some instances the brain hemisphere dominance of their selections could not be determined. Therefore, the number of usable selections rather than selectors was used in determining the frequencies expected; these were adjusted to reflect the proportional representation of left and right brain hemisphere dominant subjects in the overall study population (see Table 11). Again the chi square statistic was used to analyze the results, and these are reported in Table 25. As may be seen by reviewing this table, rather than preferring fellow left brain hemisphere dominant classmates as work project group members, the left brain hemisphere dominant selectors chose right brain hemisphere dominant classmates. The result for Part (a), although significant, is not in the direction hypothesized so Hypothesis 9, Part (a) is not supported. It may be remembered that in the analysis of Hypothesis 7, left brain hemisphere dominant selectors also indicated a preference for right brain hemisphere dominant supervisors. These results will be discussed in further detail in Chapter 5.

Table 25

Selection of Preferred Work Project Group Members by Left Brain Hemisphere Dominants

\begin{tabular}{lrrrrr}
\hline Group & \multicolumn{1}{c}{ fe } & fo & df & $x^{2}$ & $p$ \\
Right Brain Dominants & 62.37 & 77 & & & \\
Left Brain Dominants & 168.63 & 154 & 1 & $4.69^{\mathrm{a}}(\underline{C}=.14)<.05$ \\
\hline
\end{tabular}

Usable Selections $=231$

a Chi square using the Yates Correction formula. 
Hypothesis 9, Part (b) stated that, "In the selection of work project group members, right brain hemisphere dominant selectors will choose significantly more right brain hemisphere dominant selectees." The chi square analysis for Part (b) may be found in Table 26. As may be seen, right brain hemisphere dominant selectors indicated a preference for right brain hemisphere dominant work project group members. The resultant chi square is $6.44(\mathbb{R}<.05)$ in the direction hypothesized so Hypothesis 9, Part (b) is supported by these data.

Table 26

Selection of Preferred Work Project Group Members by Right Brain Hemisphere Dominants

\begin{tabular}{lccccc}
\hline Group & fe & fo & df & $x^{2}$ & 0 \\
Left Brain Dominant & 63.51 & 53 & & & \\
Right Brain Dominant & 23.49 & 34 & 1 & $6.41^{a}(\underline{C}=.26)<.05$ \\
\hline
\end{tabular}

Usable Selections $=87$

a Chi square using the Yates Correction formula.

Summary of Results

To summarize the results in Chapter 4 in regard to the specific hypotheses, there were two categories of hypotheses: those related to the relationship between learning style and brain hemisphere dominance, and those relating to selection. In regard to the hypotheses relating to learning style and brain hemisphere dominance, the first two hypotheses, in which a relationship between overall left and overall right brain hemisphere dominance was hypothesized to be related to specific portions of the Kolb diagram, were not supported. In Hypothesis 3, specific relationships were hypothesized between scales on the Kolb and scales on the Herrmann instrument. Those relating to Reflective Observation/Right Cerebral and Active Experimentation/Left Limbic were not supported; those relating to Concrete Experience/Right Limbic and Abstract Conceptualization/Left Cerebral were supported. 
In regard to the selection hypotheses, Hypotheses 4 and 5 , in which selection of supervisors and subordinates based on the Kolb instrument was examined, were not supported. In Hypothesis 6, in which work project group membership based on the Kolb was examined, only the portion concerned with Accommodators was supported. Hypotheses 7 through 9 were concerned with selection based on the Herrmann instrument as preferred supervisors, subordinates or work project group members. Only Hypothesis 9, Part (b), in which right brain hemisphere dominant selectors chose significantly more right brain hemisphere dominant work project group members, was supported. There follows in Chapter 5 a further discussion of the results reported in this Chapter. In addition, some recommendations are made regarding research directions and implications of the present study. 


\section{CHAPTER 5}

\section{Discussion}

The discussion related to this study is presented in several broad categories. These include 1) the ability to predict overall left or right brain hemisphere dominance based on the results of the Kolb LSI, 2) the relationships found between the specific dimensions of the LSI and the Herrmann instrument, 3) findings related to the selection of individuals for work-related activities, and 4) information that may be of interest to others relating to the two instruments used in this study.

\section{Left or Right Brain Hemisphere Dominance Based on Kolb}

In formulating Hypotheses 1 and 2 of this study, several considerations were present. Based on previous reports (Bush, 1984; Kolb, 1985) including the pilot for this study, a relationship befween overall brain hemisphere dominance and the Kolb learning style model was hypothesized. From a practical point of view, it was felt that the ability to identify some relationships between the Kolb instrument, which is quick and easy to administer and score, and the Herrmann instrument, which takes considerably longer to score, would allow users to provide additional feedback to students, trainees and workshop participants. In the pilot study, for example, it was possible to identify $57 \%$ of the right brain hemisphere dominant subjects $(n=7)$ and $91 \%$ of the left brain hemisphere dominant subjects $(n=23)$ by inspection of their placement on the Kolb diagram (see Figures 1 and 2). Kolb (1985) suggests that right brain hemisphere dominance is related to Concrete Experience, and that left brain hemisphere dominance is related to Abstract Conceptualization. Finally, Bush (1984) stated that there was a relationship between left brain hemisphere dominance, as measured by the Herrmann, and both the Abstract Conceptualization and Active Experimentation subscales of the Kolb. Based on this, relationships were hypothesized between overall right brain hemisphere dominance and both the Concrete Experience and Reflective Observation subscales of the Kolb LSI and between overall left brain hemisphere dominance and both 
the Abstract Conceptualization and Active Experimentation Kolb subscales. The Pearson product moment correlation between right brain hemisphere dominance and Concrete Experience was $.41(\mathrm{Q}<.01)$, and the correlation between right brain hemisphere dominance and Reflective Observation was $-.22(2<.01)$, so the first hypothesis was not supported. In regard to the second hypothesis, a correlation of .23 $(2<.01)$ was found between left brain hemisphere dominance and Abstract Conceptualization, whereas the correlation between left brain hemisphere dominance and Active Experimentation was -.03 (NS). For this reason the second hypothesis was not supported either. Although the moderate correlation between right brain hemisphere dominance and Concrete Experience was satisfactory, and there was a low but significant correlation between left brain hemisphere and Abstract Conceptualization, further correlations were performed in an effort to find what, if any, significant relationships might exist between the dimensions represented by these two instruments. This was also necessitated by the failure of the other two predicted correlations to materialize and by an interest in augmenting the literature regarding these factors. The correlations between overall right and left brain hemisphere dominance and the Kolb subscales and combination scores are presented in Table 27.

Table 27

Pearson Product Moment Correlations Between Right/Left Brain Hemisphere Dominance and Kolb LSI Scales ${ }^{\text {a }}$

\begin{tabular}{lcc}
\hline Kolb Scale & Right Dominance & Left Dominance \\
\hline Concrete Experience & .41 & -.40 \\
Reflective Observation & -.22 & .23 \\
Abstract Conceptualization & -.20 & .23 \\
Active Experimentation & $\mathrm{NS}$ & $\mathrm{NS}$ \\
Abstract Conceptualization minus & & .37 \\
Concrete Experience & -.36 & $\mathrm{NS}$ \\
Active Experimentation minus & $\mathrm{NS}$ & \\
$\quad$ Reflective Observation & &
\end{tabular}

$\underline{n}=125$

a All probabilities designated significant are at the $\mathrm{p}<.01$ level. 
It may be seen from Table 27 that right brain hemisphere dominance, while correlating moderately with Concrete Experience, does not appear to correlate with any other dimension measured by the Kolb LSI. Conversely, it may also be seen that left brain hemisphere dominance, although having a low correlation with Abstract Conceptualization $(r=.23, \mathfrak{p} .<.01)$, also correlates with Reflective Observation at approximately the same level $([=.23, \mathrm{R}<.01)$.

Since Reflective Observation had been hypothesized to be correlated with overall right brain hemisphere dominance and now appears to have a low correlation with overall left brain hemisphere dominance, a further review of this dimension of the Kolb LSI is required. In addition, the Active Experimentation dimension of the Kolb LSI, while hypothesized to be correlated with left brain hemisphere dominance, shows no correlation whatsoever with either left or right brain hemisphere dominance (see Table 27). In addition, the combination score, AE-RO, is not correlated with left or right brain hemisphere dominance either.

\section{The Limbic/Cerebral Factors}

An initial effort to clarify this issue involved examination of a dimension measured by the Herrmann but not included in the first two hypotheses, this being the limbic and cerebral aspect. It may be remembered from the Review of the Literature, that an individual who presents as primarily right or left brain hemisphere dominant will have a combination of cerebral or limbic factors within this dominance. Thus, an individual who is assessed as primarily left brain hemisphere dominant but with great strength in the cerebral area will be very different from another individual also assessed as primarily left brain hemisphere dominant but with great strength in the limbic area. In order to assess any significant relationships between the Kolb LSI and the cerebral/limbic dimension, additional correlations were performed and are reported in Table 28. 
Table 28

Pearson Product Moment Correlations Between Cerebral/Limbic Dimensions and Kolb LSI Scales a

\begin{tabular}{lcc}
\hline Kolb Scale & Overall Cerebral & Overall Limbic \\
\hline Concrete Experience & -.22 & .27 \\
Reflective Observation & NS & NS \\
Abstract Conceptualization & .49 & -.41 \\
Active Experimentation & -.17 & NS \\
Abstract Conceptualization minus & & \\
$\quad$ Concrete Experience & .41 & -.40 \\
Active Experimentation minus & NS & NS \\
Reflective Observation & & \\
\hline
\end{tabular}

\section{$\underline{n}=125$}

a All probabilities designated as significant are at $\mathrm{R}<.01$ level

Review of these data from the standpoint of the Concrete Experience and Abstract Conceptualization dimensions points up the importance of including this aspect in the overall discussion of relationships between the two instruments. It may be seen by reviewing Table 28 that a moderate, but unhypothesized relationship appears between Concrete Experience and the overall limbic $(I=.27, \mathrm{R}<.01)$, while the relationship between Abstract Conceptualization and the overall cerebral $(r=.49,0<.01)$ is actually stronger than the hypothesized relationship between Abstract Conceptualization and left brain hemisphere dominance $([=.23, \mathbb{R}<.01$; see Table 27$)$. Therefore, it is suggested that consideration of the total limbic/cerebral dimension must be involved in any further discussion of the relationships between these two instruments. Specific Relationships Between Subscales

To facilitate inclusion of the limbic/cerebral dimension, a further examination of the relationships between the subscales of the Kolb LSI and Herrmann instruments, which were initially dealt with in Hypothesis 3, may be helpful. In testing Hypothesis 3, 
relationships were hypothesized and found between Concrete Experience and Right Limbic $(r=.42, \mathrm{p}<.01)$ and Abstract Conceptualization and Left Cerebral $(\mathrm{r}=.42, \mathrm{p}<.01)$. Hypothesized relationships between Reflective Observation and Right Cerebral $([=-.16, N S)$ and Active Experimentation and Left Limbic $([=.03, N S)$ however, were not found to exist. To give further information regarding the subscales of the Kolb LSI and the Herrmann, additional correlations were conducted and are presented in Table 29.

Table 29

Pearson Product Moment Correlations Between Subscales of the Kolb LSI and The Herrmann ${ }^{b}$

\begin{tabular}{lcclccc}
\hline \multirow{2}{*}{ Kolb Factor } & \multicolumn{2}{c}{ Right } & & \multicolumn{2}{c}{ Left } \\
\cline { 2 - 3 } \cline { 5 - 6 } Cerebral & Limbic & & \multicolumn{2}{c}{ Cerebral } & Limbic \\
Concrete Experience & .22 & $.42^{\mathrm{a}}$ & & -.40 & $\mathrm{NS}$ \\
Reflective Observation & $\mathrm{NS}$ & $\mathrm{NS}$ & & $\mathrm{NS}$ & .23 \\
Abstract Conceptualization & $\mathrm{NS}$ & -.37 & & $.42^{\mathrm{a}}$ & $\mathrm{NS}$ \\
Active Experimentation & $\mathrm{NS}$ & $\mathrm{NS}$ & & $\mathrm{NS}$ & NS \\
\hline
\end{tabular}

$$
\underline{n}=125
$$

a Hypothesized relationship

b All relationships designated as significant are at the $\mathfrak{Q}<.01$ level.

\section{Foundations for Future Investigation}

A review of the data presented in Tables 27,28 , and 29 , suggests some possible relationships beyond and instead of those originally hypothesized. It may be suggested, for example, that the strongest possible relationship between right brain hemisphere dominance and Kolb LSI scales exists between this factor and Concrete Experience $(\mathrm{r}=.41, \mathrm{Q}<.01)$, as hypothesized. In regard to overall left brain hemisphere dominance, although Abstract Conceptualization is significantly correlated at $\underline{r}=.23$ ( $\mathrm{p}$ $<.01$ ) as hypothesized, the relationship between Reflective Observation and left brain hemisphere dominance $(r=.23, \mathrm{p}<.01)$ should also be examined (see Table 27$)$. 
Examination of Table 28 indicates that the strongest correlation to Abstract Conceptualization is neither of these factors, but rather the overall cerebral dimension $([=.49, \mathbb{R}<.01$, see Table 28). Similarly, review of Table 29 reveals that the strongest correlation with Reflective Observation is not to the hypothesized Right Cerebral, but rather with the Left Limbic $([=.25,2<.01$, see Table 29$)$. When Hypothesis 3 , of which this last was a part, was formulated the only available data had been from the pilot study in which a low/moderate but nonsignificant correlation $([=.30, n=30, N S)$ had been found. Since a moderate and significant relationship had been found between Abstract Conceptualization and the Left Cerebral $(I=.50, \mathrm{R}<.01)$ and a low/moderate but nonsignificant correlation was found between Concrete Experience and Right Limbic $([=33, n=30, N S)$ in the pilot, and in the absence of other data, the most sensible course seemed to be to superimpose the Herrmann and Kolb instruments on each other and look for relationships that appeared from the verbal descriptions of each to have potential significance. Now it seems clear not only that examination of the relationships between these two instruments cannot ignore the impact of the cerebral/limbic measures, but it also appears that the two are not measuring precisely the same dimensions. While it would appear, as indicated, that Concrete Experience is most highly correlated with overall right brain hemisphere dominance, Abstract Conceptualization is not highly correlated with overall left brain hemisphere dominance. Rather, it appears to be most highly correlated with the overall cerebral dimension.

Before assuming that this constitutes a comparison of divergent factors, however, it may be best to review the nature of each instrument, and the theory it represents. It may be remembered from Chapter 3 that Concrete Experience and Abstract Conceptualization were assessed to be satisfactorily bipolar in nature $(r=-.46, n=133$, $\mathrm{R}<.01$; see Table 5) as suggested by Kolb's theory. In a similar fashion, Active Experimentation and Reflective Observation are satisfactorily bipolar $([=-.52$, $\mathrm{n}=133, \mathrm{R}<.01$; see Table 5). In addition, these two dimensions are also independent of 
each other as demonstrated by the correlation between the combination scores, AC-CE and $A E-R O(I=-.26, n=133, R<.01$; see Table 5$)$. In regard to the Herrmann scores, the overall right and overall left were found to be bipolar $([=-.84, n=126,2<.01)$, as were the overall cerebral and limbic factors $([=-.73, n=126, p<.01)$, as stated in Herrmann's model. It must be remembered, however, that Herrmann's model states that the overall right comprises varying amounts of cerebral and limbic as does the overall left. Therefore, the two bipolar dimensions, leftright and cerebral/limbic, should not be independent. Correlations between the overall dimensions of the Herrmann reveal this to be the case, as when the overall right and overall limbic correlate at .47 $(n=126, R<.01)$, and the overall left and overall cerebral correlate at .18 $(n=126, R$ <.02), which tend to indicate the overlapping relationships within the Herrmann Model. Proposed Relationships

From the standpoint of seeking relationships between the Herrmann and the Kolb, now it would appear that if Herrmann's dimensions are to be superimposed on Kolb's diagram, the overall right would probably appear at the top as related to Concrete Experience (see Figure 3). Overall left, however, might fall diagonally across the bottom (Abstract Conceptualization) and right side (Reflective Observation), thus depicting the cerebral and limbic aspects of left brain hemisphere dominance. Conversely, the overall cerebral would lie across the bottom of the diagram as related to Abstract Conceptualization, while the overall limbic is best represented as a diagonal area over the top (Concrete Experience) and right side (Reflective Observation). This leaves the left side of the Kolb diagram (Active Experimentation) free, which is supported by examination of the correlations relating to this dimension. Although negatively correlated with Reflective Observation $([=-.51, D<.01)$, which supports the concept of bipolarity, this dimension does not appear to be measured in any way by any of the scales of the Herrmann (see Tables 27, 28, and 29). 


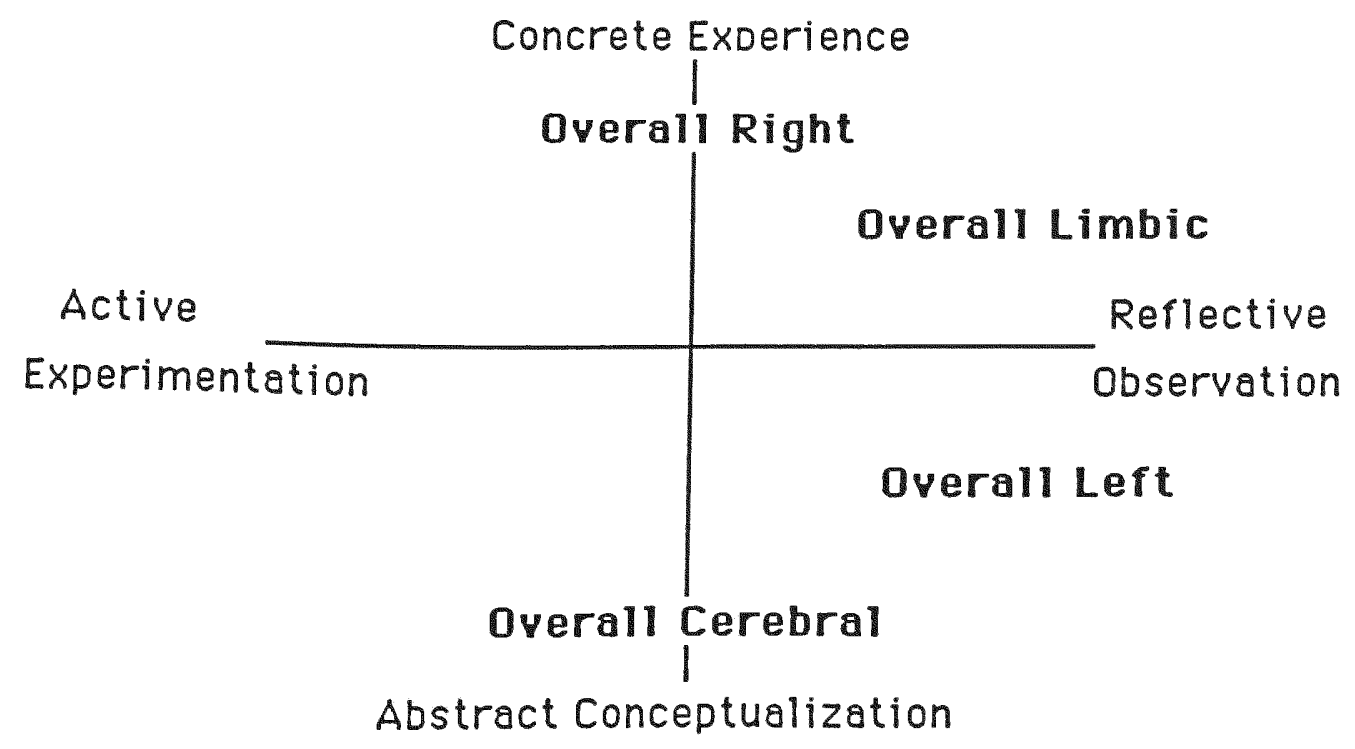

Figure 3: Suggested Relationships Between the Herrmann Overall Scores and the Kolb LSI Diagram.

Eoundations for Proposals

In order to aid in illustrating and examining these proposals more completely, several scattergrams were produced. The first of these, Figure 4, provides a visual display on the Kolb diagram of those individuals who were assessed as more right brain hemisphere dominant than left brain hemisphere dominant $(n=33)$. A review of this scattergram reveals that $20(61 \%)$ of the 33 individuals involved fall above a horizontal line drawn at the 50th percentile on the diagram. If the horizontal line is dropped to fall at the 60 th percentile, $23(70 \%)$ of the predominantly right brain hemisphere dominant individuals fall above the line, while dropping the line to the 70th percentile allows $26(79 \%)$ to fall within the designated area. This visual display is somewhat supported by a regression analysis performed using the Overall Right scores of the total usable sample $(n=125)$, and the combination score, AC-CE. Here the E-ratio was 18.32 ( $\mathrm{n}=125, \mathrm{n}<.001, \underline{S E}=20.26$ ), although predictability was low. 


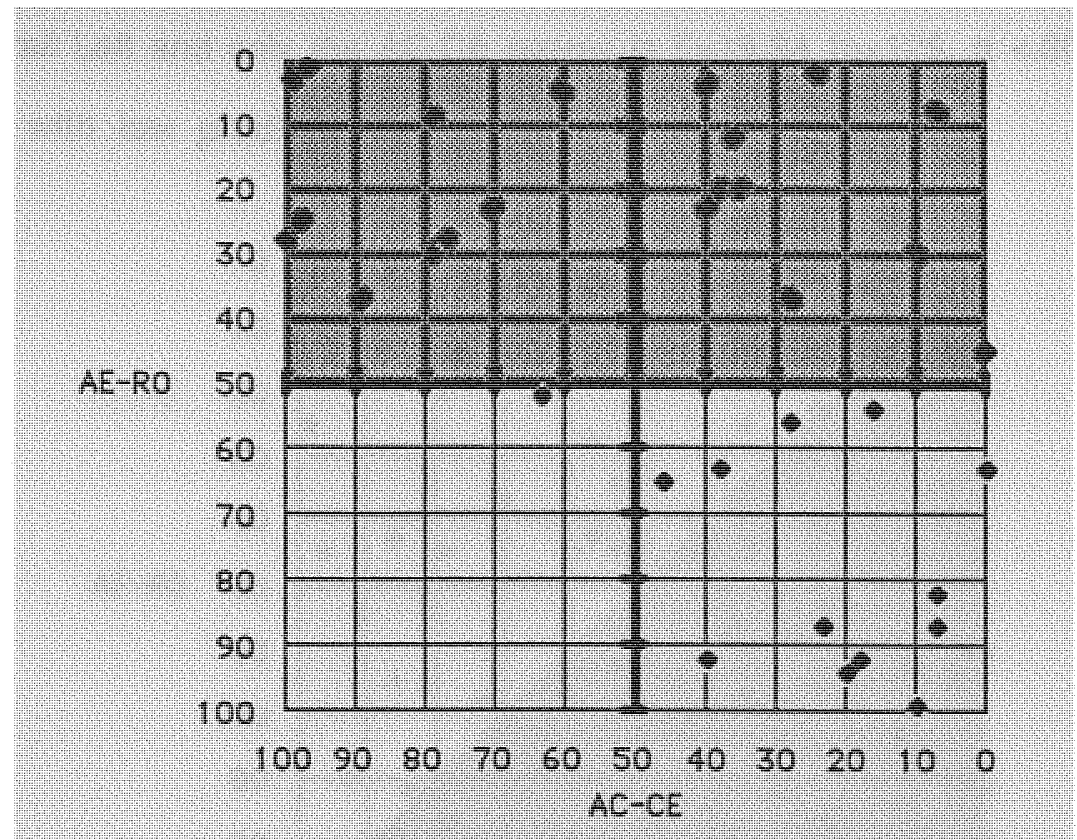

Figure 4: Right Brain Hemisphere Dominant Subjects Displayed on the Kolb Diagram $\mathrm{n}=33 ; \mathrm{AE}-\mathrm{RO}=$ Active Experimentation minus Reflective Observation; AC-CE=Abstract Conceptualization minus Concrete Experience.

When the left brain hemisphere dominant subjects $(n=85)$ are depicted on a scattergram using the Kolb diagram (see Figure 5), 61 (72\%) fall below and to the right of a diagonal line drawn from the lower left corner of the diagram to the upper right corner. If this diagonal line is moved up and to the left so that it begins at the 90 th percentile mark in the lower left and extends to the 10th percentile mark on the upper right, $66(78 \%)$ of the left brain hemisphere dominant subjects now fall below and to the right of the line. Finally, if the line is moved one more square up and to the left, so that it begins at the 80th percentile in the lower left and extends to the 20th percentile in the upper right, $73(86 \%)$ of the 85 left brain hemisphere dominant subjects fall below and to the left of the diagonal line (see Figure 5). Again, this is somewhat supported, but with low predictability by a multiple regression using the Overall Left scores of all subjects and the two combination scores, $A C-C E$ and $A E-R O$, with $E=9.61$ $(\mathrm{n}=125, \mathrm{Q}<.0003, \mathrm{SE}=18.28)$. The somewhat stronger relationship is obtained using 
the Overall Left and only the AC-CE scores is $E=19.24$ ( $n=125, Q<.0001, S E=20.26$ ), but still with low predictability.

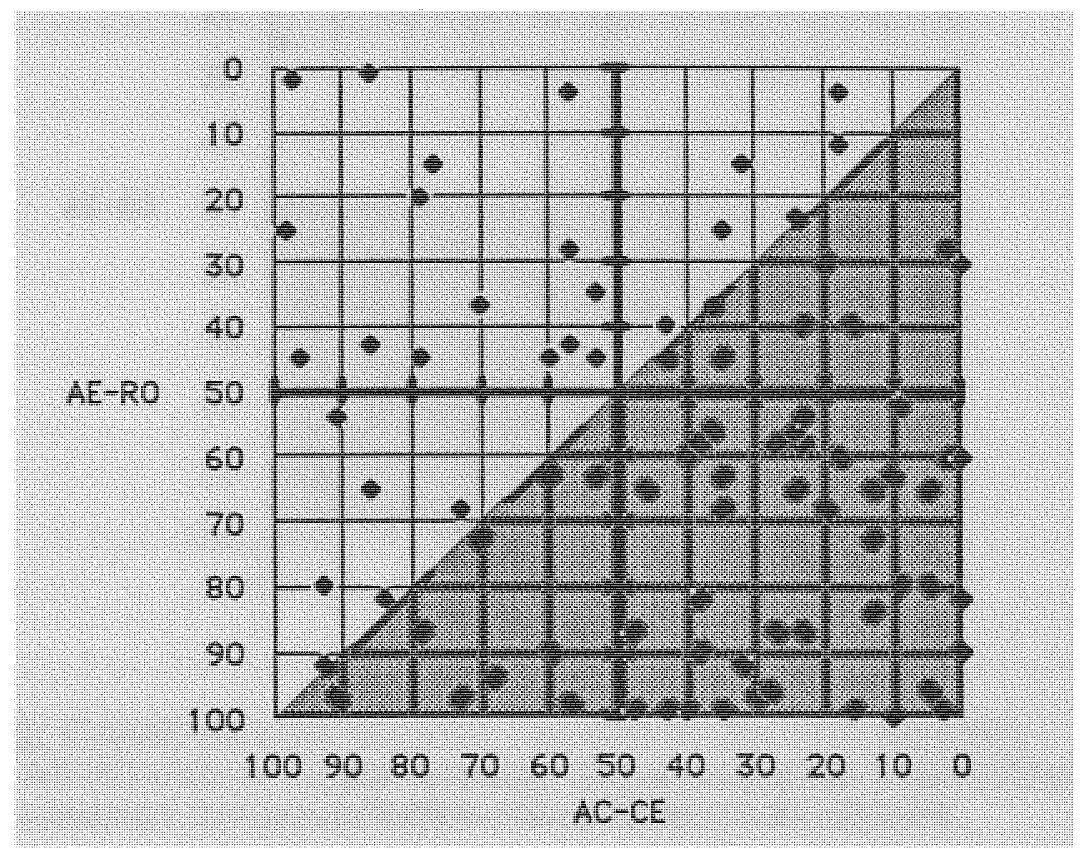

Fiqure 5: Left Brain Hemisphere Dominant Subjects Depicted on the Kolb Diagram $\mathrm{n}=85 ; \quad A E-R O=$ Active Experimentation minus Reflective Observation; $\mathrm{AC}-\mathrm{CE}=\mathrm{Abstract}$ Conceptualization minus Concrete Experience.

When the predominantly cerebral subjects $(n=44)$ are depicted on the Kolb diagram (see Figure 6$)$, it may be seen that $32(73 \%)$ of them fall below a horizontal line drawn at the 50th percentile. If the line is moved up to the 40 th percentile, $37(84 \%)$ of them fall below this line, which would appear to represent the close relationship between the Overall Cerebral and Abstract Conceptualization. A regression analysis using the Overall Cerebral scores of the total usable sample $(n=125)$ and the AC-CE scale, the E-ratio is $24.79(\mathrm{R}<.0001, \mathrm{SE}=12.66)$, which tends to support this relationship although with low predictability. 


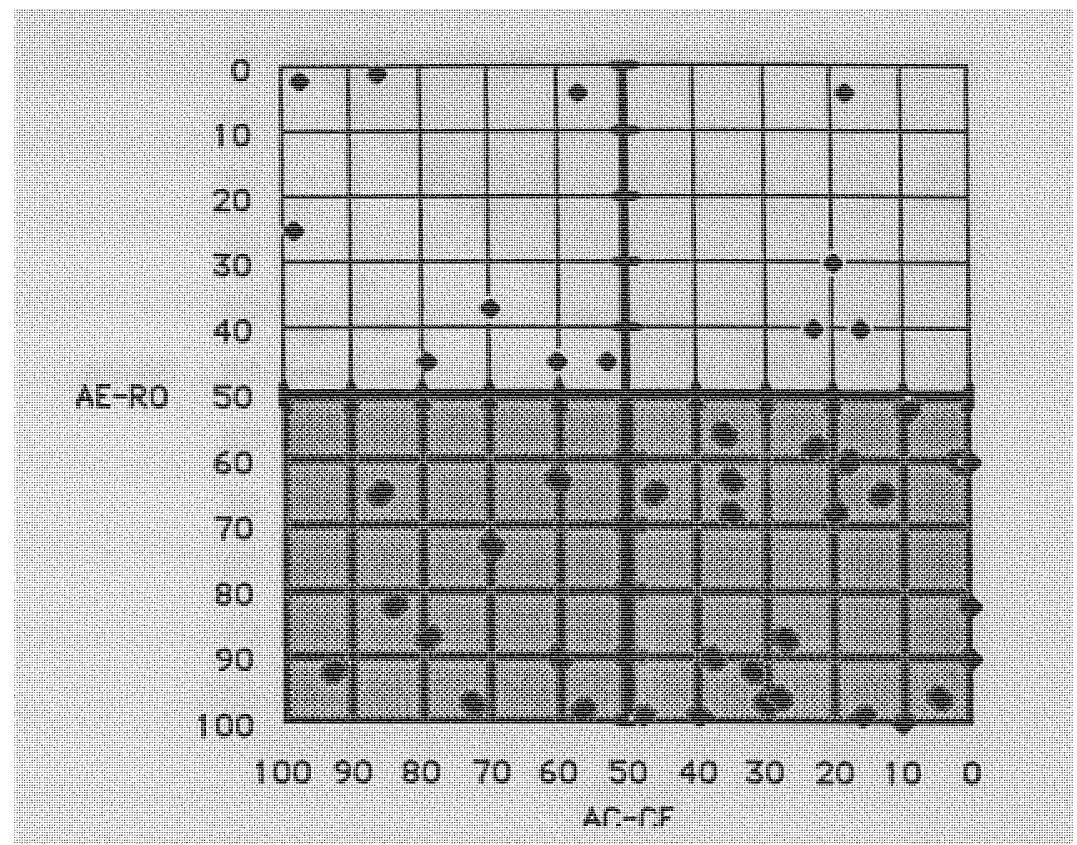

Figure 6: Overall Cerebral Subjects Depicted on the Kolb Diagram; $\mathrm{n}=44 ; \mathrm{AE}-\mathrm{RO}=$ Active Experimentation minus Reflective Observation; $\mathrm{AC}-\mathrm{CE}=\mathrm{Abstract}$ Conceptualization minus Concrete Experience.

Finally, when the Overall Limbic subjects $(n=72)$ are depicted on the Kolb diagram (see Figure 7 ), $49(68 \%)$ fall above and to the right of a line drawn diagonally from 0 at the upper left to 0 at the lower right. When the line is dropped toward the lower left so that it connects the 10th percentile marks on the two axes, $57(79 \%)$ of the Overall Limbics fall above and to the right. Dropping the line one step further to the lower left so that it connects the 20 th percentile points allows $59(82 \%)$ of the Limbics to fall above and to the right. Again a multiple regression using the Overall Limbic scores of the total usable sample $(\mathrm{n}=125)$, and the combination scores, $A C-C E$ and $A E-R O$, tends to support this conception $(E=11.55, \mathrm{D}<.0001, \underline{S E}=15.69)$; the Overall Limbic regressed against the combination score AC-CE alone, however, still yields better results although with a low level of predictability $(E=22.94, R<.0001, S E=15.65)$. 


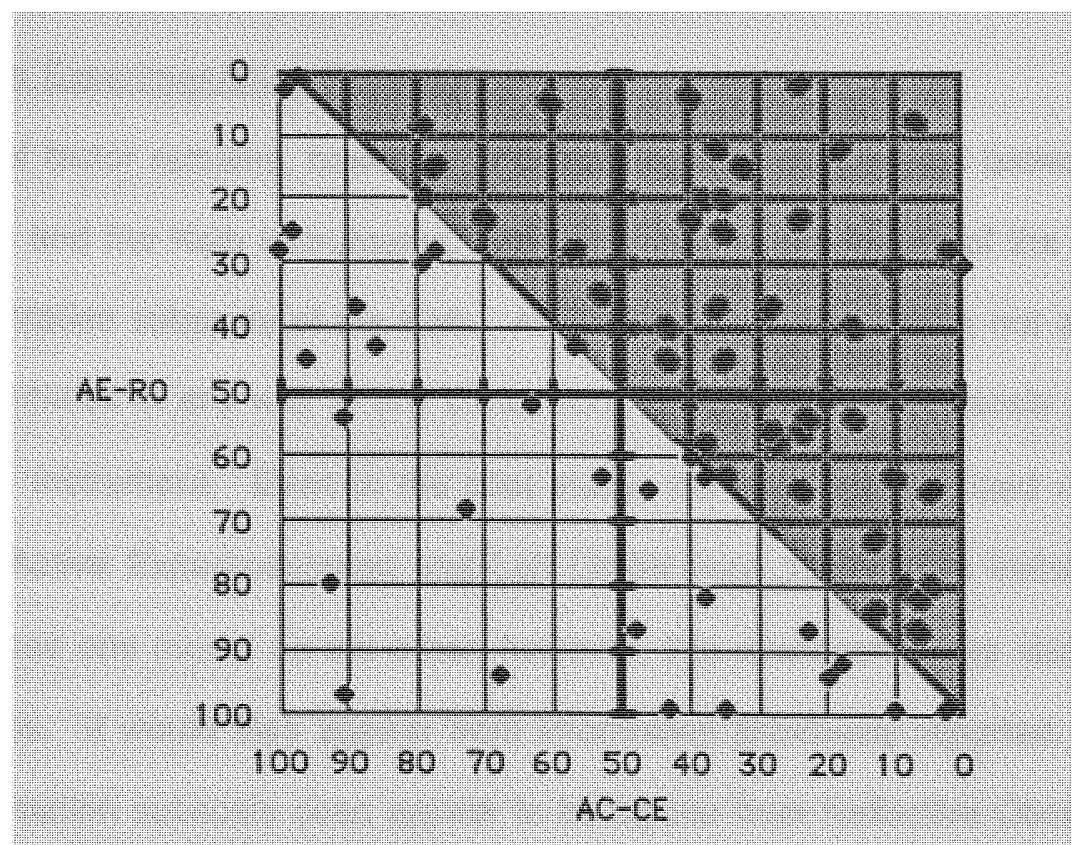

Eigure 7: Predominantly Limbic Subjects Depicted on the Kolb Diagram; $\mathrm{n}=72 ; \mathrm{AE}-\mathrm{RO}=$ Active Experimentation minus Reflective Observation; AC-CE=Abstract Conceptualization minus Concrete Experience.

\section{Summary of Kolb and Herrmann Findings}

In summary, it would now appear that considerations of the relationships between the Herrmann and Kolb instruments must take into account both the overall leftright dimensions, but also the overall cerebral/limbic dimensions of the Herrmann. In addition, it must be remembered that the bipolarity and independence of the dimensions of the Kolb and the bipolarity of the independent factors and interrelatedness of the overall dimensions of the Herrmann preclude directly superimposing one model on the other. Within this context, however, it would appear that further research might be warranted to explore the relationships between the overall right and Kolb's Concrete Experience, overall concrete and Abstract Conceptualization, overall left and a combination of Abstract Conceptualization and Reflective Observation, and overall limbic and Concrete Experience and Reflective Observation. 


\section{The Active Experimentation Subscale}

A final factor remains, however, in discussing the relationships between the Herrmann and the Kolb instruments, and this concerns the nature of the Active Experimentation subscale of the Kolb. As stated previously, it does not appear that this subscale relates in any way to any dimension, either overall or subscale and the Herrmann instrument. Even in the pilot study, the later hypothesized relationship between Active Experimentation and Left Limbic was .15 (NS); to initially attempt to superimpose one model on the other, however, this relationship was stated within the hypotheses. It would also appear from information previously reported, that the Active Experimentation subscale does appear to be bipolar from Reflective Observation and independent of both Concrete Experience and Abstract Conceptualization (see Table 5). There remains, however, Bush's (1984) report of a relationship between overall left brain hemisphere dominance and Active Experimentation. In addition, the unanticipated lack of Convergers found in the study sample needs to be reviewed. An analysis of the sample study was conducted in comparison to Kolb's norm group (1986) using t-tests. It was found that the study sample differed significantly from the norm group on the Active Experimentation subscale $(\mathrm{I}=6.07, \mathrm{p}<.01)$ and on the combination score, AE-RO $(I=5.44, p<.01)$. The means and standard deviations of the study sample and the norm group are reported in Table 30 .

Several characteristics of the study sample may help to explain this difference with the resultant lack of Convergers, which is the learning style that is high in Abstract Conceptualization and Active Experimentation (see Figure 2). The norm group had 163 $(11 \%)$ more females than males, whereas the study sample had $26(19 \%)$ more males than females. Several earlier studies have indicated that males tend to score higher on Abstract Conceptualization than do females (Kolb, 1976, 1985; Strange, 1978). In addition, both Messick (1976) and Witkin (1976) found more females in their Field Dependent category, which tended to be more active than introspective. Another study 
showed that business people in general score higher on Abstract Conceptualization than the general population (Dunn, 1982).

Table 30

Comparison of Means and Standard Deviation of Subscales of the Kolb LSI (1985) Norm Group and the Study Sample

\begin{tabular}{|c|c|c|c|c|}
\hline \multirow[b]{2}{*}{ Scale } & \multicolumn{2}{|c|}{ Norm Group $(n=1.446)$} & \multicolumn{2}{|c|}{ Study Group $(n=133)$} \\
\hline & Mean & S.D. & Mean & S.D. \\
\hline Concrete Experience & 26 & 6.8 & 26 & 7.5 \\
\hline Reflective Observation & 30 & 6.5 & 31 & 7.1 \\
\hline Abstract Conceptualization & 30 & 6.7 & 32 & 7.0 \\
\hline Active Experimentation & 35 & 6.9 & 31 & 8.1 \\
\hline Active Experimentation mir & & & & \\
\hline Reflective Observation & 5.4 & 11.0 & -1 & 13.3 \\
\hline Abstract Conceptualization & & & & \\
\hline Concrete Experience & 4.3 & 11.4 & 6 & 12.4 \\
\hline
\end{tabular}

Given that all the subjects in the study sample were in management-related studies and that $117(87 \%)$ of them work, this may also have impacted the sample characteristics. On the other hand, Kolb (1986) found that the tendency toward Active Experimentation as opposed to Reflective Observation increases with both age and education, although other studies report the opposite (Dorsey \& Pierson, 1984). Almost $50 \%$ of his norm group was younger than any of the study sample, and only $5 \%$ of the norm group was the equivalent of the study sample in terms of educational level. In view of the absence of more specific data, it would appear that the difference in educational level between the norm group and the study sample might be the reason for the differences between the two groups. It might be conjectured that graduate students would tend to be both more Abstract and also more Reflective than the population at large. It would seem logical that more risk-taking persons, i.e., those scoring higher on Active Experimentation, would be more likely to be engaged in experiential study of business and management rather 
than committing themselves to the systematic study of the subject implied by involvement in a graduate program. This does not, however, totally explain away the differences between previous groups who took the OLSI and the study sample who took the LSI, given the high level of reported correlation between the two $(\underline{r}=.91$, Kolb, 1986). Further study focusing on the distribution of graduate students, particularly in management studies, on the Kolb LSI might be worthy of consideration. Further conjecture, however, based on earlier studies using different models, terminology, and measures, seems only to compound the problems mentioned in Chapter 2 concerning the contradictory and difficult terminology associated with learning style studies.

\section{Considerations Regarding Selection}

In hypothesizing the outcomes regarding others with whom the subjects would prefer to work, a directionality based on other loosely related research was made (Cohen, 1981; Elster, 1977; Lesnik-Oberstein \& Cohen, 1984; Levinson, 1980; Strot, 1985, Witkin, 1976). In essence, for Hypotheses 4 through 9, this involved the suggestion that individuals would prefer to work with persons like themselves, whether that similarity was based on learning style or on brain hemisphere dominance. Although it was found that Accommodators did prefer to work with other Accommodators in work project groups (Hypothesis 6, Section (d), see Table 20), and that right brain hemisphere dominant individuals preferred working with other right brain hemisphere dominant people as work project group members (Hypothesis 9, Part (b), see Table 26), these results involved sufficient contradictions to warrant great caution.

Closer examination of Table 20 reveals, for example, that Accommodators not only selected fellow Accommodators for work project groups, but they also selected Convergers in greater numbers than were expected. The other preference indicated in this Table is the underrepresentation of Assimilators in their selections as compared to the number that would be expected given their proportional representation in the study population. In an application setting using a Research and Development team, it was 
observed that Accommodators were likely to be impatient with Assimilators (Carlson, Keane \& Martin, 1984); it may be that this factor is reflected in the selection findings rather than the more generalized concept that individuals will tend to select others like themselves. However, when all the selections for supervisor, subordinate, and work project group members are combined from all the selectors, it was found that Assimilators were also underrepresented in overall selections $\left(\underline{x}^{2}=28.65\right.$, actual $\underline{D}$ $<.001$; see Table 31).

\section{Table 31}

Qverall Selections for Supervisor. Subordinate, and Work Project Group Member by All Selectors

\begin{tabular}{lrrrrr}
\hline Group & \multicolumn{1}{c}{ fe } & fo & df & $x^{2}$ & $p$ \\
\hline Divergers & 119.91 & 147 & & & \\
Assimilators & 268.37 & 206 & & & \\
Convergers & 68.52 & 89 & & & \\
Accommodators & 114.20 & 129 & 3 & $28.65(\underline{C}=.22)$ & $<.05$
\end{tabular}

Usable Selections $=571$

Closer examination of the selection data also reveals that Assimilators contributed to these findings because their own selections indicated they preferred working with Divergers or Convergers as supervisors (Hypothesis 4, Section (b), see Table 13), with Divergers as subordinates (Hypothesis 5, Section (b), see Table 16), and with Divergers or Convergers as work project group members (Hypothesis 6, Section (b), see Table 20).

On the other hand, study participants were also asked to identify those classmates they preferred not working with as supervisors, subordinates and work project groups members. Analysis of these choices yielded no significant results except when overall selections by all learning styles were reviewed. Here Assimilators were not identified as fellow workers the students preferred not to work with, while Divergers were 
identified as non-preferred $\left(\underline{x}^{2}=10.58, \mathrm{p}<.05\right.$, see Table 32). Further analysis revealed that the selections by Assimilators indicated they identified Divergers as the co-workers they preferred not to work with $\left(\underline{x}^{2}=8.93, \mathrm{D}<.05\right.$, see Table 33). These results seem contradictory when compared with the apparent preference by Assimilators for Divergers indicated earlier. If these results are accepted, it would appear that Assimilators may prefer some Divergers while not wanting to work with others. The conditions and circumstances surrounding these preferences must remain, however, open to question.

Table 32

Selections as Non-Preferred Co-Workers by All Learning Styles

\begin{tabular}{lrrrrr}
\hline Group & fo & fo & df & $x^{2}$ & $p$ \\
\hline & 113.40 & 144 & & & \\
Divergers & 253.80 & 230 & & & \\
Assimilators & 64.80 & 58 & & & \\
Convergers & 108.00 & 108 & 3 & $10.58(\underline{c}=.14)<.05$ \\
Accommodators & & & & & \\
\hline
\end{tabular}

Usable Selections $=540$

Table 33

Selections as Non-Preferred Co-Workers by Assimilators

\begin{tabular}{lrrrrr}
\hline Group & \multicolumn{1}{c}{ fe } & fo & df & $x^{2}$ & 0 \\
Divergers & 55.65 & 73 & & & \\
Assimilators & 124.55 & 104 & & & \\
Convergers & 31.80 & 33 & & & \\
Accommodators & 53.00 & 55 & 3 & $8.93(\underline{C}=.18)$ & $<.05$ \\
\hline
\end{tabular}

Usable Selections $=265$

In addition to the factors already mentioned, the pattern of distribution of learning styles within the classes used in the study requires that caution be used in drawing conclusions based on these data (see Table 9). Although the distribution closely approximates the overall distribution in many instances, in some cases, uneven 
distributions mean that students had little or no opportunity to intereact with others of different Learning Styles. The most extreme example, of course, is Group 3 in which only one Accommodator was found. This individual obviously had no opportunity to select another student with the same Learning Style; likewise, his or her classmates had very little opportunity to select an Accommodator since only one was available. The overall lack of Convergers in the study population made analysis difficult overall and impossible in regard to this group (see Table 9).

In regard to the data concerning Hypotheses 7 through 9, which dealt with selection based on right/left brain hemisphere dominance, the only significant finding was the preference of left brain hemisphere dominants to work with right brain hemisphere dominants (see Table 21). This finding is consistent with the above data in that Assimilators tend to be left brain hemisphere dominant whereas Divergers tend toward more right brain hemisphere dominance. An interesting result became apparent in the process of evaluation of the data concerning the left brain hemisphere dominants choices. In three of the groups, Groups 2, 4 and 6, there seemed to be a tendency for left brain hemisphere dominants to prefer right brain hemisphere dominants overall in their selections. In the other four groups, however, this tendency was not apparent (see Table 34).

Table 34

Chi Squares of Overall Selections by Group for Left Brain Hemisphere Dominants

\begin{tabular}{|c|c|c|c|c|c|c|c|}
\hline \multirow[b]{2}{*}{ Group } & \multicolumn{2}{|c|}{ Select Lefts } & \multicolumn{3}{|c|}{ Select Rights } & \multirow[b]{2}{*}{$x^{2 a}$} & \multirow[b]{2}{*}{ c } \\
\hline & fe & fo & fe & fo & $d f$ & & \\
\hline Group $1, n=11$ & 36 & 39 & 13 & 11 & 1 & .66 & NS \\
\hline Group 2, $\bar{n}=13$ & 43 & 34 & 20 & 29 & 1 & 5.72 & $.55<.05$ \\
\hline Group 3, $\underline{n}=17$ & 61 & 62 & 7 & 6 & 1 & .31 & NS \\
\hline Group $4, \bar{n}=16$ & 28 & 22 & 7 & 13 & 1 & 6.49 & $.54<.05$ \\
\hline Group 5, $\bar{n}=15$ & 49 & 46 & 23 & 26 & 1 & .56 & NS \\
\hline Group 6, $\underline{n}=13$ & 33 & 23 & 21 & 31 & 1 & 8.65 & $.40<.05$ \\
\hline Group $7, \underline{n}=15$ & 32 & 30 & 11 & 13 & 1 & .34 & NS \\
\hline
\end{tabular}

a Chi squares with Yates Correction formula 
In addition, in two of the groups, Group 1 and 3, where nonsignificant results occurred, when the left brain hemisphere dominants were asked to identify those classmates with whom they preferred not to work, they specified right brain hemisphere dominant classmates (see Table 35 ). The only other significant results from questions involving individuals the subjects preferred not to work with came from right brain hemisphere dominants in Groups 5 and 6 (see Table 35).

Table 35

Significant Results from Selection Data Regarding Classmates with Whom Subjects Preferred Not to Work

\begin{tabular}{|c|c|c|c|c|c|c|c|}
\hline \multirow[b]{2}{*}{ Selectors } & \multicolumn{2}{|c|}{ Selects Lefts } & \multicolumn{2}{|c|}{ Selects Bights } & \multirow[b]{2}{*}{ df } & \multirow[b]{2}{*}{$\underline{x}^{2 a}$} & \multirow[b]{2}{*}{$C \quad 0$} \\
\hline & fe & fo & fe & fo & & & \\
\hline Lefts, Group $1(n=11)$ & 27 & 19 & 10 & 18 & 1 & 8.85 & $.67<.05$ \\
\hline Lefts, Group $3(n=17)$ & 53 & 42 & 7 & 18 & 1 & 22.27 & $.75<.05$ \\
\hline Rights, Group $5(n=7)$ & 22 & 28 & 11 & 5 & 1 & 4.28 & $.62<.05$ \\
\hline Rights, Group $6(n=8)$ & 20 & 29 & 12 & 3 & 1 & 11.11 & $.76<.05$ \\
\hline
\end{tabular}

a Chi squares with Yates Correction formula

Review of the characteristics of the subjects in Groups 2, 4, and 6, as opposed to Groups $1,3,5$, and 7 , was done in an effort to understand the different findings within these groups. It was felt that the presence in Group 2 of a number of SpoAd majors who tend to take many of their classes together, and the presence in Groups 4 and 6 of a number of MSM students (see Table 2) who were near the end of their programs, and who had taken a number of classes together might be the key to the observed differences. Further investigation revealed that in classes 2,4 , and 6 , a majority of the students knew five or more of their classmates prior to taking the class in which the study was conducted. In Groups 1, 3, 5, and 7, however, the majority of the students knew one or less of their classmates prior to the class. Further research might be conducted to 
investigate the effect of time on selection of left or right brain hemisphere dominants, particularly in view of the data presented in Table 35. These findings run counter to Witkin's (1976) findings that not only is there a high level of liking between persons of similar style, but that this relationship may develop in less than an hour of exposure. The response of the left brain hemisphere dominants to prefer not to work with right brain hemisphere dominants in two of the classes in which the students knew none or very few of their classmates prior to entering that class would appear to further support future research in this direction. Additional efforts to find possible explanations, such as the degree of limbic or cerebral orientation on the part of the selectees yielded no significant results.

\section{Summary}

The results of this study generally fell in the areas of 1) providing information regarding both the Herrmann and Kolb instruments overall, 2) providing information regarding the relationships between the two instruments, and 3) suggesting directions for future research, particularly in the area of selection and brain hemisphere dominance.

In Chapter 3, reported correlations of both instruments' internal characteristics support not only their bipolarity but also their respective theoretical bases (see Table 5). In regard to bipolarity in the Kolb instrument, Abstract Conceptualization and Concrete Experience were found to be correlated at - .46 ( $n=133, n<.01)$; Reflective Observation and Active Experimentation were correlated at $-.52(n=133, p<.01)$. In the Herrmann instrument, the Overall Left and Overall Right dimensions were correlated at - $.84(n=126, R<.01)$; the Overall Cerebral and Overall Limbic dimensions were correlated at - .73 ( $n=126, R<.01)$.

Reliabilities of both instruments were reported for this study. Split-half correlations of .85 to $.90(n=133,2<.01$, see Table 4) for each of the factors on the Kolb were found. Test-retest correlations for the Herrman ranged from .67 to .81 
( $n=30, R<.01$, see Table 6 ). Concerns were raised, however, regarding the norms of the Kolb LSI, particularly on the Active Experimentation subscale when it is used with older subjects and with those involved in graduate study. Comparison of the study group with the norm group revealed significant differences on the Active Experimentation

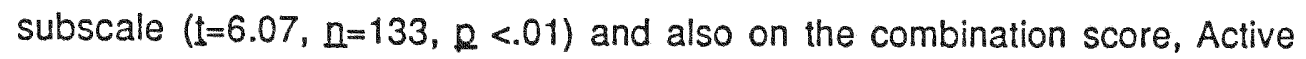
Experimentation minus Reflective Observation ( $I=5.44, n=133, R<.01)$.

In regard to the relationships between the two instruments, it has been found that there is a correlation between right brain hemisphere dominance and Concrete Experience $([=.41, n=125, \mathrm{D}, .01$, see Table 27); a correlation also exisis between left brain hemisphere dominance and Abstract Conceptualization $(I=.23, D=125, R<.01$, see Table 27). It is proposed, however, that the more profitable direction for future research in this area would involve the relationship between the Overall Cerebral dimension and Abstract Conceptualization ( $I=.49, n=125, \mathrm{D}<.01$, see Table 28). In addition, relationship was found between the Right Limbic dimension and Concrete Experience $([=.42, n=125, n<.01$, see Table 29) and between the Left Cerebral dimension and Abstract Conceptualization $(\mathfrak{I}=.42, \mathrm{n}=125, \mathrm{R}<.01$, see Table 29). Again, ideas for future research based on the theoretical basis for the two models and the respective instruments have been presented.

Finally, in the area of selection for specific organizational roles and its possible relationship to learning style and brain hemisphere dominance, a direction for additional research has been suggested. In general, it was found that there is not good evidence to support the overall concept that selection was based on learning style or brain hemisphere dominance. In some instances, however, individuals with some learning styles seemed to prefer others of the same or different learning styles. There appeared, for example, to be a preference by right brain hemisphere dominants to select other right brain hemisphere dominants in some situations. Also, over time, it appeared that left brain hemisphere dominants may shift from an initial preference for not working 
with right brain hemisphere dominants to a later preference for working with right brain hemisphere dominants. The results regarding the effect of time on selection as it related to brain hemisphere dominance suggests some future directions for research in this area. Otherwise, the determining factors in selection remain unclear. 


\section{References}

Agor, W. H. (1983). Brain skills development in management training. Iraining and Development Journal, 37 (4), 78-83.

Agor, W. H. (1983, August). Tomorrow's intuitive leaders. The Futurist 17 (4), pp. 49-53.

Agor, W. H. (1984). Intuitive management. Englewood Cliffs, NJ: Prentice-Hall.

Albrecht, K. (1980). Brain power. Englewood Cliffs, NJ: Prentice-Hall.

Albrecht, K. (1983). Earth and sky--a meeting of minds: Getting through to people with mind-to-mind communication. Iraining and Development Journal 37 (10), 70-75.

Assagioli, R. (1973). Psychosynthesis: A technique for the use of intuition. In R. E. Ornstein (Ed.), The nature of human consciousness (pp. 336-342), New York: Viking.

Banks, G. N. (1977). An examination of the relationships among the teacher's learning style, principal's learning style and the degree of teacher satisfaction with the principal's job performance. (Doctoral dissertation, University of MissouriKansas). Dissertation Abstracts International, 38, 6419A.

Barrie, M.E. (1984). Variability in learning style and its relationship to learning performance in introductory computer courses for adult learners. (Doctoral dissertation, University of Toronto). Dissertation Abstracts International, 45. 2726 A.

Beaumont, J. G., Young, A. W., \& McManus, I. C. (1984). Hemisphericity: A critical review. Cognitive Neuropsychology. 1 191-212.

Black, R.A. (1983). A match of learning style to teaching style based on use on hemisphere dominance theory to enhance learning of creative thinking skills. (Doctoral dissertation, University of Georgia). Dissertation Abstracts International. 45. 393A.

Blakeslee, T. R. (1982). Brain behavior research. In Student Learning Styles and Brain Behavior (pp. 185-191). Reston, VA: National Association of Secondary School Principals.

Blakeslee, T. R. (1983). The right brain. New York: Berkley Books.

Blaylock, B. K. (1981, December). Method for studying perception of risk. Psychological Reports. 49. pp. 899-902.

Bloom, F. E., Lazerson, A., \& Hofstadter, L. (1985). Brain. mind and behavior New York: W. H. Freeman.

Bogen, J. E. (1973). The other side of the brain: An appositional mind. In R. E. Ornstein (Ed.), The nature of human consciousness (pp. 101-124). New York: Viking. 
Bogen, J. E. (1977). Some educational aspects of hemispheric specialization. In M. C. Wittrock (Ed.), The human brain (pp. 133-152). Englewood Cliffs, NJ: PrenticeHall.

Bonen, R. C. (1977). A study of the relationship between both the cognitive style of the principal and the principal-faculty cognitive style match and the principal's leadership effectiveness as perceived by the staff. (Doctoral dissertation, St. Johns University). Dissertation Abstracts International 38, 559A.

Bub, D., \& Whitaker, H. A. (1980). Language and verbal processes. In M. C. Wittrock (Ed.) The brain and psychology (pp. 211-244). New York: Academic Press.

Bunderson, C. V., Olsen, J. B., \& Herrmann, W. E. (1978, December). Patterns of brain dominance and their relationships to tests of cognitive processing. personality and learning style. (Available from Ned Herrmann, Applied Creative Services, Lake Lure, NC).

Bush, C. M. (1984). Cognitive style and lateral brain dominance in relation to career choice and job satisfaction of computer professionals. (Doctoral dissertation, University of Texas at Arlington). Dissertation Abstracts International, 46, 266B.

Cafferty, E. (1980). An analysis of student performance based upon the degree of match between the cognitive style of teachers and the educational match cognitive style of the students. (Doctoral dissertation, University of Nebraska).

Carlsson, B., Keane, P., \& Martin, J. B. (1994). R\&D organizations as learning systems. In D.A. Kolb, I.M. Rubin, \& J. M. McIntyre (Eds.), Organizational psychology: Readings on Human Behavior in Organizations (4th ed., pp. 34-58). Englewood Cliffs, NJ: Prentice-Hall.

Carricato, D. L. (1982). The implementation and evaluation of a practical management development course based on experiential learning. (Doctoral dissertation, University of Pittsburgh, 1984). Dissertation Abstracts International, 44, 19A.

Christensen, P. R., Guilford, J. P., Merrifield, D. R., \& Wilson, R. C. (1960). Alternate uses. Beverly Hills, CA: Sheridan Psychological Services.

Christiano, J., \& Robinson, S. E. (1982). Leadership and cognitive styles of college student leaders. Journal of College Student Personnel 23, 520-524.

Cohen, D. M. (1981). Relationship between personality and cognitive characteristics of raters and ratees in relation to job performance evaluations. (Doctoral dissertation, New York University). Dissertation Abstracts International 424. 38568.

Coleman, S. M. (1979). Cognitive style and cerebral asymmetry: Response latency in lateralized short term memory as a function of hemisphere dominance. (Doctoral dissertation, St. Johns University). Dissertation Abstracts International. 41. 343B.

Cone, W. H. (1982, February). Brain research findings may improve decision making. NASSP Bulletin 66 (451), pp. 67-72.

Corballis, M. C. (1980). Laterality and myth. American Psycholegist, 35, 284-295. 
Coulson, L. T., \& Strickland, A. G. (1983). The minds at the top: An analysis of the thinking style preferences of superintendents of schools and chief executive officers. Journal of Creative Behavior 17 163-174.

Cronbach, L. J., \& Snow, R. E. (1977). Aptitudes and instructional methods: A handbook for research on interactions. New York: Irvington.

Daves, N. L. (1984). An investigation of the relationship between learning computer programming and cognitive abilities and learning style. (Doctoral dissertation, University of Southern California). Dissertation Abstracts International. 45. 2447A.

Davidman, L. (1981). Learning style: The myth, the panacea, the wisdom" Phi Delta Kappan. 62, 641-645.

Deikman, A. J. (1973a). Deautomatization and the mystic experience. In R. E. Ornstein (Ed.), The nature of human consciousness (pp. 216-233), New York:Viking.

Deikman, A. J. (1973b). Bimodal consciousness. In R. E. Ornstein (Ed.), The nature of human consciousness (pp. 67-86), New York:Viking.

Dorsey, O. L., \& Pierson, M. J. (1984, June). A descriptive study of adult's learning styles in a nontraditional education program. Lifelong Learning. 7 (8) pp. 8-11.

Doyle, W., \& Rutherford, B. (1984, Winter). Classroom research on matching learning and teaching styles. Theory Into Practice. 23, pp. 20-25.

Dunn, M. B. (1982). Preferred learning styles of teachers as determined by Kolb's Learning Style Inventory. (Doctoral dissertation, George Peabody College for Teachers of Vanderbilt University). Dissertation Abstracts International, 43, 1937 A.

Dunn, R. (1984, Winter). Learning style: State of the science. Theory Inte Practice. 23. pp. 11-19.

Dunn, R. (1983, February). Can students identify their own learning styles? Educational Leadership, 40, (5), 60-62.

Dunn, R., Dunn, P., \& Price, G. E. (1978). Learning style inventery. Lawrence, Kansas: Price Systems.

Dunn, R., Cavanaugh, D. P., Eberle, B. M. \& Zenhausern, R. (1982). Hemispheric preference: The newest element of learning style. The American Biology Teacher. 44. 291-194.

Edwards, B. (1979). Drawing on the right side of the brain. Boston: J.P. Tarcher.

Elster, K. R. (1977). Sex bias in promotion decisions for males and females in managerial and nonmanagerial positions. (Doctoral dissertation, llinois Institute of Technology). Dissertation Abstracts International. 38, 4518B.

Federico, P. A. (1984). Event-related-potential (ERP) correlates of cognitive styles, abilities and aptitudes. Persenality and Individual Differences. 5. 575-585. 
Ferrell, B. G. (1981). A factor analytic comparison of four learning style instruments. Journal of Educational Psychology. 75 (1), 33-41.

Firestein, R. L., \& Treffinger, D. J. (1983). Ownership and converging: Essential ingredients of creative problem solving. Jeurnal of Creative Behavior 17 (1), 3238.

Freedman, R. D., \& Stumpf, S. A. (1978). What can one learn from the Learning Style Inventory? Academy of Management Journal 21, 275-282.

Freedman, R. D., \& Stumpf, S. A. (1980). Learning style theory: Less than meets the eye. Academy of Management Review, 5. 445-447.

Gardner, R. (1959). Cognitive control: A study of individual consistencies in cognitive behavior. Psychological Issues. 4, 22-30.

Gay, L. (1987). Educational Research (3rd Ed.). Columbus, OH: Charles E. Merrill.

Gazzaniga, M. S. (1967, August). The split brain in man. Scientific American. 217 (2), pp. 24-29.

Gazzaniga, M. S. (1972, May-June). One brain--Two minds? American Scientist. 311-317.

Gazzaniga, M. S. (1983, May). Right hemisphere language following brain bisection: A 20 year perspective. 38 (Part 1, 5), pp. 525-537.

Gazzaniga, M. S. (1985, November). The social brain. Psychology Today, 19 (11), pp. 28-38.

Geller, L. M. (1979). Reliability of the Learning Style Inventory. Psychological Beports. 44, 555-561.

Giannini, A. J., Barringer, M. E., Giannini, M. C., \& Loisell, R. H. (1984). Lack of relationship between handedness and infuitive and intellectual (rationalistic) modes of information processing. Jeurnal of General Psychology, 11, 31-37.

Gillespie, H. R. (1980). An investigation of current management/leadership style of manufacturing executives in American industry. (Doctoral dissertation, United States University). Dissertation Abstracts International, 41, 3177A.

Gonsalves, S. V. (1983, June). Selected bibliography on cognitive styles. Perceptual and Motor Skills, 56, pp. 723-234.

Good, T. L., \& Stipek, D. J. (1983). Individual differences in the classroom: A psychological perspective. In G.D. Fenstermacher (Ed.), Individual differences and the commen curriculum. 82nd Yearbook of the National Society for the Study of Education, (Part 1, pp 9-43). Chicago: University of Chicago.

Gordon, L. V. (1976). Sunvey of interpersonal values revised manual. Chicago: Science Research Associates. 
Gorovitz, E. S. (1982). The creative brain II: A revisit with Ned Herrmann. Iraining and Development Journal, 6 (2), 74-85.

Grasha, A. F. (1984). Learning styles: The journey from Greenwich Observatory (1796) to the college classroom (1984). Improving College and University Teaching. 32 , 305-317.

Gregorc, A. F. (1979a). Learning/teaching styles: Their nature and effects. In Student learning siyles: Diagnosing and Prescribing Programs (pp. 19-26). Reston, VA:National Association of Secondary School Principals.

Gregorc, A. F. (1979b). Learning/teaching styles: Potent forces behind them. Educational Leadership 36, pp. 234-236.

Gregorc, A. F. (1984, Winter). Style as a symptom: A phenomenological perspective. Theory into Practice 23, pp. 51-55.

Grochow, J. (1973). Cognitive style as a factor in the design of interactive decisionsupport systems. (Doctoral dissertation, Massachusetts Institute of Technology, Sloan School of Management, 1973).

Guilford, J. P. (1977). Three faces of intellect. In J. C. Nunnally, Psychemetric theory (pp. 448-464). New York: McGraw-Hill.

Guilford, J. P. (1980). Cognitive styles: What are they? Educational and Psychological Measurement, 40, 715-735.

Gypen, J. L. M. (1981). Learning-style adaptation in professional careers: The case of engineers and social workers. (Doctoral dissertation, Case Western Reserve University). Dissertation Abstracts International 41, 4853A.

Hardyck, C., \& Haapanen, R. (1979). Educating both sides of the brain: Educational breakthrough or neuromythology? Journal of School Psychology. 17, 219-230.

Harpaz, I. (1983). Asymmetry of cognitive functioning as a possible predictor for vocational counseling and personnel classification. Journal of Vocational Behavior. 23, 305-317.

Hart, L. A. (1983). Human brain and human learning. New York: Longman.

Hatta, T. (1984, December). Lateral eye movement and hemisphere asymmetry: Effects of question type, task type, and individual differences. Cortex 20, pp. 543536.

Haustein, H. D. (1981). Human resources, creativity and innovation: The conflict between Homo faber and Homo ludens. Behavioral Science 26, 243-255.

Heist, P., \& Yonge, G. (1968). Emnibus personality inventory manual. New York: The Psychological Corporation.

Henderson, J. C., \& Nutt, P. C. (1980, April). The influence of decision style on decision making behavior. Management Science, 26, 371-386. 
Hendrick, H.W. (1979). Differences in group problem-solving behavior and effectiveness as a function of abstractness. Journal of Applied Psychology. 64, 518525.

Herrmann, N. (1978). Herrmann Participant Survey Form. Lake Lure, NC:Applied Creative Services.

Herrmann, N. (1981). The creative brain. Iraining and Development Journal, 35 , 10-16.

Hudson, L. (1975). Human beings. Garden City, NY: Anchor.

Hunt, D. E. (1979). Learning style and student needs: An introduction to conceptual level. In Student learning styles: Diagnosing and prescribing programs (pp. 2738). Reston, VA: National Association of Secondary School Principals.

Hyman, R., \& Rosoff, B. (1984, Winter). Matching learning and teaching styles: The joy and what's in it. Theory Inte Practice. 23 (1), 35-43.

Janis, I. L. (1984). Groupthink. In D. A. Kolb, I. M. Rubin, \& J. M. Mclntyre (Eds.) Organizational psychology: Readings on human behavior in organizations (4th ed, pp. 166-176). Englewood Cliffs, NJ: Prentice-Hall.

Jeffrey, W. E. (1980). The developing brain and child development. In M. C. Wittrock (Ed.), The brain and psychology (pp. 345-367). New York: Academic Press.

Kadunc, N. J. (1982). Jungian psychological types of educational and development project managers and their preferences for project and organizational characteristics. (Doctoral dissertation, Ohio State University). Dissertation Abstracts International. 43, 2518A.

Kagan, J. (1966). Reflection-impulsivity: The generality and dynamics of conceptual tempo. Journal of Abnormal Psychology Z1, 17-24.

Katz, A. N. (1983). Creativity and individual differnces in asymmetrical cerebral hemisphere functioning. Empirical Studies of the Arts, 1, pp. 3-16.

Kaushansky, M. (1984). The implications of the lateralized brain model for educational practice: A critical analysis of the research base. (Doctoral dissertation, Simon Fraser University). Dissertation Abstracts International. 46 , $380 \mathrm{~A}$.

Keefe, J. W. (1979). Learning style: An overview. In Student learning styles: Diagnosis and prescribing programs (pp. 1-17). Reston, VA: National Association of Secondary School Principals.

Kerlinger, F. N. (1973). Eoundations of behavioral research New York: Holt, Rinehart and Winston.

Kidder, T. (1981). The soul of a new machine New York: Avon.

Kimura, D. (1985, November). Male brain, female brain: The hidden difference. Esychology Tedax, 19 (11), pp. 50-58. 
Kinsbourne, M. (1980). Cognition and the brain. In M. C. Wittrock (Ed.) The brain and psychology (pp. 325-343). New York: Academic Press.

Kinsbourne, M., \& Hiscock, M. (1978). Cerebral lateralization and cognitive development. In M. C. Wittrock (Ed.) The human brain (169-222). Englewood Cliffs, N.J.: Prentice-Hall.

Koch, C. K. (1984). Assessment of dominant learning styles and preferences for teaching methods in adult students attending a small liberal arts college. (Doctoral dissertation, Southern Illinois University at Edwardsville). Dissertation Abstracts International. 45, 1610A.

Kolb, D.A. (1976). Learning style inventory: Technical manual, Boston: McBer.

Kolb, D. A. (1984). Experiential learning. Englewood Cliffs, NJ: Prentice-Hall.

Kolb, D. A. (1985). Learning-Style Inventory Boston, MA: McBer.

Kolb, D. A., Rubin, I. M., \& McIntyre, J. M. (1984). Organizational psychology: An experiential approach to organizational behavior (4th ed.). Englewood Cliffs, NJ: Prentice-Hall.

Kotar, M. E. (1980). An investigation of a learning style inventory with selected educational groups. (Doctoral dissertation, Illinois State University). Dissertation Abstracts International. 42, 177A.

Kuchler, C. J. (1983). Hemispheric laterality and cognitive style. (Doctoral dissertation, University of North Dakota). Dissertation Abstracts International, 44, $1597 \mathrm{~B}$.

Lawrence, G. (1982). Personality structure and learning style: Uses of the MyersBriggs Type Indicator. In Student learning styles and brain behavior (pp. 92-105). Reston, VA: National Association of Secondary School Principals.

Lee, D. (1950). Codification of reality: Lineal and nonlineal. Psychosomatic Medicine. 12. $89-97$.

Leflar, S. M. (1980). Implementing a learning styles inventory. Jeurnal of Developmental and Remedial Education, 5. (Special issue, 4-5), 18.

Lesnik-Oberstein, M., \& Cohen, L. (1984). Cognitive style, sensation seeking and assortative mating. Journal of Personality and Social Psychology 46, 112-117.

Levinson, D. M. (1980). Perceived congruence between manager and chosen successor. (Doctoral dissertation, Columbia Teachers College). Dissertation Abstracts international. $41,3618 \mathrm{~B}$.

Levy, J. (1980). Cerebral asymetry and the psychology of man. In M. C. Wittrock (Ed.) The brain and psychology (pp. 245-321). New York: Academic Press.

Levy, J. (1983, January). Research synthesis on right and left hemispheres: We think with both sides of the brain. Educational Leadership. 40 (4), pp. 66-71. 
Levy, J. (1985, May). Right brain, left brain: Fact and fiction. Psychology Today 19 , pp. 38-39.

Likert, R. (1984). The nature of highly effective groups. In D. A. Kolb, I. M. Rubin, \& J. M. Mclntyre (Eds.), Organizational psychology: Readings on human behavior in organizations (pp. 153-165). Englewood Cliffs, NJ: Prentice-Hall.

Lynch, D. (1983). BrainMap. Ft. Collins, CO: Brain Technologies.

MacLean, P. D. (1978). A mind of three minds: Educating the triune brain. In M. C. Wittrock (Ed.), The human brain (pp. 308-342). Englewood Cliffs, N.J.: Prentice-Hall.

Madden, D. J., \& Nebes, R. D. (1980). Visual perception and memory. In M. C. Wittrock (Ed.), The brain and psychology (pp. 141-210). New York: Academic Press.

Manz, C. C., \& Sims, H. P. (1982, September). The potential for 'groupthink' in autonomous work groups. Human Relations, 35. pp. 773-784.

Martindale, C., Hines, D., Mitchell, L., \& Corello, E. (1984). EEG alpha asymmetry and creativity. Personality and Individual Differences. 5, 77-86.

McCall, R. J. (1984). Effects of learning style and learning environment on achievement by levels of learning. (Doctoral dissertation, University of Oklahoma). Dissertation Abstracts International. 44. 3245A.

McCallum, R. S., \& Glynn, S. M. (1979). Hemispheric specialization and creative behavior. Jeurnal of Creative Behavior. 13. 263-273.

McCausland, M. J. (1982). Right hemisphere language dominance: An exploratory study of the interaction of cerebral dominance and hemisphere preference. (Doctoral dissertation, St. Johns University). Dissertation Abstracts International. 43. $2023 B$.

McMullen, W., \& Cahoon, A. (1979). Integrating abstract conceptualizing with experiential learning. Academy of Management Review, 4, 453-458.

Mednick, S. A., \& Mednick, M. T. (1971). Remote associates test. New York: HoughtonMifflin.

Merritt, S. L., \& Marshall, R. C. (1984). Reliability and construct validity of ipsative and normative forms of the learning style inventory. Educational and Psychological Measurement. 44. (pt. 1, 2). 463-472.

Messick, S. (1976). Personality consistencies in cognition and creativity. In S. Messick (Ed.) Individuality in learning. (pp. 4-23). San Francisco: Josey-Bass.

Mintzberg, H. (1984). Planning on the left side and managing on the right. In D. A. Kolb, I. M. Rubin, \& J. M. Mcintyre (Eds.), Qrganizational psycholegv: Readings on human behavior in organizations (4th ed., pp. 187-198). Englewood Cliffs, NJ: Prentice-Hall.

Mirabile, C. S., \& Glueck, B. C. (1979). Motion sickness susceptibility and solution choice in a pragmatic paradox. Neuropsychobiology 5 46-49. 
Myers-Briggs, I. (1962). The Myers-Briggs type indicator manual. Princeton, NJ: Educational Testing Service.

Norris, C. J. (1984). A discussion of the brain hemisphere characteristics and creative leadership among selected educational administrators in Tennessee. (Doctoral dissertation, University of Tennessee). Dissertation Abstracts international 45. 3256A.

Oltman, P. K., Raskin, E., Witkin, H. A. (1971). Group embedded figures test. Palo Alto, CA: Consulting Psychologists.

Ornstein, R. E. (1972). The psychology of consciousness. San Francisco: W. H. Freeman.

Ornstein, R. E. (1973). The nature of human consciousness, New York: Viking Press.

Ornstein, R. E. (1976). The mind field, New York: Viking Press.

Owens, W., \& Limber, J. (1983, June). Lateral eye movements as a measure of cognitive ability and style. Perceptual and Motor Skills, 56. pp. 711-719.

Piatt, J. G. (1983, December). Brain processing preferences: Key to an organization's success. NASSP Bulletin. 67 (467) pp. 64-69.

Pigg, K. E., Busch, L., \& Lacy, W. B. (1980, Summer). Learning styles in adult education: A study of county extension agents. Adult Education 30. pp. 233-244.

Plovnick, M. (1975). Primary care career choices and medical student learning styles. Journal of Medical Education, 50, 849-855.

Pollack. S. R. (1984). The relationship between matching university student's learning styles and their teacher's learning style and business school course achievement. (Doctoral dissertation, University of Southern California). Dissertation Abstract International 45 3310A.

Posey, E. J. (1984). Learning style inventory: Implementation research. Journal of Developmental and Remedial Education. $I$ (3), 16-18.

Practical Application of Research (PAR). (1980, December). Newsletter of Phi Delta Kappa. Center of Education, Development and Research.

Randolph, W., \& Posner, B. (1979). Designing meaningful learning situations in management: A contingency decision-tree approach. Academy of Management Beview. 4. 459-467.

Reinken, M. L. L. (1977). The relationship between learning style and laboratory design in human relations training. (Doctoral dissertation, University of South Carolina). Dissertation Abstracts International, 38. 7238A.

Restak, R. M. (1979). The other difference between boys and girls. In Student learning styles: Diagnosing and prescribing programs (pp. 75-80). Reston, VA: National Association of Secondary School Principals. 
Robey, D., \& Taggart, W. (1981). Measuring managers' minds: The assessment of style in human information processing. Academy of Management Review, 6. 375-383.

Ryberg, R. J. (1982). Organizational strategic types: Differences between preferences for alternative types with cognitive style influences and enacted environmental implications. (Doctoral dissertation, Syracuse University). Dissertation Abstracts International. 43. 3970A.

Sanders, G. S., \& Malkis, F. S. (1982, August). Type A behavior, need for control and reactions to group participation. Qrganizational Behavior and Human Performance. 30. pp. 71-86.

Schkade, L. L., \& Potvin, A. R. (1981). Cognitive style, EEG waveforms and brain levels. Human Systems Management. 2. 329-331.

Schmeck, R. R., \& Lockhart, D. (1983, February). Introverts and extroverts require different learning environments. Educational Leadership 40 (5), pp. 54-55.

Schweiger, D. M. (1983). Measuring managers' minds: A critical reply to Robey and Taggart. Academy of Management Review, 8, 143-151.

Scott, W. A., Osgood, D. W., \& Peterson, C. (1979). Cognitive structure: Theory and measurement of individual differences. Washington, DC: V.H. Winston \& Sons.

Serrapore, P. F. (1977). A rationale and design to train adults to develop their nondominant learning styles. (Doctoral dissertation, University of Pittsburgh). Dissertation Abstracts International, 38, 7126A.

Sims, R. R. (1981) Assessing competencies in experiential learning: A person-job congruence model of effectiveness in professional careers. (Doctoral dissertation, Case Western Reserve University). Dissertation Abstracts International. 42. $1219 \mathrm{~B}$.

Smith, L. H., \& Renzulli, J. S. (1984, Winter). Learning style preferences: A practical approach for classroom teachers. Theory into Practice. 23. pp. 44-50.

Sood, J. H., \& Adams, P. (1984). Model of management learning styles as a predictor of export behavior and performance. Journal of Business Research. 12. 169-182.

Stabell, C. (1973). The impact of a conversational computer system on human problem solving behavior. Unpublished working paper, Massachusetts Institute of Technology, Sloan School of Management, Boston.

Strange, C. C. (1978). Intellectual development, motive for education and learning styles during the college years: A comparison of adult and traditional-age college students. (Doctoral dissertation, lowa State University). Dissertation Abstracts International. $39.4768 \mathrm{~A}$.

Strot, E. M. (1985). Attractiveness of students with convergent and divergent learning styles to teachers with convergent and divergent learning styles. (Doctoral dissertation. University of Miami). Unpublished doctoral dissertation.

Stumpf, S. A., \& Freedman, R. D. (1981). The learning style inventory: Still less than meets the eye. Academy of Management Review, 6 . 297-299. 
Taggart, W., \& Robey, D. (1981). Minds and managers: On the dual nature of human information processing and management. Academy of Management Review, 6 , 187195.

Taggart, W., Robey, D., \& Taggart, B. (1982). Decision styles education: An innovative approach. Exchange: The Organizational Behavior Teaching Journal, Z 17-24.

Taggart, W., \& Torrance, E. P. (1984). Human information processing survey administrator's manual. Bensenville, III: Scholastic Testing Services.

Talbot, R. (1983, April-June). Learning styles in different situations. Creativity and Innovation Network. Manchester, England: University of Manchester. pp. 65-70.

Tenore, E. J. (1984). An exploratory study of the inter-relationships among variables which impinge on cognitive/learning styles. (Doctoral dissertation, University of Massachusetts). Dissertation Abstracts International 45, 1697A.

Teyler, T. J. (1977). An introduction to the neurosciences. In M. C. Wittrock (Ed.), The human brain. (pp. 3-38). Englewood Cliffs, NJ: Prentice-Hall.

Thies, A. P. (1979). A brain behavior analysis of learning styles. In Student learning styles: Diagnosing and prescribing programs (pp. 55-61). Reston, VA: National Association of Secondary School Principals.

Thies, A. P. (1983). The biology of attention. Early Years, 13 (7), 18.

Thompson, R. A. (1984, March). Language, the brain, and the question of dichotomies. American Anthropologist 86. pp. 98-105.

Torrance, E. P. (1966). Torrance tests of creative thinking. Personnel Press.

Torrance, E. P. (1982). Hemisphericity and creative functioning. Journal of Research and Development in Education. 15 (3), 29-37.

Torrance, E. P., \& Frasier, M. M. (1983, Winter). Style of learning and thinking and biographical inventory measures. Creative Child and Adult Quarterly \&. pp. 206210.

Trowbridge, A. V. (1978, May). Evolution of triune brain consciousness. ManEnvironment Systems, \& pp. 105-112.

West, R. F. (1982). A construct validity study of Kolb's learning style types in medical education. Jeurnal of Medical Education. 57 794-796.

Witkin, H. A. (1976). Cognitive style in academic performance and in teacher-student relations. In S. Messick (Ed). Individuality in learning (pp. 38-78). San Francisco: Jossey Bass.

Witkin, H. A., Dyk, R. B., Faterson, H. F., Goodenough, D. R., \& Karp, S. A. (1962). Psycholegical differentiation. New York: John Wiley. 
Witkin, H. A., Moore, C. A., Goodenough, D. R., \& Cox, P. W. (1977). Field-dependent and field-independent cognitive styles and their educational implications. Beview of Educational Research. 47, 1-64.

Wittrock, M. C. (1978). Education and the cognitive processess of the brain. In M. C. Wittrock (Ed.) The human brain (pp. 61-102). Englewood Cliffs, N.J.: PrenticeHall.

Wittrock, M. C., Beatty, J, Bogen, J. E., Gazzaniga, M. S., Jerison, H. J., Krashen, S. D., Nebes, R. D., Teyler, T. J. (1977). The human brain. Englewood Cliffs, NJ: Prentice-Hall.

Woelfi, N. (1984). Individual differences in online search behavior: The effect of learning styles and cognitive abilities on process and outcome. (Doctoral dissertation, Case Western Reserve University). Dissertation Abstracts International. 46. 7A.

Wood, J. T. (1981). Sex differences in group communications: Directions for research in speech communications and sociometry. Journal of Group Psychotherapy, Esychodrama and Sociometry 34, 24-31.

Wonderlic, E. F. (1972) Wonderlic personnel test. E. F. Wonderlic \& Associates.

Yantis, B., \& Nixon, J. E. (1982, September). Interpersonal compatibility: Effect on simulation games outcomes. Simulation and Games. 13. pp. 337-349.

Zangwill, O. L. (1976). Thought and brain. British Journal of Psychology 67 301314.

Zelniker, T., \& Jeffrey, W. E. (1976). Reflective and impulsive children: Strategies for information processing underlying differences in problem solving. Monographs of the society for research in child development. 41 (5), 1-52. 


\section{APPENDIXA}

Demographics of Test-Retest Group

\begin{tabular}{|c|c|c|}
\hline Eacter & Test-Retest Group $(n=30)$ & Study Population $(n=134)$ \\
\hline $\begin{array}{l}\text { Males } \\
\text { Females }\end{array}$ & $\begin{array}{l}20(67 \%) \\
10(33 \%)\end{array}$ & $\begin{array}{l}80(60 \%) \\
54(40 \%)\end{array}$ \\
\hline $\begin{array}{c}\text { Age } 21-24 \\
25-29 \\
30-39 \\
40-49 \\
50 \text { plus }\end{array}$ & $\begin{array}{l}6(20 \%) \\
9(30 \%) \\
9(30 \%) \\
6(20 \%)\end{array}$ & $\begin{array}{l}23(18 \%) \\
42(33 \%) \\
41(32 \%) \\
15(12 \%) \\
7(5 \%)\end{array}$ \\
\hline $\begin{array}{l}\text { Black } \\
\text { Non-Hispanic Caucasian } \\
\text { Hispanic } \\
\text { Other }\end{array}$ & $\begin{array}{c}8(27 \%) \\
17(57 \%) \\
4(13 \%) \\
1(3 \%)\end{array}$ & $\begin{array}{l}17(13 \%) \\
67(51 \%) \\
29(22 \%) \\
19(14 \%)\end{array}$ \\
\hline $\begin{array}{l}\text { MSM Student } \\
\text { MBA Student } \\
\text { MHM Student } \\
\text { SpoAd Student } \\
\text { MIS Student } \\
\text { Other }\end{array}$ & $\begin{array}{l}25(83 \%) \\
2(7 \%) \\
= \\
3(10 \%) \\
=\end{array}$ & $\begin{array}{c}60(45 \%) \\
30(22 \%) \\
21(16 \%) \\
17(13 \%) \\
4(3 \%) \\
2(1 \%)\end{array}$ \\
\hline
\end{tabular}




\section{Consent Form}

Dear Participant:

As a part of the research involved in preparation of my doctoral dissertation, I am collecting information concerning graduate students in managementrelated studies. This research focuses on the possible correlation between the student's learning or problem solving style and his or her brain hemisphere dominance. It also is intended to explore the possible relationships between learning style/orain hemisphere dominance and the way we tend to select others as preferred bosses, subordinates or coworkers on special projects. If you agree to participate in this study, you will be asked to complete several survey instruments designed to measure learning style and brain hemisphere dominance. You will also be asked to indicate which classmates you would select as preferable bosses, subordinates or co-workers. The information you provide will be kept completely confidential and used only for the purpose of this research. Results will be reported in such a way that individual participants cannot be identified. You will also be asked to provide certain demographic data such as your age, sex, etc., so that I can eliminate possible problems in the research data. These demographics will also remain confidential and be used only as a part of this research effort.

In return for participating in my study, you will be provided with information regarding your own learning style and brain hemisphere dominance and an explanation of these factors. The selection portion of the study (as boss, subordinate, co-worker) will only be available as group data and not reported in terms of individuals selected. If you agree to serve as a participant in this research study, please indicate your agreement by signing and dating the bottom of this letter.

Thank you for your help.

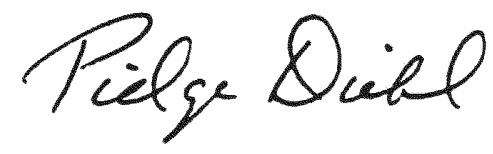

I agree to participate in this study according to the guidelines specified above.

Name

Date 
Bingraphical Data for study

Name

Address

I currently sttend (plesse check one) St. Thamas University

FIU

My degree program is: MBA MSM MHM Spo Ad

other (plegse specify)

My undergraduate major was Year completed

Mug occupation is Yeors of experience

If you are a manager, at what level would you describe yourself? (Plesse check one)

ist line supervisor Middle Monagement Senior Management

Personal demographics:

Sex: Mole Female Age in years:

Ethnic background:

Black Americon Caucrsian Hispanic (born in USA)

Hispanic (born outside USA in Moved here in

other: (plesse specify)

All information provided by study participants will be kept completely canfidential and used only for the purposes of this research study. 
I AM IISUALLY
a)
Early
b) On time
a) Very neat and organized
c) A little late
b) Adequately neat and organized
d) Very late
c) Not very neat and organized

I AM

\section{HANDEDNESS}

5. Which picture most closely resembles the way you hold a pencil? Mark A, B, C. or D
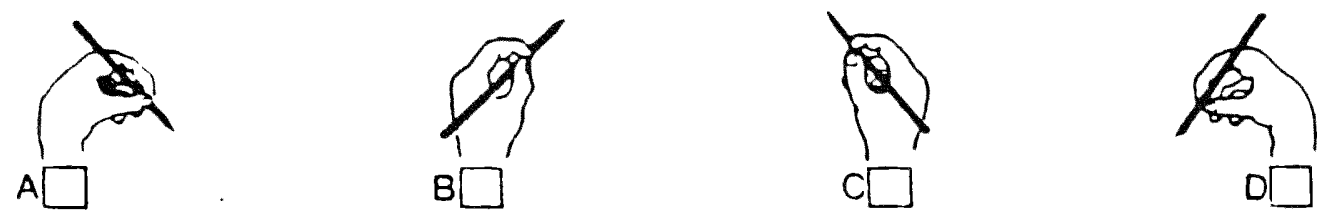

6. Strength and direction of your handedness: Mark A, B, C. D. or E.
$A \square$
$B \square$
C—
Primary Left
Primary Left
Some Right
Bolli Hinds
Equal
$D \square$
Primary Right
Some Lelt

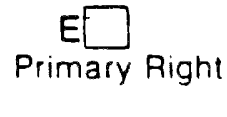

\section{BEST/WORST SUBJECTS}

Thinking back to your best worst subjects in elementary or secur dary school please rank the following subjects with a 1.2. or 3 on the basis of how well you did Rank all three subjecis: 1 is best. 2 is second. 3 is thrrd best Record your ranks in the boxes. and on the answer sheet, it it is provided
$\square 7$ Math
8 Foreign Language
9. English

\section{WORK ELEMENTS}

Indicate your responite to s.xh of the work elernen's below using the following key
5 - Work I do hesi ol all
$3=$ Neutral
$2=$ Work $1 d u$ poorly
$4=$ Work I do we!!
$1=$ Work I do worst of all

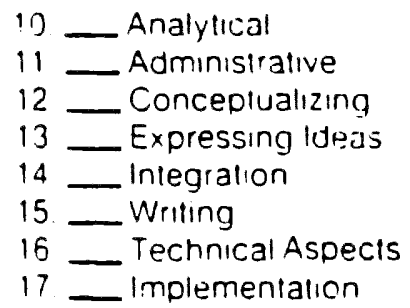

18 - Planning
19 - Interpersonal Aspects
20 Problem Solving
21 - Innovaling
22 Teaching. Training
23 Organizalion
24 - Creative Aspects
25 - Financial Aspects

\section{KEY DESCRIPTORS}

Select the eight adjectives which best describe the way you see yourselt and mark a " 2 " by each. Then change a single " 2 " 10 a " 3 " for the adjective which best describes you Mark the seven " 2 ' $s$ " and one " 3 " on your answer sheet, it it is provided

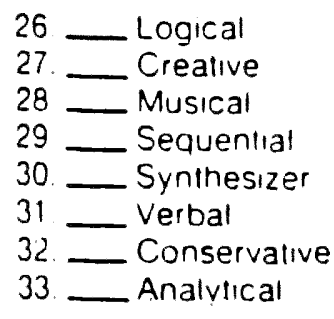

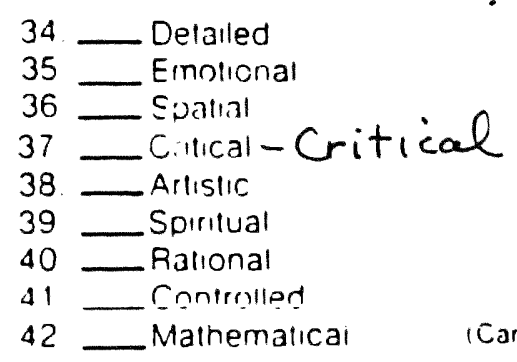

(Can see the lorest as contrasted with the trees)

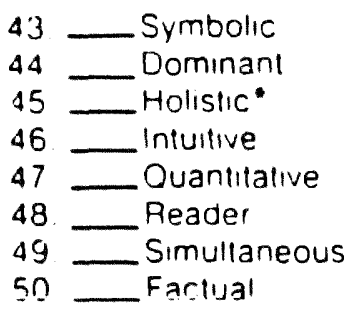

PAGE 1 - GO TO PAGE 2 


\section{HOBBIES}

Indicale all hobbies you are actively engaged in by markirg a 3 for your major nobby " 2 " for primary hobbies and "1" to your secondary hobbies

51 - Arts Cialts
52 - Boating
53 - Camping Hiking
54 Cards
55 - Collecling
56 - Cooking
57 - Creative Willing
58 - Fishing
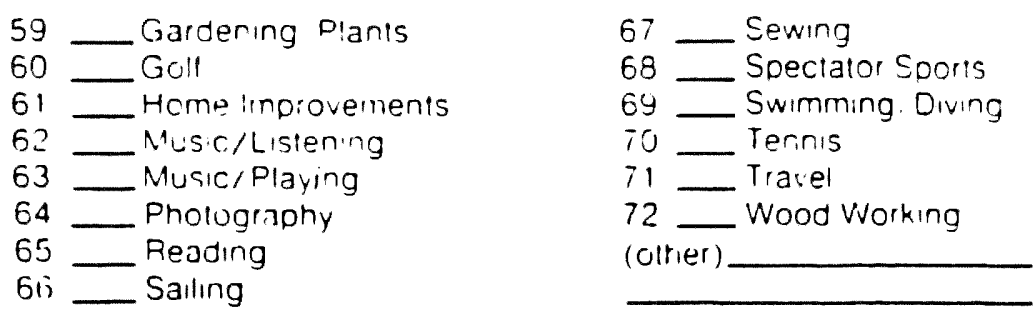

VII. ENERGY LEVEL

73. Thinking about your energy level or "drive". SELECT the ONE which best represents you. Mark A. B. or C.
$A$
"Day Person"
Day/Nigh: Equally

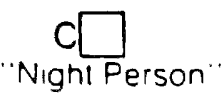

\section{MOTION SICKNESS}

74 Have you ever experienced motion sickness (nausea. vomiling) in response 10 any kind of vehicular motion (such as car. boat. plane. bus, train, amusement ride)? Number of times: Mark A. B. C. or D
$A \square$
None
B
$\square_{3-10}$

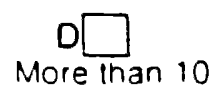

75. Can you read while traveling in a car withoul stomach awareness. tieadache. nausea or vomiting?

Mark A or $B$.

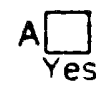

Bo

\section{ADJECTIVE PAIRS}

Which word or phrase in each pair is more descriptive of yourself? Mark only $A$ or $B$ even it the choice is a difficult one. Do not leave any questions unmarked.

\section{Column A Column B}

76. $\square$ Conservative
Analyst
78.
79.
Ouantitative
80.
Problem Solver
81. $\square$ Ontrolled
82. $\square$ Feelinal
83. $\square$ Interpersonal
84. $\square$ Spiritual
85. $\square$ Detailed
86. $\square$ Originate Ideas
87. $\square$ Warm. Friendly

Column A

88. $\square$ Imaginailve
89. $\square$ Original
90. $\square$ Creative
91. $\square$ Controlled
92. $\square$ Musical
93. $\square$ Simultaneous
94. $\square$ Communicator
95. $\square$ Technical Things
96. $\square$ Well Organized
97. $\square$ Rigorous Thinking
98. $\square$ Like Things Planned
99. $\square$ Technical

Column B

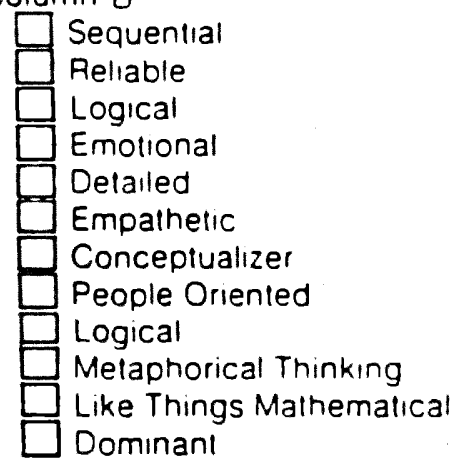

\section{EXTROVERSION/INTROVERSION}

100 Where would you place yoursell on this scale? Mark an " $X$ " on the scale, between extrovert and introvert.

EXTROVERT

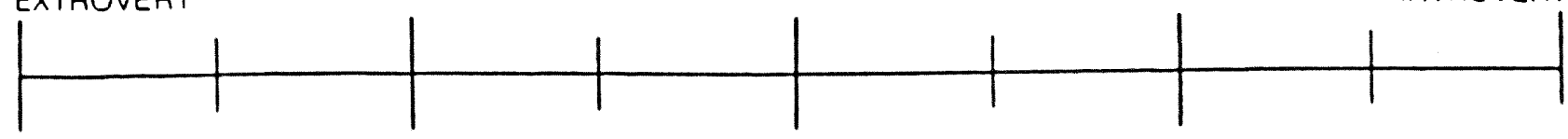


Name-

DIRECTIONS: Answer each question by marking ari " $x$ " in the appropriate column. If an answer sheet is provided. use the ariswer sneet to record your answers.

1. I feel that a step-by-step method is best for solving problems.

2 Daydreaming has provided the impetus for many of iny more important problems.

3 I like people who are most sure of their conclusions

4 I would rather be known as a reliable than an imaginctive person.

5. I often get my best ideas when doing nothing in particuiar.

6 . Irely on hunches and the reeling of "rightness" or "wrongness" when moving toward the solution to a problem.

$i$. I sometimes get a kick out of breaking the rules and doing things i'm not supposed to do.

8. Much of what is most important in life cannot be expressed in words

9. I'm basically more competitive with others than self-competitive.

10. I would enjoy spending an entire day " alone with my thoughts."

11. I dislike things being uncertain and unpredictable.

12. I prefer to work with others in a team effort rather than solo.

13. It is important for me to have a place for everything and everything in its place.

14. Unu, ual ideas and daring concepts interest and intrigue me

15. I prefer specific instructions to those which leave many details optiunal.

16. Kriow-why is more important than know-how

17. Thorough planning and organization of time are mandatory for solving difficult problems.

18. I can frequently anticipate the solutions to my problems.

19. I tend to rely more on my first impressions and feelings when making judgements than on a careful analysis of the situation.

20. I feel that laws should be strictly enforced.

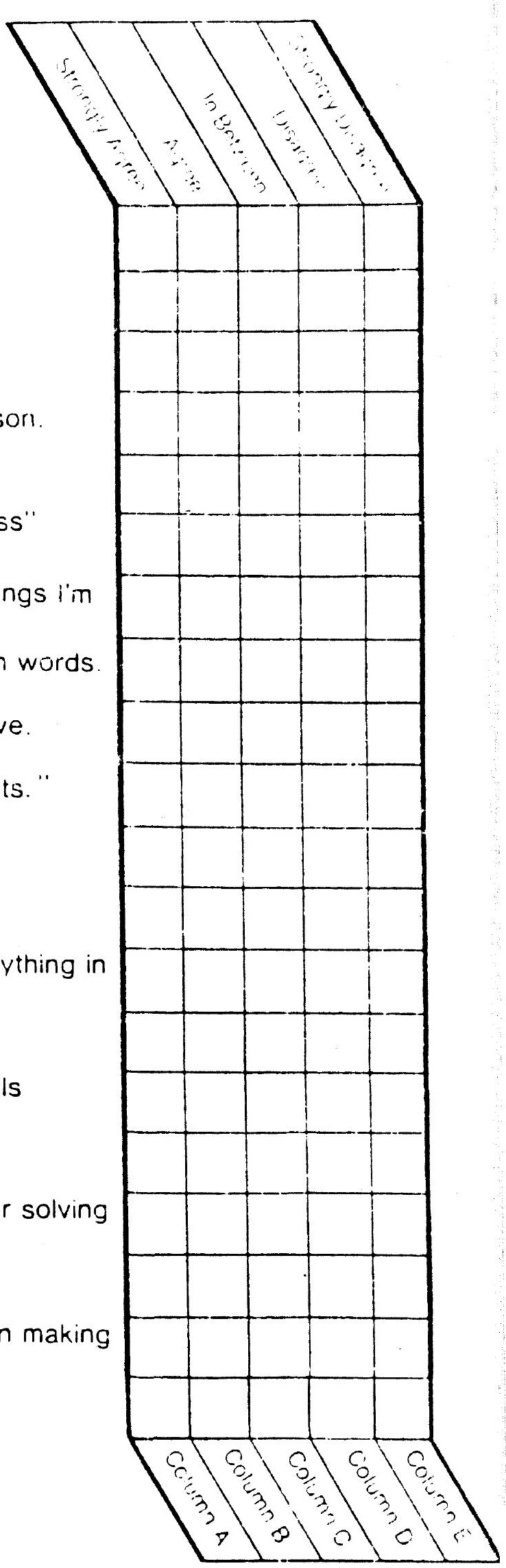




\section{Leairning-Style Inventory: Instructions}

The Learning-Style Inventory describes the way you learn and how you deal with ideas and day-to-day situations in your life. Below are 12 sentences with a choice of four endings. Rank the endings for each sentence according to how well you think each one fits with how you would go about learning something. Try to recall some recent situations where you had to learn something new, perhaps in your job. Then, using the spaces provided, rank a " 4 " for the sentence ending that describes how you learn best, down to a "1" for the sentence ending that seems least like the way you would learn. Be sure to rank all the endings for each sentence unit. Please do not make ties.

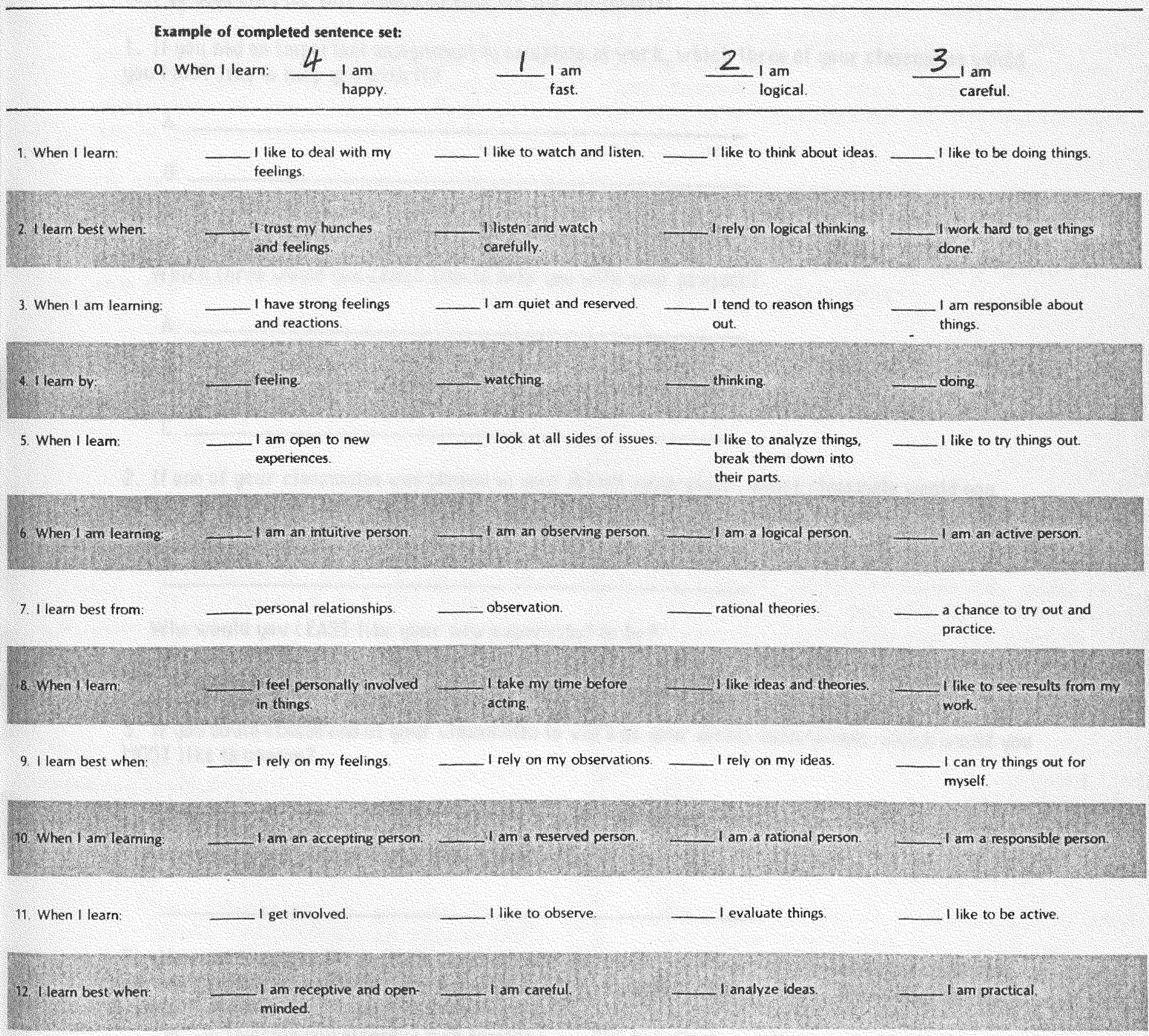

Copyright (C) 1981 David A. Kolb, revised 1985. All rights reserved. No part of this publication may be reproduced or transmitted in any form or by any means, electronic or mechanical, including photocopy, xerography, recording, or any information storage and retrieval system, without permission in writing 


\section{Selection Dats}

On the attached page is a list of your classmates. Fram this list, would you please select the individuals who best fit the following categuries? You may use a name more than unce; all results sill be used unly for this study and kept stictly confidential.

1. If you had an inpurtant assignment to complete at work, which three of your classmates would you MOST like to telp you with it?

A.

8.

C.

Which three would you LEAST like to help you with your project?

A.

B.

C.

2. If one of your classmates was chosen as your direct supervisor, which class mate would you Most like your new supervisor to be?

Who would you LEAST like your fiew supervisor to be?

3. If you could choose one of your classmates to wark as your direct sutordinate, which would you Most like to choose?

Who would you be LEAST likely to choose?

To allow me to assess the possible bases of your decisions, would you please indicate beside each ferson's name above whether you know this person outside of class in any of the following ways?

"W" to indicate you alresdy work together " $\mathrm{H}$ " to indicate you live near each other

"L" to indicate you have other classes logether now or in the past

"F" to indicate this person is a friend outside schoul or work

If there are factars other than those indicated sbove that influenced your choices, would you please indicate below what those factors are? 
Dear Participant:

Thank you for helping with my study. Your results on the two instruments are reported on this page. On this side is a diagram explaining the concept behind the Learning style Inventory. This theory, which is explained in detail by Dr. David Kolb in his book, Experiential Learning, holds that learning or problem solving is based on four dimensions: concrete experience, reflective observation, abstract conceptualization and active experimentation. All are necessary for the complete learning experience but each of us tends to emphasize some of these skills more than others. Your tendencies in this area are reflected in the diagram below with a more complete explanation of the particular style you favor.

On the other side is your feedback from the Brain Hemisphere Dominance Survey. More information on this concept is available from Ned Herrmann of Lake Lure, North Carolina. Mr. Herrmann's scheme breaks hemisphere dominance not only into left/right dimensions, but also includes the cerebral or thinking aspect and the feeling or limbic portion. Again, thanks for your help!

\section{CONCRETE EXPERIENCE (CE)} ("Feeling')

\section{ACTIVE \\ EXPERIMENTATION (AE) \\ ("Doing")}

The Accormodator is an active, risk-taker, seeks opportunities, is intuitive, relies on others for information, will discard theory if it doesn't fit the facts. Strengths are getting things done, risk taking and leadership. May not complete work on time, be somewhat impractical and not goal directed. Can also be seen as "pushy." $\begin{array}{lllllllllllll}48 & 43 & 42 & 41 & 40 & 39 & 38 & 37 & 363534 & 32.302928 & 25 & 16 & 16 \\ 13 & 13\end{array}$ ini e

The Converger is a problem solve 3 makes decisions, is practic2 $2 \%$ uses deductive reasoning, is controlled in emotions, more technical than people-oriented. Usually does well on conventional I.Q.' tests, but can be seen as boring and too conventional.

$100 \%$
The Diverger is imaginative, aware of meaning and valuefoo\%ees many perspectives to form a whole, interested in people, feeling-oriented, good at brainstorming, but may seem scatterbrained. Sometimes has difficulty making decisions and may feel paralyzed by alternatives.

$20 \%$

REFLECTIVE
OBSERVATION (RO)
("Watching")

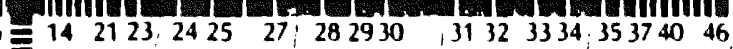

The Assifilator is a theorist who uses inductive reasoning and likes to develop intricate and "elegant" theories. This person is more interested in ideas than in people, is not overly concerned about practicality, is good at analysis but may be tedious. Although good at planning and creating models, may be seen as spinning castles in air. 


\section{RESULTS}

Profile Code

Overall Left Score

I Cerebral Left

II Limbic Left

Overall Right Score

III Limbic Right

IV Cerebral Right

Visual Profile (See Below)

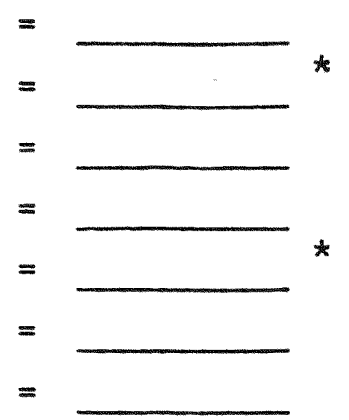

* Unscaled

INTERPRETATION

$\begin{array}{cccc}\text { Profile Code: } & 1=67-100 & 2=34-66 & 3=0-33 \\ \begin{array}{ccc}\text { Strong } \\ \text { Area }\end{array} & \begin{array}{c}\text { Functional } \\ \text { Area }\end{array} & \begin{array}{c}\text { Underdeveloped } \\ \text { Area }\end{array}\end{array}$

Descripturs: Left Mode: Verbal/Mathematical

Right Mode: Visual/Spatial

Cerebral Mode: Thlnking

Limbic Mode: Feeling

I Cerebral Left Analytical

Logical

Technical

(A Problem Solver)

\section{Limbic Left}

Conservative

Controlled

Organlzed

(A Planner)

\section{CEREBAAL}

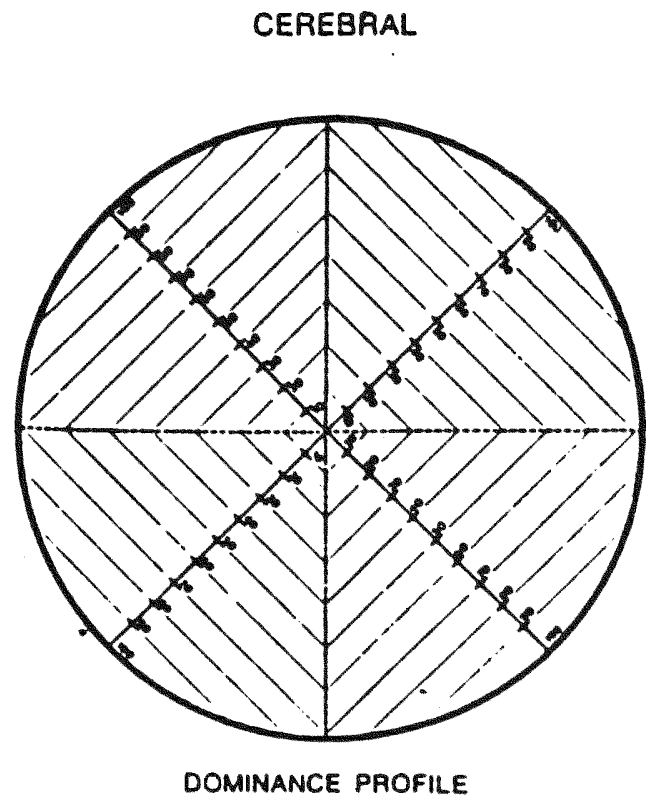

RIOHT

MODE
IV Cerebral Right

Artistic

Creative

Holistic

(A Synthesizer)
III Limbic Right

Emotional

Interpersonal

Musical

(A Talker) 
Title of Thesis: Learning Style and Brain Hemisphere Dominance:

Interrelationships and Influences on Organizational Role Selection

Full Name: $\quad$ Helen Leitch Diehl

Place and

Date of Birth: Steubenville, Ohio; May 10, 1937

Elementary and Keith Laboratory School, Indiana, Pennsylvania

Secondary Mellon Junior High School, Mt. Lebanon, Pennsylvania

Education: Mt. Lebanon Senior High School, Mt. Lebanon, Pennsylvania

Colleges and Muskingum College, 1955-1958, Bachelor of Arts

Universities: Florida International University, 1973-1975, Master of Science in

Counselor Education

Memberships: National Honor Society

Cwens

Phi Alpha Theta

American Society for Training and Development

American Society for Personnel Administrators

Work History: Director, Master of Science in Management Program, Graduate School at St. Thomas University, 1984 to Present

Assistant Vice President and Manager, Management Training and

Development, Southeast Bank, NA, 1981 to 1983

Management Trainer, Mount Sinai Hospital, 1978 to 1981

Major: $\quad$ Community College Teaching, Emphasis in Adult Education

Cognates: Management; Counselor Education

Date: $\quad$ September 1,1986

Signed

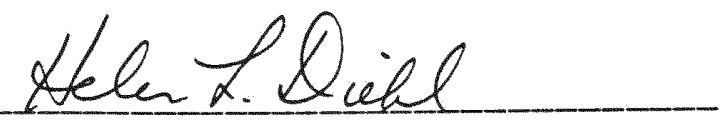

